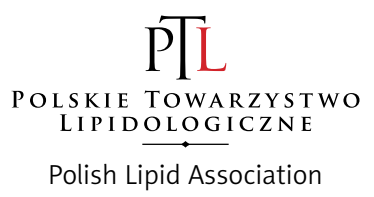

Polish Lipid Association
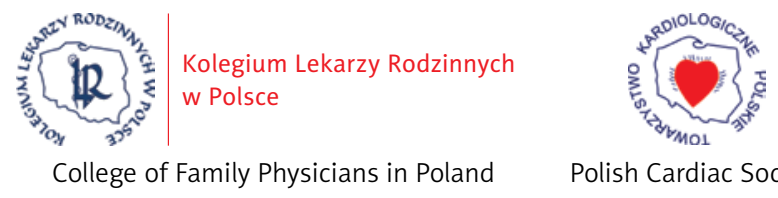

Polish Cardiac Society

\title{
PoLA/CFPiP/PCS Guidelines for the Management of Dyslipidaemias for Family Physicians 2016
}

Authors (members of the Steering Committee): Maciej Banach ${ }^{1}$, Piotr Jankowski², Jacek Jóźwiak Barbara Cybulska ${ }^{4}$, Adam Windak ${ }^{5}$, Tomasz Guzik ${ }^{6}$, Artur Mamcarz ${ }^{7}$, Marlena Broncel ${ }^{8}$, Tomasz Tomasik ${ }^{9}$

Contributors: Jacek Rysz ${ }^{10}$ (member of the Executive Committee of the Polish Lipid Association [PoLA], reviewer appointed by PoLA), Agnieszka Jankowska-Zduńczyk ${ }^{11}$ (National Consultant for Family Medicine, reviewer appointed by the College of Family Physicians in Poland [CFPiP]), Piotr Hoffman ${ }^{12}$ (President of the Polish Cardiac Society [PCS], reviewer appointed by PCS), Agnieszka Mastalerz-Migas ${ }^{13}$ (President of the Polish Society of Family Medicine [PSFM] supporting PoLA/CFPiP/PCS Guidelines, reviewer appointed by PSFM)

${ }^{1}$ Department of Hypertension, Chair of Nephrology and Hypertension, Medical University of Lodz, Lodz, Poland

${ }^{2} 1^{\text {st }}$ Department of Cardiology, Interventional Electrocardiology and Hypertension, Institute of Cardiology, Jagiellonian University Medical College, Krakow, Poland ${ }^{3}$ Institute of Health and Nutrition Sciences, Czestochowa University of Technology, Czestochowa, Poland

${ }^{4}$ National Food and Nutrition Institute, Warsaw, Poland

${ }^{5}$ Department of Family Medicine, Chair of Internal Medicine and Gerontology, Jagiellonian University Medical College, Krakow, Poland

${ }^{6}$ Department of Internal Diseases and Rural Medicine, Jagiellonian University Medical College, Krakow, Poland

${ }^{7} 3^{\text {rd }}$ Department of Internal Diseases and Cardiology, $2^{\text {nd }}$ Faculty of Medicine, Medical University of Warsaw, Warsaw, Poland

${ }^{8}$ Department of Internal Diseases and Clinical Pharmacology, Medical University of Lodz, Lodz, Poland

${ }^{9}$ Department of Family Medicine, Chair of Internal Medicine and Gerontology, Jagiellonian University Medical College, Krakow, Poland

${ }^{10}$ Department of Nephrology, Hypertension and Family Medicine, Chair of Nephrology and Hypertension, Medical University of Lodz, Lodz, Poland

${ }^{11}$ AGAMED Specialist Medical Practice, Piaseczno, Poland

${ }^{12}$ Department of Congenital Cardiac Defects, Institute of Cardiology, Warsaw, Poland

${ }^{13}$ Chair and Department of Family Medicine, Wroclaw Medical University, Wroclaw, Poland

Submitted: 2 November 2016

Accepted: 5 November 2016

Arch Med Sci 2017; 13, 1: 1-45

DOI: 10.5114 /aoms.2017.64712

Copyright (c) 2016 Termedia \& Banach
Corresponding author: Prof. Maciej Banach President of the Polish Lipid Association Head of the Department of Hypertension Chair of Nephrology and Hypertension Medical University of Lodz 113 Zeromskiego St 90-549 Lodz, Poland e-mail: maciej.banach@umed. lodz.pl

The Guidelines have been officially approved and supported by the Polish Society of Family Medicine (PSFM). With the consent of Authors and Editorial Boards of respective journals, the Guidelines are published in parallel in Archives of Medical Science (PoLA recommendation), Lekarz Rodzinny (official journal of CFPiP), Kardiologia Polska (official journal of PCS), and Lekarz POZ (official journal of PSFM). 


\section{CONTENTS}

1. Preamble

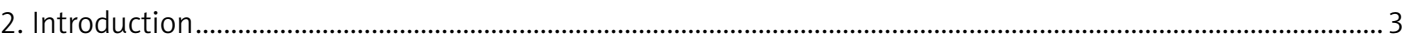

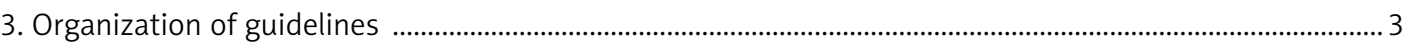

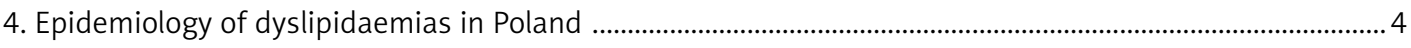

5. Dyslipidaemias as a risk factor and stratification of CV risk .................................................................... 6

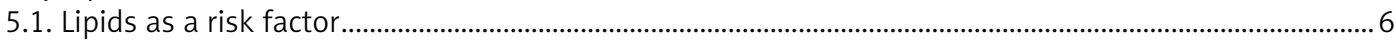

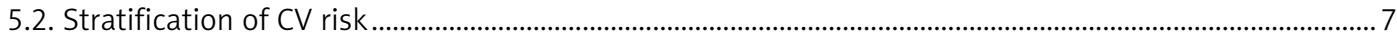

6. Recommendations for the assessment of constituent parameters of the lipid profile and its limitations ...... 9

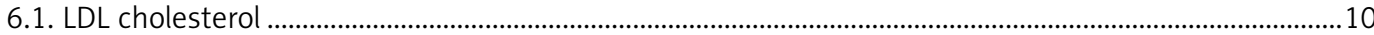

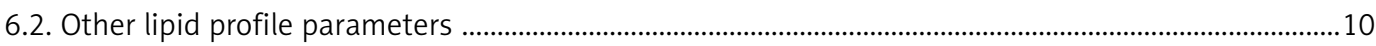

7. Dyslipidaemia treatment targets (risk-related target values) ........................................................................11

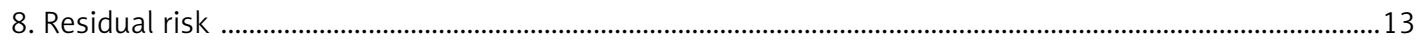

9. Non-pharmacological prevention and treatment of dyslipidaemias .............................................................13

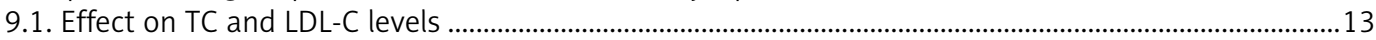

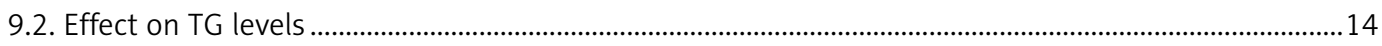

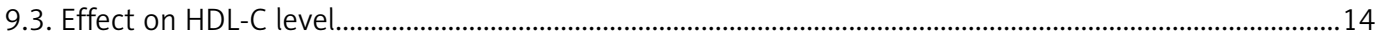

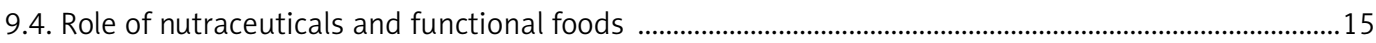

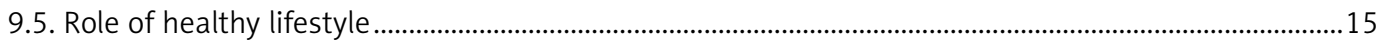

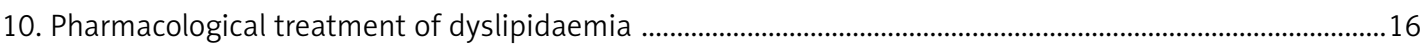

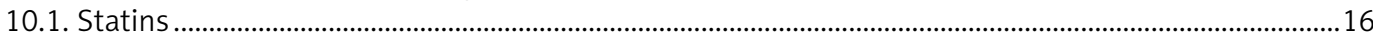

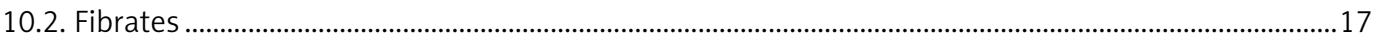

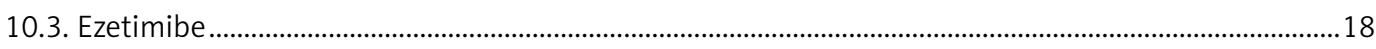

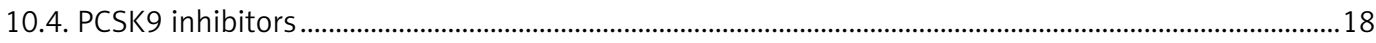

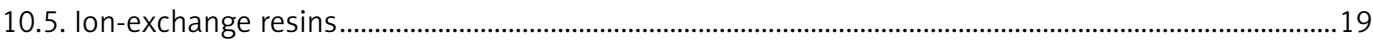

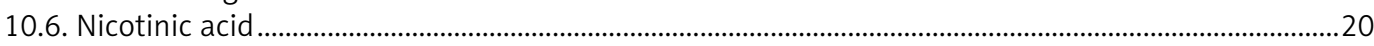

10.7. Drug combinations and future perspectives ..........................................................................................20

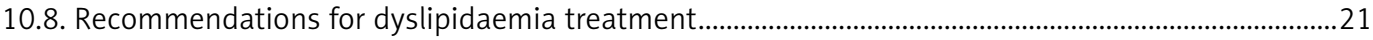

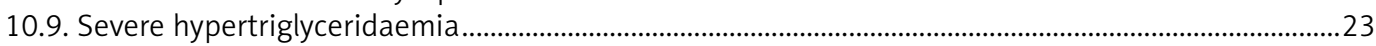

11. LDL-C apheresis - methodology and indications ...........................................................................................2

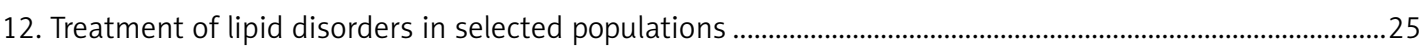

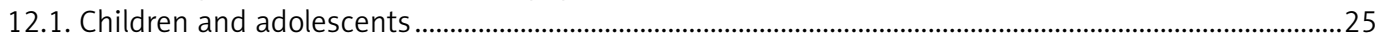

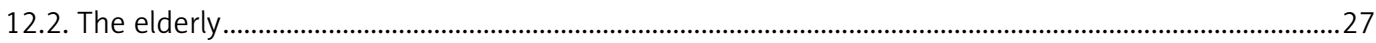

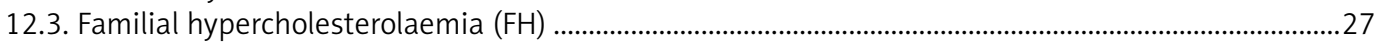

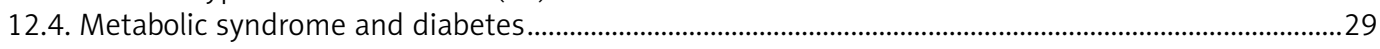

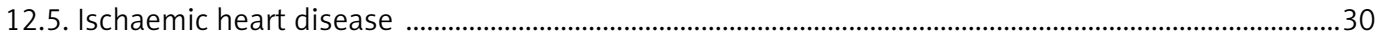

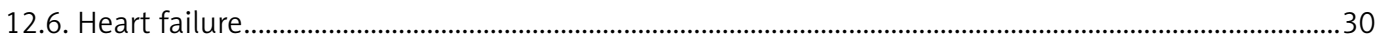

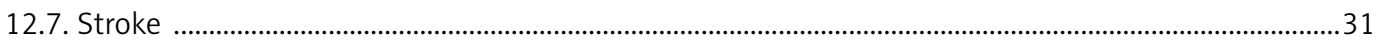

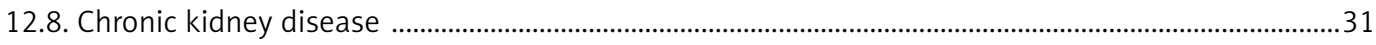

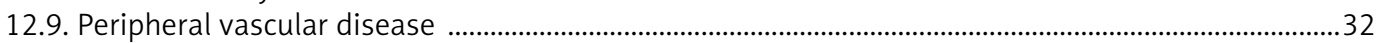

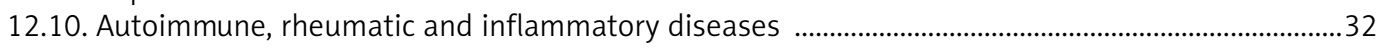

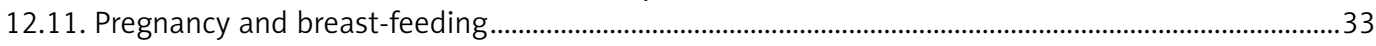

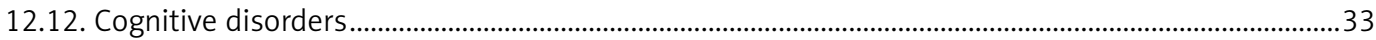

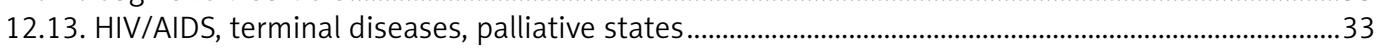

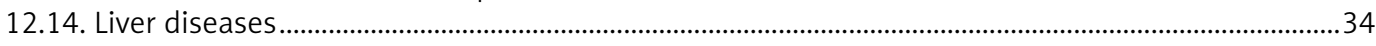

13. Adverse effects associated with dyslipidaemia treatment/statin intolerance................................................35

14. Recommendations for monitoring lipids and biochemical parameters during dyslipidaemia treatment ....36

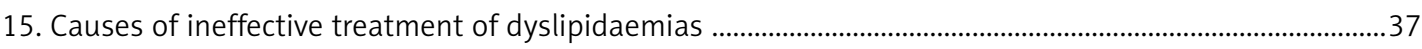

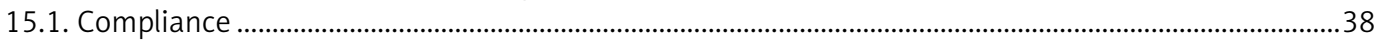

15.2. Adherence, non-response (non-adherence) and persistence ..............................................................38

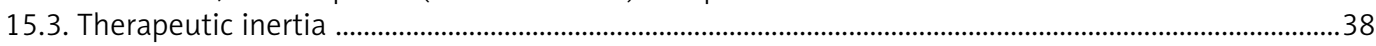

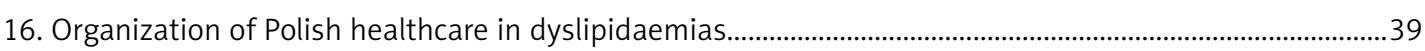

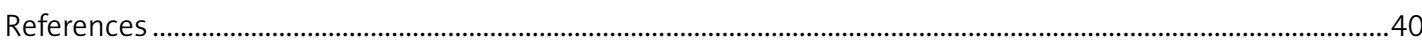




\section{PREAMBLE}

For many years, dyslipidaemias failed to receive the attention they deserve, both in Poland and across the world. In many cases, the most common recommendation given to patients suffering from lipid disorders was to change their diet and lifestyle. Despite multiple educational efforts undertaken by medical societies in Poland, including the signatories of the Guidelines, the knowledge of patients about this independent risk factor continues to be very limited even today. As a result, there are nearly 20 million hypercholesterolaemic patients in Poland [1]. Furthermore, there are no medical (lipid) clinics specializing in the treatment of lipid disorders, and existing outpatient clinics are not usually dedicated specifically to dyslipidaemias, but metabolic disorders and/or endocrine conditions. Not uncommonly, patients receive treatment in cardiac outpatient clinics. The existing state of affairs stems partly from systemic constraints, which pose a hindrance to the establishment of a network of lipid outpatient clinics - even though a total of 70 lipidologists have already been certified by the Polish Lipid Association (PoLA). This is precisely why the problem of familial hypercholesterolaemia $(\mathrm{FH})$ in Poland was not recognized as significant for many years. Few physicians were able to consider low density lipoprotein cholesterol (LDL-C) concentrations in excess of $190 \mathrm{mg} / \mathrm{dl}(4.9 \mathrm{mmol} / \mathrm{l})$ or total cholesterol (TC) concentrations of $290 \mathrm{mg} / \mathrm{dl}$ (7.5 $\mathrm{mmol} / \mathrm{l})$ and more as potentially caused by genetically conditioned disease and, taking the matter further, classify patients presenting with such disorders into high and very high cardiovascular risk groups [2]. This is why the treatment of patients with the most severe lipid disorders with apheresis is practically non-existent in Poland, with only three treatment centres available to patients. In contrast, in neighbouring countries (Germany, Czech Republic), nationwide $\mathrm{FH}$ registries have been kept for many years. Germany, in addition, has the largest number of medical centres offering apheresis treatment in Europe.

It was first noted about a dozen years ago in the estimation of long-term (20-year) risk or lifetime risk that dyslipidaemias represented an independent risk factor for cardiovascular (CV) events. It thus follows that optimal effective treatment of lipid disorders is as important as the therapy of diabetes or arterial hypertension [3]. What is more, even if dyslipidaemia treatment is undertaken, further challenges must be faced such as failure to use/prescribe statins at doses corresponding to the level of $\mathrm{CV}$ risk (the situation may affect as much as $80 \%$ of all treated patients), discontinuation of therapy [4], lack of effective combination treatment aimed at reducing residual risk or fail- ure to ensure appropriate management of undesirable treatment-related effects [3, 5].

In view of the situation outlined above, the PoLA, the College of Family Physicians in Poland (CFPiP) and the Polish Cardiac Society (PCS) have jointly identified a need to draft the first guidelines regulating the management of dyslipidaemias and addressed to family physicians, as they are usually the first to diagnose lipid disorders and they are largely responsible for the initial therapeutic decisions and for the continuation of lipid-lowering therapy (LLT).

\section{INTRODUCTION}

Dyslipidaemias are the most common yet the least well-controlled risk factor for cardiovascular disease (CVD) in Poland [1]. The main modifiable risk factors for atherosclerosis and its complications including ischaemic heart disease (IHD), stroke and peripheral artery disease (PAD) are: smoking, type 2 diabetes, arterial hypertension, inappropriate diet and eating habits, inadequate physical activity as well as the resulting overweight and obesity [6]. As shown by epidemiological studies conducted in Poland, there is a nationwide growth in the above risk factors (with the exception of smoking in the majority of age groups), which is attributable to the increasing prevalence of poor eating habits and sedentary lifestyle [1]. The elimination of risk factors represents one of the greatest challenges to be faced in the domain of public health. In order to rise to up to the challenge, wide-ranging population prevention measures are needed. However, family physicians as well as other health professionals (cardiologists, internists) have a special responsibility towards high-risk patients. The group definitely comprises a considerable proportion of dyslipidaemia patients. Consequently, dyslipidaemia management should be an element of a broader strategy targeted at lowering total CV risk and, hence, reducing mortality, morbidity and disability associated with CVD.

\section{ORGANIZATION OF GUIDELINES}

Members of the Steering Committee responsible for developing the Guidelines were selected by the PoLA, CFPiP and PCS as experts in the treatment of patients suffering from dyslipidaemias. The Steering Committee performed a detailed review of published evidence regarding the management of dyslipidaemia including the diagnosis, treatment, prevention and critical evaluation of diagnostic and therapeutic procedures including the assessment of the benefit-to-risk ratio. The level of evidence and the strength of recommendations with respect to particular management options were weighed and graded according to 
Table I. Classes of recommendations included in the Guidelines

Recommendation class

\begin{tabular}{|lcc|}
\hline Class I & $\begin{array}{c}\text { There is scientific evidence and/or general agreement } \\
\text { that a given treatment/procedure is beneficial, useful } \\
\text { and effective }\end{array}$ & Is recommended/is indicated \\
\hline Class II & $\begin{array}{c}\text { Data from scientific studies are ambiguous and/or there } \\
\text { is a divergence of opinion about the usefulness/efficacy } \\
\text { of a given treatment/procedure }\end{array}$ & \\
\hline Class IIa & $\begin{array}{c}\text { The weight of evidence/opinion is in favour of the } \\
\text { usefulness/efficacy of a given treatment/procedure }\end{array}$ & Should be considered \\
\hline Class IIb & $\begin{array}{c}\text { Available evidence/opinion does not corroborate the } \\
\text { usefulness/efficacy of a given treatment/procedure }\end{array}$ & May be considered \\
\hline Class III & $\begin{array}{l}\text { There is scientific evidence and/or general agreement } \\
\text { that a given treatment/procedure is not useful/effective, } \\
\text { and in some cases may be harmful }\end{array}$ & Is not recommended \\
&
\end{tabular}

Table II. Levels of evidence

\begin{tabular}{|cc|}
\hline Level of evidence A & Data derived from multiple randomized clinical studies or meta-analyses \\
\hline Level of evidence B & Data derived from a single randomized clinical trial or large non-randomized trials \\
\hline $\begin{array}{c}\text { Level of evidence C } \\
\end{array}$ & $\begin{array}{c}\text { Consensus of opinion of experts and/or data derived from small studies, retrospective } \\
\text { studies and registries }\end{array}$ \\
\hline
\end{tabular}

widely recognized classifications which are outlined in Tables I and II. To meet the needs of the target group and ensure the ease of use of the Guidelines, the class and strength of recommendations were applied only to the key provisions, particularly those raising the most doubts and questions, and having the greatest practical significance for dyslipidaemia therapy. Each chapter is additionally summarized in frames, with a focus on points to be remembered by physicians as well as key recommendations.

Experts from the panels writing and reviewing the Guidelines filled in declaration of interest forms with respect to all relationships which might be seen as either actual or potential sources of conflicts of interest. Following the final approval of the contents of the Guidelines, the final version of the document is scheduled for parallel publication in Archives of Medical Science (recommendation by PoLA), Lekarz Rodzinny (official journal of CFPiP), Kardiologia Polska (official journal of PCS), and Lekarz POZ (official journal of PSFM).

Family physicians and medical professionals of other specialties treating patients with lipid disorders are encouraged to take full account of the Guidelines in the process of evaluating the clinical status of their patients, and determining and implementing medical strategies for the prevention, diagnosis and treatment of dyslipidaemias. However, the Guidelines do not override in any way the individual responsibility of physicians to make appropriate and accurate decisions taking into account the condition of a given patient, in consultation with that patient, and, where neces- sary, with the patient's guardian or carer. It is also the responsibility of health professionals to verify the rules and regulations applicable to drugs and devices at the time of their prescription/use.

\section{EPIDEMIOLOGY OF DYSLIPIDAEMIAS IN POLAND}

Dyslipidaemias are the most widespread CV risk factor, which has also been demonstrated in Polish observational cohort (screening) studies. The key studies together with study sample selection methods and study periods are summarized in Table III.

Depending on the study sample selection, the incidence of dyslipidaemias in Poland is estimated at $60-70 \%$ of the population over 18 years of age $[7,8]$. The initial data obtained on the prevalence of hyperlipidaemia (Pol-MONICA study) revealed hypercholesterolaemia in slightly more than $70 \%$ of women and nearly $73 \%$ of men [9]. In the study, a higher proportion of men $(60 \%)$ than women (53\%) was shown to have LDL levels higher than the normal range [9]. Reduced concentrations of high density cholesterol (HDL) were noted in nearly $2 \%$ of women and $10 \%$ of men, and elevated concentrations of triglycerides (TG) were present in $6 \%$ of women and $21 \%$ of men [9]. In the next study (SPES), hypercholesterolaemia was noted in nearly $56 \%$ of the subjects ( $58 \%$ of women and $52 \%$ of men) [10]. The results, however, were not nationwide in scope, and were limited to the total area of the former Polish provinces: Warszawskie with Tarnobrzeskie (Pol-MONICA), and Katowickie with Bielskie (SPES). 
Table III. Polish epidemiological studies on dyslipidaemia by method of subject selection for observation

\begin{tabular}{|cccc|}
\hline $\begin{array}{c}\text { Studies with random sample selection } \\
\text { from the general population }\end{array}$ & Year(s) of the study & Acronym & $\begin{array}{c}\text { Studies involving active } \\
\text { primary care patients }\end{array}$ \\
\hline Acronym & $1984-1993$ & SPES & Year(s) of the study \\
\hline Pol-MONICA & 2002 & POLSCREEN & 1997 \\
\hline NATPOL III PLUS & $2003-2005$ & LIPIDOGRAM2003 & 2002 \\
\hline WOBASZ & 2011 & LIPIDOGRAM2004 & 2003 \\
\hline NATPOL 2011 & $2013-2014$ & LIPIDOGRAM2006 & 2004 \\
\hline WOBASZ II & & LIPIDOGRAM 5 YEARS & 2006 \\
\hline & & LIPIDOGRAM2015 & $2015-2016$ \\
\hline
\end{tabular}

Subsequent data on the prevalence of dyslipidaemia in Poland are based on two random study samples encompassing the entire country, i.e. NATPOL III PLUS and WOBASZ studies. In NATPOL, the incidence of hypercholesterolaemia was estimated at $59.5 \%$ in men and $62 \%$ in women. In WOBASZ, the respective figures were $67 \%$ and $64 \%[11,12]$. The NATPOL study found that the LDL-C level was above the normal range in almost identical proportions of men and women (55\%) [11]. In WOBASZ, increased concentrations of LDL-C were observed in $60 \%$ of men and $55 \%$ of women [12]. The proportions of patients with reduced HDL-C concentrations in the NATPOL study were $17 \%$ for men and $6 \%$ for women. In WOBASZ, the figures were $15 \%$ and $17 \%$, respectively [11, 12]. Based on the NATPOL study, hypertriglyceridaemia in Poland was shown to occur in $30 \%$ of the subjects, with a higher incidence in men than in women (38\% vs. $23 \%$ ) [5]. In WOBASZ, increased TG concentrations were observed in 31\% of men and $20 \%$ of women [12].

Based on the US guidelines the National Cholesterol Education Program Adult Treatment Panel III (NCEP ATPIII), a significant prevalence of lipid disorders was also determined in three nationwide Polish studies: LIPIDOGRAM2003, LIPIDOGRAM2004 and LIPIDOGRAM2006. The final databases for the studies included a total of over 49,000 patients treated by primary care physicians [13-15]. In LIPIDOGRAM2003, the mean concentrations of lipid profile parameters were: TC - $228 \mathrm{mg} /$ dl $(5.9 \mathrm{mmol} / \mathrm{l}), \mathrm{LDL}-\mathrm{C}-140 \mathrm{mg} / \mathrm{dl}(3.6 \mathrm{mmol} / \mathrm{l})$, $\mathrm{HDL}-\mathrm{C}-57 \mathrm{mg} / \mathrm{dl}(1.5 \mathrm{mmol} / \mathrm{l}), \mathrm{TG}-156 \mathrm{mg} / \mathrm{dl}$ $(1.8 \mathrm{mmol} / \mathrm{l})$ [13]. Hypercholesterolaemia $>200 \mathrm{mg} /$ $\mathrm{dl}(>5.2 \mathrm{mmol} / \mathrm{l})$ was found in $72 \%$ of the subjects, with a higher incidence among women than in men (76\% vs. $67 \%)$. Elevated LDL-C concentrations $>160 \mathrm{mg} / \mathrm{dl}(4.1 \mathrm{mmol} / \mathrm{l})$ were noted in $28 \%$ of the study subjects, more frequently in women than in men (30\% vs. $24 \%$ ). Reduced HDL-C con- centrations $<40 \mathrm{mg} / \mathrm{dl}(1.0 \mathrm{mmol} / \mathrm{l})$ were observed in $6 \%$ of the study subjects, $12 \%$ of men and $3 \%$ of women. Increased TG concentrations > $200 \mathrm{mg} /$ $\mathrm{dl}(2.3 \mathrm{mmol} / \mathrm{l})$ were revealed in $22 \%$ of the subjects, more frequently in men than in women $(26 \%$ vs. $19 \%)$ [13]. Mean concentrations of different lipid profile parameters and proportions of values above the normal range in consecutive studies LIPIDOGRAM2004 [14] and LIPIDOGRAM2006 [15] - are shown in Figure 1 and Table IV.

In the next study, NATPOL 2011, the mean concentrations of lipid profile parameters for men and women respectively were: TC $-197.1 \mathrm{mg} / \mathrm{dl}$ (5.1 mmol/l) and $198.6 \mathrm{mg} / \mathrm{dl}(5.1 \mathrm{mmol} / \mathrm{l}), \mathrm{LDL}-\mathrm{C}$ - $123.6 \mathrm{mg} / \mathrm{dl}(3.2 \mathrm{mmol} / \mathrm{l})$ and $123.7 \mathrm{mg} / \mathrm{dl}(3.2$ $\mathrm{mmol} / \mathrm{l}), \mathrm{HDL}-\mathrm{C}-45.8 \mathrm{mg} / \mathrm{dl}(1.2 \mathrm{mmol} / \mathrm{l})$ and 54.1 $\mathrm{mg} / \mathrm{dl}(1.4 \mathrm{mmol} / \mathrm{l}), \mathrm{TG}-140.9 \mathrm{mg} / \mathrm{dl}(1.6 \mathrm{mmol} / \mathrm{l})$ and $104.0 \mathrm{mg} / \mathrm{dl}(1.2 \mathrm{mmol} / \mathrm{l})$. Lipid profile parameters in excess of the normal range were noted in the following proportions of subjects: TC $>190 \mathrm{mg}$ ( $4.9 \mathrm{mmol} / \mathrm{l})-54.3 \%$ (54.3\% of men and $54.4 \%$ of women), LDL-C > $115 \mathrm{mg} / \mathrm{dl}(3.0 \mathrm{mmol} / \mathrm{l})-57.8 \%$ (58.3\% of men and $57.3 \%$ of women), HDL-C $<40 \mathrm{mg} / \mathrm{dl}(1.0 \mathrm{mmol} / \mathrm{l})-32.5 \%$ of men, HDL-C $<45 \mathrm{mg} / \mathrm{dl}(1.2 \mathrm{mmol} / \mathrm{l})-22 \%$ of women, TG > $150 \mathrm{mg} / \mathrm{dl}(1.7 \mathrm{mmol} / \mathrm{l})-21,1 \%$ (28.4\% of men and $14.0 \%$ of women) [1].

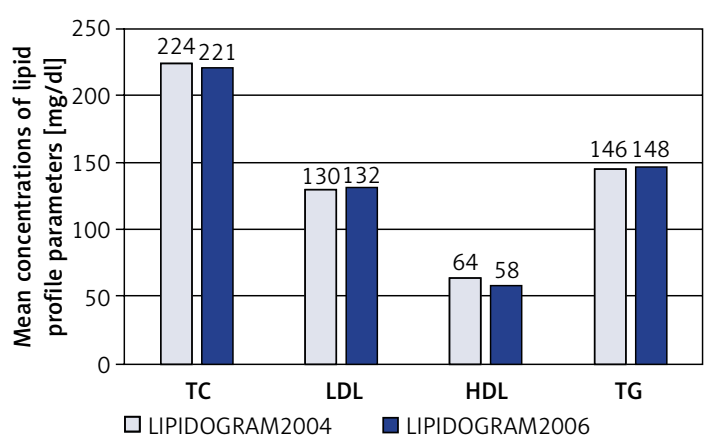

Figure 1. Mean concentrations of lipid profile parameters in LIPIDOGRAM2004 and LIPIDOGRAM2006 
Table IV. Percentages of lipid profile parameter concentrations above the normal range in LIPIDOGRAM2004 and LIPIDOGRAM2006 studies

\begin{tabular}{|cccc|}
\hline \multicolumn{1}{|c|}{ LIPIDOGRAM2004 } & \multicolumn{2}{c|}{ LIPIDOGRAM2006 } \\
\hline Concentration criteria & $\%$ & Concentration criteria & $\%$ \\
\hline $\mathrm{TC}>200 \mathrm{mg} / \mathrm{dl}$ & 69 & $\mathrm{TC}>200 \mathrm{mg} / \mathrm{dl}$ & 66 \\
\hline $\mathrm{LDL}-\mathrm{C}>160 \mathrm{mg} / \mathrm{dl}$ & 21 & LDL-C $>160 \mathrm{mg} / \mathrm{dl}$ & 22 \\
\hline $\mathrm{LDL}-\mathrm{C}>130 \mathrm{mg} / \mathrm{dl}$ & 48 & LDL-C $>130 \mathrm{mg} / \mathrm{dl}$ & 49 \\
\hline $\mathrm{LDL}-\mathrm{C}>100 \mathrm{mg} / \mathrm{dl}$ & 79 & $\mathrm{LDL}-\mathrm{C}>100 \mathrm{mg} / \mathrm{dl}$ & 79 \\
\hline $\mathrm{HDL}-\mathrm{C}<40 \mathrm{mg} / \mathrm{dl}$ & 4 & $\mathrm{HDL}-\mathrm{C}<40 \mathrm{mg} / \mathrm{dl}$ & 19 \\
\hline $\mathrm{TG}>200 \mathrm{mg} / \mathrm{dl}$ & 18 & $\mathrm{TG}>200 \mathrm{mg} / \mathrm{dl}$ & 37 \\
\hline $\mathrm{TG}>150 \mathrm{mg} / \mathrm{dl}$ & 35 & $T G>150 \mathrm{mg} / \mathrm{dl}$ \\
\hline
\end{tabular}

In the WOBASZ II study, which was conducted 2 years later, hypercholesterolaemia was found in $70.3 \%$ of men and $64.3 \%$ of women aged $>20$ years (67.1\% of the total study population). Furthermore, hypertriglyceridaemia with normal cholesterol concentrations was observed in 5.6\% of men and $2.4 \%$ of women. Reduced HDL-C concentrations with normal TC and TG levels were found in $5.1 \%$ of men and $7.3 \%$ of women. Overall, at least one dyslipidaemia type was detected in $81.0 \%$ of men and $74.0 \%$ of women. As much as $60.6 \%$ of subjects with hypercholesterolaemia were not aware of the fact, and only $6 \%$ received effective treatment and achieved reference concentrations of their lipid profile parameters [16].

LIPIDOGRAM 5 YEARS, a prospective Polish nationwide cohort study $(n=1,841)$ covering a period of 5 years (2004-2010), conducted in a population of primary care patients treated due to dyslipidaemia, found that the lipid profile parameters were not effectively reduced in approximately $50 \%$ of subjects with TC concentrations above the normal range and in over $30 \%$ of patients with elevated LDL-C and TG concentrations [7]. Evidence for the lack of efficacy of dyslipidaemia treatment was also supplied by the earlier screening studies: LIPIDOGRAM2004 and LIPIDOGRAM2006 [17-20].

Inadequate control of hypercholesterolaemia was also shown in patients after hospitalization for IHD within the framework of the Cracow Programme for Secondary Prevention of Ischaemic Heart Disease [21]. Target LDL-C concentrations $<70 \mathrm{mg} / \mathrm{dl}(<1.8 \mathrm{mmol} / \mathrm{l})$ were noted in only $28.1 \%$ of the patients. In $71.9 \%, 38.6 \%, 24.4 \%$ and $10.3 \%$ of the subjects, however, LDL-C concentrations were $\geq 70 \mathrm{mg} / \mathrm{dl}(\geq 1.8 \mathrm{mmol} / \mathrm{l}), \geq 100 \mathrm{mg} / \mathrm{dl}(\geq 2.5$ $\mathrm{mmol} / \mathrm{l}), \geq 115 \mathrm{mg} / \mathrm{dl}(\geq 3.0 \mathrm{mmol} / \mathrm{l})$ and $\geq 160 \mathrm{mg} / \mathrm{dl}$ ( $\geq 4.0 \mathrm{mmol} / \mathrm{l})$, respectively [21]. Studies conducted over the past 20 years suggest that the success rate in achieving the recommended LDL-C level in patients with IHD has not changed in relation to the end of the $20^{\text {th }}$ century [22]. The success rate in achieving target LCL-C levels in patients who are treated in primary care does not deviate significantly from the success rate in patients declaring that their treatment is prescribed by physicians in specialist cardiac outpatient clinics [22].

Preliminary, still unpublished results of the recently completed study LIPIDOGRAM2015 show elevated TC concentrations $>190 \mathrm{mg} / \mathrm{dl}(>4.9 \mathrm{mmol} / \mathrm{l})$ in $58 \%$ of active primary care patients aged $>18$ years. LDL-C concentrations > $115 \mathrm{mg} / \mathrm{dl}$ ( $>3.0 \mathrm{mmol} / \mathrm{l}$ ) were seen in $61 \%$ of the patients, and reduced $\mathrm{HDL}-\mathrm{C}$ levels $(<40 \mathrm{mg} / \mathrm{dl}(<1.0 \mathrm{mmol} / \mathrm{l})$ in men and $<45 \mathrm{mg} / \mathrm{dl}(<1.2 \mathrm{mmol} / \mathrm{l})$ in women) were determined in $14 \%$ of the study subjects. Increased concentrations of TG $>150 \mathrm{mg} / \mathrm{dl}$ ( $>1.7 \mathrm{mmol} / \mathrm{l}$ ) were observed in $33 \%$ of the patients.

\section{KEY POINTS TO REMEMBER}

Based on the assumption that a family physician in his/her standard medical practice provides care to about 2,500 patients including over $75 \%$ of adults [1], and the estimated prevalence of dyslipidaemia in Poland is $60-70 \%$ in the population over 18 years of age, it can be inferred that every physician has under his/her care about 1,100-1,300 people with dyslipidaemias including up to 10 patients with familial hypercholesterolaemia [23, 24].

\section{DYSLIPIDAEMIAS AS A RISK FACTOR AND STRATIFICATION OF CV RISK}

\subsection{Lipids as a risk factor}

Available results of scientific research point to a direct link between the concentrations of TC, LDL-C and non-HDL-C (total cholesterol concentration minus $\mathrm{HDL}$ cholesterol concentration) and the risk of myocardial infarction (MI), stroke and fatal CVD [3, 6]. Large meta-analyses suggest that a $1 \mathrm{mmol} / \mathrm{l}$ difference in TC concentration is associated with an increase in the risk of death from IHD by $120 \%$ in patients aged $40-49$ years, by $75 \%$ in 
Table V. Definitions of cardiovascular risk groups [6]

\begin{tabular}{|ll|}
\hline Very high risk & - Cardiovascular disease (CVD) documented by invasive or non-invasive testing (abnormal ECG \\
& waves, coronary angiography, nuclear medicine methods, stress echocardiography, ultrasound \\
& imaging of carotid plaques), previous acute coronary syndrome (ACS), coronary revascularization \\
& procedure, ischaemic stroke or transient cerebral ischaemia, or peripheral artery disease (PAD) \\
& - Type 1 or 2 diabetes with at least one $\mathrm{CV}$ risk factor and/or target organ complications (such as \\
& urinary albumin excretion in the range of $30-300 \mathrm{mg} /$ day) \\
& - Severe CKD (GFR $\left.<30 \mathrm{ml} / \mathrm{min} / 1.73 \mathrm{~m}^{2}\right)$ \\
& - 10 -year risk of fatal CVD calculated by Pol-SCORE $\geq 10 \%$
\end{tabular}

patients aged $50-59$ years, by $47 \%$ in patients aged 60-69 years, by $27 \%$ in patients aged $70-79$ years and by $18 \%$ in patients aged $80-89$ years [25]. The above data, however, should not be interpreted as suggesting that the risk of hypercholesterolaemia in elderly people is lower. In fact, due to a significantly higher CV risk, hypercholesterolaemia is associated with a greater number of CV events and deaths in the elderly population than in younger age groups [6]. The correlation of LDL-C and non-HDL-C concentrations with patient prognosis has been shown to persist even after incorporating other risk factors including HDL-C and TG concentrations [26].

Whereas high LDL-C and non-HDL-C concentrations are correlated with an increased CV risk, a high concentration of HDL-C is associated with a risk reduction. The association has been shown to remain significant even after taking into account other risk factors including concentrations of the non-HDL-C fraction and TG [26]. The role of low HDL-C concentration as a risk marker is less prominent in patients with atherosclerosis and in the group of patients treated with statins. It must also be emphasized that all therapeutic interventions aimed at reducing the (residual) CV risk as a result of increase in $\mathrm{HDL}-\mathrm{C}$ concentration have given negative results to date, which may be attributable to the so-called dysfunctional HDL-C occurring in patients with conditions accompanied by an increased inflammatory process and/or oxidative stress (e.g. obesity, smoking, diabetes, IHD, chronic kidney disease (CKD)) [6, 27].

A high TG concentration is associated with an elevated risk of serious cardiovascular events. Some analyses, however, show that the association is no longer evident when other risk factors are taken into account - including in particular HDL-C and non-HDL-C concentrations [26]. Available studies also suggest that high TG concentra- tions are linked to increased concentrations of the most atherogenic fraction of small dense LDL cholesterol (sdLDL-C) [6].

Even though the relationship between lipids and CV risk forms a continuum, for practical reasons certain cut-off points have been adopted to define concentrations recognized as abnormal. For LDL-C, the concentration depends on the total CV risk (Table $V$ ). In low or moderate risk patients, high concentrations of LDL-C refer to values $\geq 115 \mathrm{mg} /$ $\mathrm{dl}(\geq 3.0 \mathrm{mmol} / \mathrm{l})$, in high risk patients - to levels $\geq 100 \mathrm{mg} / \mathrm{dl}(\geq 2.6 \mathrm{mmol} / \mathrm{l})$, and in very high risk patients $\geq 70 \mathrm{mg} / \mathrm{dl}(\geq 1.8 \mathrm{mmol} / \mathrm{l})$ [6].

$\mathrm{HDL}-\mathrm{C}$ concentrations of $<40 \mathrm{mg} / \mathrm{dl}(<1.0 \mathrm{mmol} / \mathrm{l})$ in men and $<45 \mathrm{mg} / \mathrm{dl}(<1.2 \mathrm{mmol} / \mathrm{l})$ in women are considered abnormal. Similarly, TG concentrations of $>1.7 \mathrm{mmol} / \mathrm{l}$ (>150 $\mathrm{mg} / \mathrm{dl}$ ) are regarded as abnormal. It must be stressed that insofar as the cut-off points defined for $L D L-C$ are recognized therapeutic targets, HDL-C and TG concentrations given above may not be regarded as therapeutic targets due to a limited scientific basis [6].

\subsection{Stratification of CV risk}

At present, total CV risk assessment is the basis for appropriate management in terms of CVD prevention and therapy [28]. In accordance with current guidelines of scientific societies, total CV risk should guide decisions on the intensity of treatment, including the introduction of pharmacological treatment of hypercholesterolaemia [6]. Total CV risk assessment also facilitates the education of patients [6]. In 2015, the Polish Cardiac Society published updated risk estimation charts dedicated to the Polish population - Pol-SCORE 2015 (Figure 2) [29].

The first step in preparing treatment recommendations for a patient with dyslipidaemia is 


\section{Pol-SCORE 2015}

\section{0-year risk of fatal cardiovascular disease}

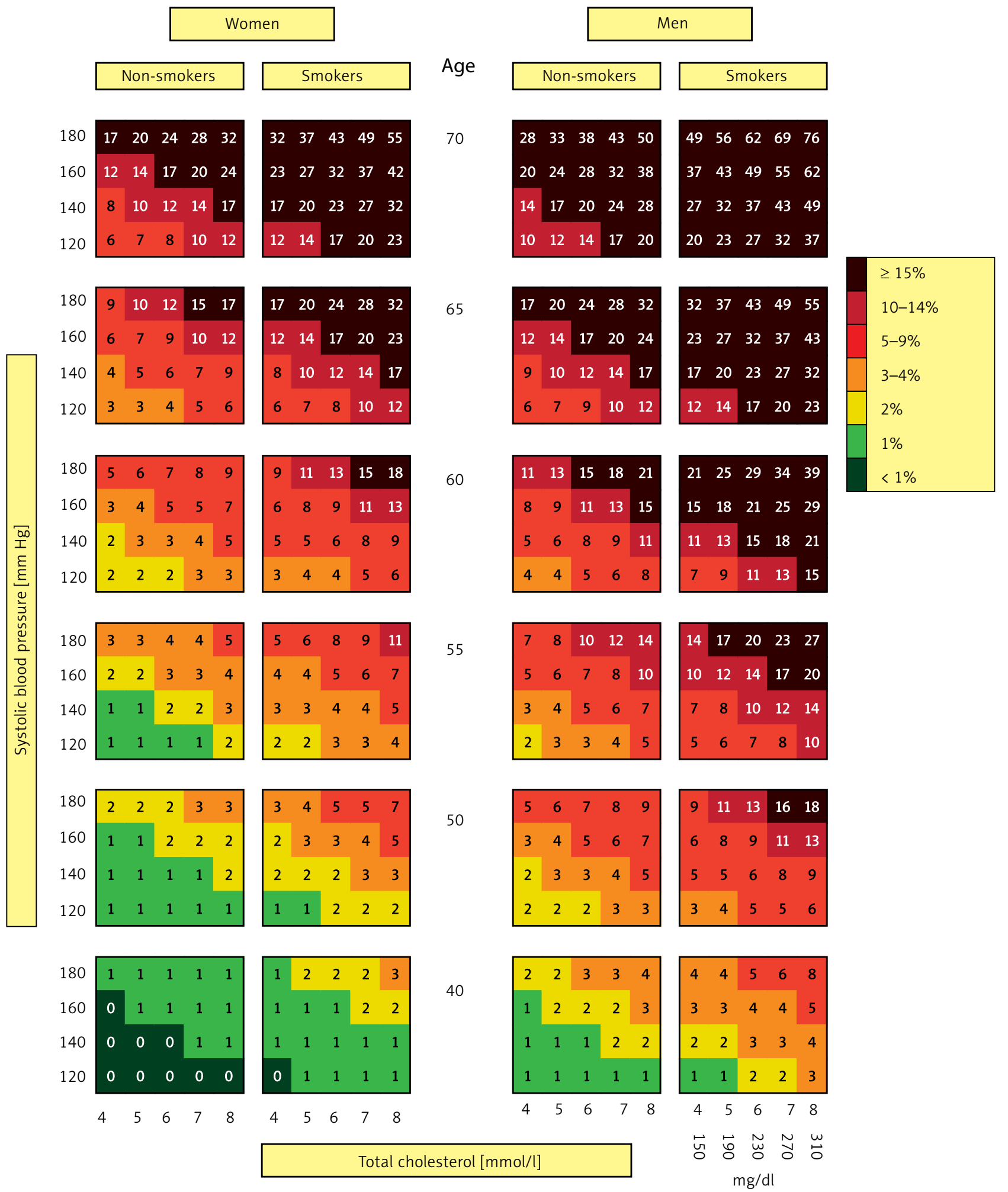

Figure 2. SCORE charts calibrated for the Polish population (Pol-SCORE 2015). The numbers in the charts represent the 10-year risk of fatal cardiovascular disease [29] 
Table VI. Factors increasing CV risk which are not included in Pol-SCORE $[6,29]$

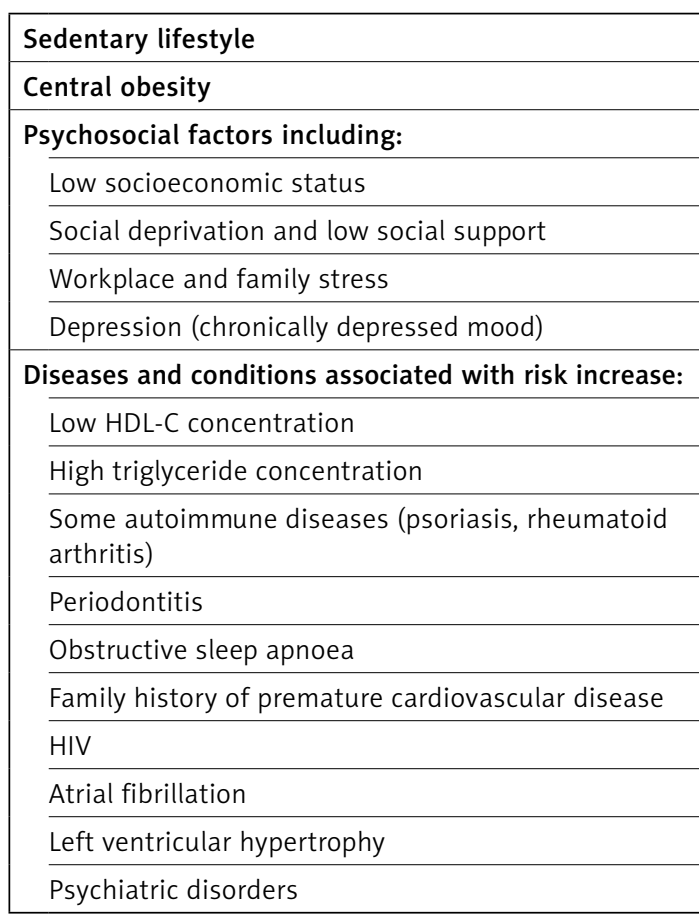

determining the $\mathrm{CV}$ risk category to which the patient belongs (Table V). It needs to be stressed that patients with a history of CV events or with a documented cardiac or vascular disease are a priori classified as being at very high risk. Also, Pol-SCORE charts should not be used to assess CV risk in patients with diabetes or CKD (with glomerular filtration rate $\left.(G F R)<60 \mathrm{~min} / 1.73 \mathrm{~m}^{2}\right)$. Such patients should be directly stratified into appropriate risk groups. In all remaining cases, CV risk is assessed on the basis of Pol-SCORE 2015 charts (Figure 2), taking into account the age and gender of patients, as well as their smoking status, TC concentration and systolic blood pressure (SBP). This is how the 10-year risk of fatal CVD is estimated.

Table $\mathrm{VI}$ presents risk factors and conditions associated with an increased CV risk, which are not included in the Pol-SCORE 2015 chart. It is advisable to take them into consideration particularly when the CV risk estimated using the chart is on the borderline between two categories (e.g. amounts to $5 \%$ ). In such cases, considering the HDL-C concentration or the presence of depression moves the patient into a higher risk category (e.g. with concomitant depression or low HDL-C concentration) or a lower risk group (e.g. with the $a b-$ sence of depression or high HDL-C concentration).

Pol-SCORE charts can be a useful tool for patient education. With their aid it is possible to show patients in an approachable manner how their CV risk level will drop after introducing an effective treatment for a particular risk factor. In the near future, the Polish Cardiac Society will pub- lish on its website a total CV risk score calculator which will allow a more accurate estimation of CV risk compared to the charts.

\section{KEY POINTS TO REMEMBER}

There is a close independent correlation between the concentration of cholesterol, primarily LDL-C, and the development of atherosclerosis and the risk of serious CV events.

\section{RECOMMENDATIONS}

- Every patient should be evaluated to determine total CV risk for the purpose of ensuring appropriate patient education and making decisions on the intensity of treatment, including the rationale to introduce pharmacological treatment of dyslipidaemia.

- Pol-SCORE 2015 should be used for the estimation of total CV risk of patients in primary prevention (see Chapter 7).

\section{RECOMMENDATIONS FOR}

\section{THE ASSESSMENT OF CONSTITUENT PARAMETERS OF THE LIPID PROFILE AND ITS LIMITATIONS}

An effective diagnosis of lipid disorders depends to a large extent on the knowledge of specific lipid profile parameters, recommended normal ranges and effects on CV risk. In daily medical practice, the most commonly evaluated lipid profile parameters include TC, LDL-C, HDL-C and TG. Recent years have also seen a multitude of reports on the role of estimating non-HDL-C, lipoprotein(a) $(\mathrm{Lp}(\mathrm{a}))$, apolipoprotein $B(A p o B)$, apolipoprotein $A 1$ (ApoA1), LDL particles (LDL-P) as well as TC/HDL-C and TG/HDL-C ratios, and many others [30].

Screening tests should be performed in individuals with at least one risk factor for CVD (e.g. arterial hypertension, nicotine dependence syndrome, diabetes, overweight, adverse family history) and in all men $>40$ years old and all women $>50$ years old - as well as patients with CVD, CKD or autoimmune disease (see Chapter 16). If the lipid profile is within the normal range, it is indicated to repeat the test at least every 3-5 years. In patients with hypercholesterolaemia, screening should be performed on a yearly basis after achieving the target concentration of LDL-C. Screening for lipid disorders should also be performed in children aged $>2$ years with a family history of dyslipidaemia including $\mathrm{FH}$ or premature CVD, and in children with other risk factors. The optimal age range for conducting lipid metabolism tests is 9-11 years. If the lipid concentrations are within the normal 
range between the ages of 9 and 11 , tests should be repeated at the age of about 18 years, as lipid profile results obtained at this age demonstrate the highest prognostic value for lipid levels over the next two decades of life.

\subsection{LDL cholesterol}

Studies conducted in recent years have shown that the determination of LDL-C plays an essential role in the diagnosis of dyslipidaemias. LDL-C is recognized as a lipid profile parameter which allows reliable stratification of CV risk, even though there are ongoing debates as to the preferred method of LDL-C determination (Friedewald formula, direct method, modified Friedewald formulas, newly proposed Martin formula) and conditions of LDL-C testing (under fasting conditions or not). The most common method of LDL-C determination is the Friedewald formula:

$$
\begin{gathered}
\text { (in } \mathrm{mg} / \mathrm{dl}): \mathrm{LDL}-\mathrm{C}=\mathrm{TC}-\mathrm{HDL}-\mathrm{C}-(\mathrm{TG} / 5) \\
\text { and (in } \mathrm{mmol} / \mathrm{l}): \mathrm{LDL}-\mathrm{C}=\mathrm{TC}-\mathrm{HDL}-\mathrm{C}-(\mathrm{TG} / 2.2) .
\end{gathered}
$$

However, it should be noted that the method may involve methodological measurement errors, since the LDL-C determination formula necessitates analyses of three separate lipid parameters: TC, HDL-C and TG. Also, the method should not be used if the TG level exceeds $400 \mathrm{mg} / \mathrm{dl}$ (> 4.5 $\mathrm{mmol} / \mathrm{l}$ ) or if fasting conditions cannot be ensured (in such cases non-HDL-C should preferably be determined). Measurement errors may also accompany very low LDL-C levels [31, 32]. Available studies show that the direct method of determining LDL-C seems comparable to the Friedewald formula and carries no risk of error in the situations described above, with the exception of hypertriglyceridaemia and very low LDL-C levels (with potential differences of $\pm 15 \mathrm{mg} / \mathrm{dl}$ ) [32]. In such cases, non-HDL-C and ApoB tests can be considered [32]. The most recent studies indicate that the Martin formula of determining LDL-C may be the most effective method, free from the limitations outlined above, however further studies are needed to verify the results obtained to date [33]. Recent data also suggest that lipid parameter tests performed under fasting or non-fasting conditions are comparable in terms of $\mathrm{CV}$ risk prediction, particularly with regard to TC, LDL-C and HDL-C. Food ingestion, however, has a significant effect on TG, as results obtained under non-fasting conditions are on average $27 \mathrm{mg} / \mathrm{dl}(0.3 \mathrm{mmol} / \mathrm{l})$ higher than under fasting conditions [32].

\subsection{Other lipid profile parameters}

Total cholesterol tests are essentially insignificant nowadays, as they are only used in determining the SCORE risk and the level of non-HDL-C, and in diagnosing patients with familial hypercholesterolaemia (in cases involving very high values, particularly over $290 \mathrm{mg} / \mathrm{dl}(7.6 \mathrm{mmol} / \mathrm{l})$ ) [32].

The concentration of HDL-C is currently irrelevant for predicting CV risk, and available studies with nicotinic acid (niacin) or cholesteryl ester transfer protein (CETP) inhibitors have failed to demonstrate any role of $\mathrm{HDL}-\mathrm{C}$ in reducing residual risk [31]. Furthermore, studies conducted in recent years have revealed a high complexity of HDL-C metabolism including the effects of inflammation, oxidative stress or glycation process on HDL-C functionality and generation of dysfunctional HDL-C which may display proatherogenic properties [34].

The determination of triglycerides may be of high relevance in patients with diabetes and metabolic syndrome accompanied by atherogenic dyslipidaemia, i.e. a condition characterized by high TG levels coexisting with low concentrations of HDL-C and high concentrations of sdLDL (the most atherogenic LDL-C fraction). Available prospective and genetic studies as well as meta-analyses have shown indisputably that high TG concentration is an independent risk factor for CV events [32].

From the practical (clinical) point of view, special attention should also be focused on non-HDL-C (calculated as the difference between TC and HDL-C) which is used for the assessment of total plasma concentration of atherogenic lipoproteins (very low density lipoprotein (VLDL) cholesterol, VLDL remnants, intermediate-density lipoproteins (IDL), LDL and $L p(a)$ ). The determination of the parameter involves no additional costs, and its values are at least as predictive as the LDL-C level. Consequently, it seems valid to recommend the determination of non-HDL-C in all lipid profile tests, particularly in high and very high risk patients who have achieved LDL-C targets (Table VII) [32].

In recent years, especially following research into proprotein convertase subtilisin/kexin type 9 (PCSK9) inhibitors, attention has focused on the special role of $L p(a)$ as an independent (of other risk factors: arterial hypertension, LDL-C, diabetes or smoking) predictor of CV risk. Due to the fact that the concentration of $L p(a)$ is largely genetically conditioned, high $\operatorname{Lp}(\mathrm{a})$ levels are often found in individuals with a family history of high concentrations of this lipid parameter often resulting in early CV events or fatal CVD $[35,36]$. As a consequence, $\operatorname{Lp}(\mathrm{a})$ determination should always be considered in symptomatic individuals with no other risk factors and with a family history of early-onset CVD of atheromatous origin and in patients with high CV risk levels (Table VIII). Every $L p(a)$ value above the $80^{\text {th }}$ percentile (50 $\mathrm{mg} / \mathrm{dl}$ ) should be regarded as a significant CV risk factor [32]. 
Table VII. Recommendations for determining lipid profile parameters as treatment targets in prevention of ischaemic heart disease

\begin{tabular}{|c|}
\hline Recommendations \\
\hline LDL-C is recommended as the primary target of therapy \\
\hline $\begin{array}{l}\text { Total cholesterol determination should be considered wh } \\
\text { of other parameters is not available }\end{array}$ \\
\hline $\begin{array}{l}\text { Non-HDL-C determination should be considered as a sec } \\
\text { of therapy, } \\
\text { - particularly in patients who have achieved target LDL-C }\end{array}$ \\
\hline $\begin{array}{l}\text { ApoB should be considered as a secondary target of ther } \\
\text { determination is possible }\end{array}$ \\
\hline HDL-C is not recommended as a target of therapy \\
\hline $\begin{array}{l}\text { Table VIII. Populations in which Lp(a) determina- } \\
\text { tion/monitoring should be considered }\end{array}$ \\
\hline Patients with premature cardiovascular disease \\
\hline Patients with familial hypercholesterolaemia \\
\hline $\begin{array}{l}\text { Patients with a history of premature CVD or elevated } \\
\text { Lp(a) concentration }\end{array}$ \\
\hline $\begin{array}{l}\text { Patients with repeated CV events despite optimal } \\
\text { lipid-lowering therapy }\end{array}$ \\
\hline $\begin{array}{l}\text { Patients with 10-year risk of fatal CVD } \geq 5 \% \text { (based on } \\
\text { Pol-SCORE) }\end{array}$ \\
\hline
\end{tabular}

\section{KEY POINTS TO REMEMBER}

- The Friedewald formula for determining LDL-C should not be used when TG concentrations exceed $400 \mathrm{mg} / \mathrm{dl}(>4.5 \mathrm{mmol} / \mathrm{l})$ and when $\mathrm{LDL}$ values are low $(\leq 100 \mathrm{mg} / \mathrm{dl}$ $(2.6 \mathrm{mmol} / \mathrm{l}))$.

- Lipid parameter tests performed under fasting or non-fasting conditions are comparable particularly with regard to TC, LDL-C and HDL-C. Food ingestion, however, has a significant effect on TG: results obtained under nonfasting conditions are on average $27 \mathrm{mg} / \mathrm{dl}$ (0.3 $\mathrm{mmol} / \mathrm{l})$ higher than under fasting conditions.

- TG determination can be of great significance in patients with diabetes and/or metabolic syndrome, which is accompanied by atherogenic dyslipidaemia.

\section{RECOMMENDATIONS}

- $\mathrm{LDL}-\mathrm{C}$ is recommended as the primary target of treatment, and non-HDL-C determination should be considered as a secondary target of therapy.

- HDL-C is not recommended as a target of therapy.

- Lp(a) determination should always be considered in patients with premature CVD (often without other CV risk factors) and/or with a family history of CVD.

\section{DYSLIPIDAEMIA TREATMENT TARGETS (RISK-RELATED TARGET VALUES)}

The greatest importance is attributed to the achievement of the therapeutic target for LDL-C [32]. It is a result of several facts which have been well-established for a long time now. Firstly, both inter- and intrapopulation epidemiological studies reveal a direct proportional relationship between the concentration of the lipoprotein and the risk of CV events, mainly of the coronary type [6, 32]. Secondly, clinical observations show that individuals with high LDL-C concentrations are under high risk of premature CVD [6]. One example is genetically determined FH [2]. Thirdly, hypercholesterolemia induced by a cholesterol-rich diet may lead to atherosclerosis in rabbits. Fourthly, cholesterol found in atheromatous plaques is known to come from LDL [37]. Finally, a decrease in LDL-C level causes a proportional reduction of CVD risk, as shown in multiple studies investigating statins [6, 31, 32]. The last finding concludes the theory on the causal role of LDL-C for the development of atherosclerosis.

The therapeutic target for LDL-C depends on the individual risk of fatal CVD during a 10-year period (Table IX) $[6,32]$. The higher the risk, the lower the LDL-C level should be (according to the theory: "the lower the better").

There are no data suggesting that low LDL-C concentrations (even $<25 \mathrm{mg} / \mathrm{dl}(0.6 \mathrm{mmol} / \mathrm{l}))$ are harmful. Also, it should be strongly stressed that after achieving the therapeutic target for LDL-C, statin treatment is continued at the same doses $[6,32]$. This is because, based on available data, the strategy continues to reduce the risk of CV events, while statin discontinuation or dose reduction after target achievement may be associated with atheromatous plaque instability and an increased risk of CV event [6, 32, 37].

Non-HDL-C and/or ApoB concentration can be a secondary target of therapy especially in patients with high TG levels [6, 32]. Non-HDL-C is a measure of TC content in all atherogenic lipoproteins, i.e. LDL, VLDL and so-called remnants. Remnants are partially catabolized lipoproteins 
Table IX. Recommendations for target LDL-C and non-HDL-C and ApoB concentrations [6, 32]

\begin{tabular}{|c|c|}
\hline Risk & Target lipid concentration \\
\hline Low: risk of fatal cardiovascular disease $<1 \%$ based on Pol-SCORE & \multirow{2}{*}{$\begin{array}{l}\text { - } \mathrm{LDL}-\mathrm{C}<115 \mathrm{mg} / \mathrm{dl}(<3 \mathrm{mmol} / \mathrm{l}) \\
\text { - Non-HDL-C }<145 \mathrm{mg} / \mathrm{dl}(<3.8 \mathrm{mmol} / \mathrm{l})\end{array}$} \\
\hline $\begin{array}{l}\text { Moderate: risk of fatal cardiovascular disease } \geq 1 \% \text { and }<5 \% \\
\text { based on Pol-SCORE }\end{array}$ & \\
\hline \multicolumn{2}{|l|}{ High: } \\
\hline $\begin{array}{l}\text { Single strong risk factor (familial dyslipidaemia, severe arterial } \\
\text { hypertension) }\end{array}$ & \multirow{4}{*}{$\begin{array}{l}\text { - } \mathrm{LDL}-\mathrm{C}<100 \mathrm{mg} / \mathrm{dl}(<2.6 \mathrm{mmol} / \mathrm{l}) \text { or } \\
\text { reduction by } \geq 50 \% \text { if the baseline value is } \\
100-190 \mathrm{mg} / \mathrm{dl}(2.6-4.9 \mathrm{mmol} / \mathrm{l}) \\
\text { - } \text { Non-HDL-C }<130 \mathrm{mg} / \mathrm{dl}(<3.3 \mathrm{mmol} / \mathrm{l})^{*} \\
\text { - } \text { Apo } \mathrm{B}<100 \mathrm{mg} / \mathrm{dl}^{* *}\end{array}$} \\
\hline $\begin{array}{l}\text { Type } 1 \text { or } 2 \text { diabetes without an additional risk factor or organ } \\
\text { damage }\end{array}$ & \\
\hline Moderate chronic kidney disease (GFR: 30-59 ml/min/1.73 m²) & \\
\hline $\begin{array}{l}\text { Risk of fatal cardiovascular disease } \geq 5 \% \text { and }<10 \% \text { based on } \\
\text { Pol-SCORE }\end{array}$ & \\
\hline \multicolumn{2}{|l|}{ Very high: } \\
\hline Diagnosed cardiovascular disease & \multirow{4}{*}{$\begin{array}{l}\text { - } \mathrm{LDL}-\mathrm{C}<70 \mathrm{mg} / \mathrm{dl}(<1.8 \mathrm{mmol} / \mathrm{l}) \text { or } \\
\text { reduction by } \geq 50 \% \text { if the baseline value is } \\
70-135 \mathrm{mg} / \mathrm{dl}(1.8-3.5 \mathrm{mmol} / \mathrm{l}) \\
\text { - } \text { Non-HDL-C }<100 \mathrm{mg} / \mathrm{dl}(<2.6 \mathrm{mmol} / \mathrm{l})^{*} \\
\text { - } \text { Apo } \mathrm{B}<80 \mathrm{mg} / \mathrm{dl}^{* *}\end{array}$} \\
\hline $\begin{array}{l}\text { Type } 1 \text { or } 2 \text { diabetes with } \geq 1 \text { risk factor or organ damage } \\
\text { (e.g. microalbuminuria) }\end{array}$ & \\
\hline Severe chronic kidney disease (GFR < 30 ml/min/1.73 m²) & \\
\hline Risk of fatal cardiovascular disease $\geq 10 \%$ based on Pol-SCORE & \\
\hline
\end{tabular}

transporting triglycerides, i.e. VLDL and chylomicrons, and have proportionally higher cholesterol content [32]. Remnants play a similar role in the development of atherosclerosis as LDL-C [32]. Increased concentrations of remnants can accompany combined hyperlipidaemia, diabetes, metabolic syndrome and CKD. ApoB is an indicator of the number of atherogenic lipoprotein particles. Every particle of LDL, VLDL and remnants contains an ApoB particle. However, experts from the European Society of Cardiology (ESC) and other societies responsible for developing the most recent guidelines for the prevention of CVD, similarly to the authors of the guidelines for the management of dyslipidaemias issued by the ESC and the European Atherosclerosis Society (EAS), have concluded that there is no sufficient evidence showing $A p o B$ to be a better prognostic factor for risk than LDL-C (or non-HDL-C) [6, 32].

Observational studies demonstrate that hypertriglyceridaemia is an independent risk factor for CVD (weaker than hypercholesterolaemia), however no therapeutic targets are available for that lipid because of lack of evidence coming from randomized controlled trials (RCTs) that would serve as a basis for establishing such targets [32, 38]. Nevertheless, TG concentrations of $>150 \mathrm{mg} / \mathrm{dl}$ (> $1.7 \mathrm{mmol} / \mathrm{l}$ ) under fasting conditions are still recognized as a marker of increased risk, and TG values of $>200 \mathrm{mg} / \mathrm{dl}(>2.3 \mathrm{mmol} / \mathrm{l}$ ) (during statin treatment) - as an indication to consider an additional treatment with fenofibrate [32, 38].

Based on observational studies, a low HDL-C concentration is a risk factor for the development of ischaemic heart disease. However, it has not been established indisputably whether it represents a causal factor [34]. Studies conducted to date on drugs increasing the concentration of HDL-C have failed to demonstrate a reduction in the risk of CV events [6, 26, 32]. Consequently, $\mathrm{HDL}-\mathrm{C}$ is not a target of therapy, however based on available epidemiological study results, $\mathrm{HDL}$ concentrations $<40 \mathrm{mg} / / \mathrm{dl}(<1.0 \mathrm{mmol} / \mathrm{l})$ in men and $<45 \mathrm{mg} / \mathrm{dl}(<1.2 \mathrm{mmol} / \mathrm{l})$ in women can be considered as markers of elevated risk [6, 32].

\section{RECOMMENDATIONS}

- The primary target in the treatment of dyslipidaemias is to reduce the LDL-C level.

- The targets of therapy depend on the risk of CV event. The higher the risk, the lower the LDL-C level should be aimed at (see Table IX).

- After achieving the LDL-C target, statin therapy should be continued at the same doses.

- In primary prevention, Pol-SCORE-based risk estimation should be performed (see Chapter 5), with the exception of patients: (a) with a history of CV event; (b) peripheral artery atherosclerosis; (c) carotid atheromatous plaques; (d) severe arterial hypertension; (e) suspected primary hypercholesterolaemia; ( $\mathrm{f}$ ) diabetes; (g) chronic kidney disease. Such patients are at very high or high risk regardless of their gender and age, and do not require an assessment based on the Pol-SCORE chart. 


\section{RESIDUAL RISK}

Residual risk refers to the probability of adverse events which persists despite taking measures aimed at risk minimization. In patients with CVD, measures reducing mortality and morbidity risks are geared towards the control of modifiable risk factors for the development of atherosclerosis. The residual risk in a dyslipidaemia patient refers to the risk of death, $\mathrm{MI}$ and stroke, which persists in that patient despite ongoing dyslipidaemia treatment and achievement of therapeutic targets (e.g. for LDL-C) [39]. Available studies investigating statins show that a decrease in LDL-C by an average of $28 \%$ causes a $31 \%$ reduction in relative risk, leaving a residual risk of $69 \%$, i.e. higher than that eliminated in the course of treatment [40].

In the prevention of CVD and treatment of dyslipidaemias, crucial importance is attributed to lipid-lowering drugs, predominantly statins, which have demonstrated a high efficacy in these indications. However, the risk remains even in individuals who, following intensive statin therapy, have achieved a decrease in LDL-C concentration to the target level [41]. Some patients could benefit from a decrease in residual risk through an earlier introduction of statin treatment, others from more intensive therapy and yet others - from combination therapy. Hence family physicians play an important role in the early diagnosis of dyslipidaemias, introduction of lifestyle changes and optimization of pharmacological therapy in patients. Other identified risk factors, such as smoking, excessive alcohol consumption, hypertension, elevated glycaemia values, overweight or obesity, and low physical activity levels, also require appropriate management [42]. Reducing the level of residual risk probably can also be accomplished through an effect on various factors: psychological (e.g. relief of stress, therapy for depression), social (e.g. assistance in gaining support and preventing social exclusion) and environmental (e.g. improvement in living and working conditions). Health professionals, quality of medical care provided to patients, organization of the healthcare system and health policy are all known to have a role in decreasing residual risk [40].

International initiatives stress that family physicians in their practice should pay a closer attention to atherogenic dyslipidaemia (elevated TG and LDL-C concentrations, low HDL-C concentration) occurring in patients with diabetes and metabolic syndrome. Atherogenic dyslipidaemia frequently remains undiagnosed and untreated, resulting in failure to achieve the potential for risk reduction [43]. So far, RCTs with fibrates and nicotinic acid have failed to demonstrate a reduction in residual risk linked to a TG decrease and HDL-C increase. The only drug which has been shown to decrease the level of residual risk (by $6 \%$ ) related to an additional LDL-C reduction is ezetimibe in combination with simvastatin [44]. Studies are ongoing to determine the effects of CEPT inhibitors (anacetrapib) and PCSK9 inhibitors (evolocumab, alirocumab) [41].

\section{KEY POINTS TO REMEMBER}

- In dyslipidaemia treatment, especially in patients with diagnosed heart disease and classified as being at high risk, aside from statins, other lipid-lowering drugs (which further decrease the LDL-C and TG levels) and combination treatment may be considered to reduce residual risk.

- In patients who have achieved LDL-C targets, residual risk is linked to a number of risk factors including arterial hypertension, hyperglycaemia, inflammatory diseases and inappropriate lifestyle. Consequently, targeted treatment also taking into account the above-mentioned disorders should be introduced.

\section{NON-PHARMACOLOGICAL PREVENTION AND TREATMENT OF DYSLIPIDAEMIAS}

One of the fundamental goals defined by ESC for the management of CV risk is the control of dyslipidaemia. The central target in controlling dyslipidaemia is to reduce the concentrations of LDL-C, i.e. the most atherogenic cholesterol fraction. According to the current guidelines, the first step involves estimating the patient's CV risk and full lipid profiling. On that basis, the management strategy which is recommended in a particular patient group should be selected. Based on the guidelines issued by the European Association for Cardiovascular Prevention and Rehabilitation (EACPR) in June 2016 [6], lifestyle modifications are recommended in all patients, while lipid-lowering drugs are indicated only in selected clinical situations. Similar recommendations are included in the ESC/EAS Guidelines for the management of dyslipidaemias issued in August 2016 [32]. The effects of non-pharmacological modifications on different lipoprotein fractions are summarized in Table X.

\subsection{Effect on TC and LDL-C levels}

The dietary factor with the strongest impact on reducing the levels of total cholesterol and low-density cholesterol fraction is a decrease in the consumption of saturated fatty acids (SFAs) and trans fats [6, 45]. Functional foods containing phytosterols have been shown to have a similar impact on TC and LDL-C $[6,32]$. For every $1 \%$ of 
Table X. Impact of non-pharmacological changes on different lipid profile parameters

\begin{tabular}{|c|c|c|c|}
\hline Impact of specific non-pharmacological changes & TC and LDL-C & TG & HDL-C \\
\hline Reduced dietary trans fats & $\begin{array}{c}+++ \\
\mathrm{A}\end{array}$ & - & $\begin{array}{c}+++ \\
\mathrm{A}\end{array}$ \\
\hline Reduced dietary saturated fats & $\begin{array}{c}+++ \\
\mathrm{A}\end{array}$ & - & - \\
\hline Increased dietary fibre & $\begin{array}{c}++ \\
\mathrm{A}\end{array}$ & - & - \\
\hline Functional foods enriched with phytosterols & $\begin{array}{c}++ \\
\mathrm{A}\end{array}$ & - & - \\
\hline Reduced alcohol intake & - & $\begin{array}{c}+++ \\
\mathrm{A}\end{array}$ & $\begin{array}{l}\text { Moderate intake } \\
\text { is acceptable }\end{array}$ \\
\hline Regular physical activity & $\begin{array}{l}+ \\
\mathrm{B}\end{array}$ & $\begin{array}{c}++ \\
\mathrm{A}\end{array}$ & $\begin{array}{c}+++ \\
\mathrm{A}\end{array}$ \\
\hline Reduced intake of mono-and disaccharides & - & $\begin{array}{c}++ \\
\mathrm{B}\end{array}$ & $\begin{array}{l}+- \\
\mathrm{C}\end{array}$ \\
\hline Reduced excessive body weight & $\begin{array}{c}++ \\
\mathrm{A}\end{array}$ & $\begin{array}{c}+++ \\
\mathrm{A}\end{array}$ & $\begin{array}{c}++ \\
\mathrm{A}\end{array}$ \\
\hline Red yeast rice supplements & $\begin{array}{c}++ \\
\mathrm{A}\end{array}$ & - & - \\
\hline Supplements containing omega 3 acids & - & $\begin{array}{c}++ \\
\mathrm{A}\end{array}$ & - \\
\hline
\end{tabular}

$A, B, C$ - levels of evidence. The strength of effect achieved with a particular intervention is marked with ' + ' or '-' in the following manner: +++ , pronounced effect, ++ less evident effect, + small effect and - no effect.

the dietary energy derived from SFAs which is replaced with monounsaturated fatty acids (MUFAs), plasma LDL-C levels decrease by $1.6 \mathrm{mg} / \mathrm{dl}$; and substitution with polyunsaturated fatty acids (PUFAs) results in a LDL-C decrease of $2.0 \mathrm{mg} / \mathrm{dl}$. The replacement of SFAs with carbohydrates translates into the lowest reduction of LDL-C $(1.2 \mathrm{mg} / \mathrm{dl})[6,32]$. Optimal dietary substitutes for products with a high SFA content are carbohydrate foods rich in fibre. Dietary fibre actively lowers the absorption of fats in the intestines. In addition, the majority of fibre-rich plant products have a low energy density which facilitates the maintenance of the recommended balance of calories. Body weight reduction, similarly to physical activity, fails to influence LDL-C in a meaningful way: a drop in LDL-C concentration by $8 \mathrm{mg} / \mathrm{dl}$ is observed for every $10 \mathrm{~kg}$ of weight loss. Importantly, however, both excess body weight and low levels of physical activity represent independent risk factors for CVD. Furthermore, a lifestyle intervention in this scope contributes significantly to a TG decrease and HDL-C increase [6, 32].

\subsection{Effect on TG levels}

The most effective interventions aimed at reducing TG levels include body weight reduction, minimization of alcohol intake, reduced consumption of monosaccharides, as well as regular physical activity [6]. Body weight loss improves insulin sensitivity in tissues, which has a direct impact on the plasma concentrations of TG. Achieving a nor- mal body weight in some patients is difficult due to an oversupply of calories contained in alcohol. Excessive alcohol intake (over 10-30 g/day) significantly elevates the concentration of TG $[6,32$, 45]. Replacing SFAs with unsaturated fatty acids significantly improves insulin sensitivity. Unfortunately, a dietary approach based on natural foods rarely ensures an adequate intake of unsaturated fatty acids, which is why n-3 PUFA supplements may be utilized [45].

In addition, TG levels are closely linked to a perturbation of carbohydrate metabolism. Excessive monosaccharide intake leads to a significant increase in TG concentrations. The best effects in reducing the fraction can be achieved through the consumption of foods with a low glycaemic index (e.g. raw fruit and vegetables, coarse grits, oat bran, cottage cheese and fish). The glycaemic index permits the identification and differentiation of foods with fast and slow rates of glucose absorption into the blood plasma. Fibre-rich plant foods make it possible to reduce the glycaemic index of food products through the absorption of glucose and its gradual release during intestinal transit $[6,45]$.

\subsection{Effect on HDL-C level}

Appropriately functional HDL have a protective effect with respect to atherogenesis. Unfortunately, pharmacological attempts to increase the levels of these lipoproteins have failed to yield satisfactory results in terms of CV risk reduction, so the 
only tools available today are based on insights from behavioural medicine [34, 45]. The most prominent increase in $\mathrm{HDL}-\mathrm{C}$ is observed following a reduction in the dietary intake of trans fats. In addition, trans unsaturated fats lead to an increase in LDL-C levels. A HDL-C increase is observed in response to an increased consumption of SFAs. Unfortunately, the increase is also associated with a rise in LDL-C, which ultimately fails to produce a beneficial effect in terms of minimizing CV risk. It should be stressed that the substitution of fats for carbohydrates as energy sources is associated with a significant decrease in HDL-C. However, no such effect has been observed to accompany the substitution of energy sources for complex carbohydrates and foods with high fibre content (with a low glycaemic index) [6, 32].

One of the HDL-C-inducing dietary habits is alcohol consumption. However, this applies exclusively to moderate alcohol consumption (up to $30 \mathrm{~g} /$ day in men and $20 \mathrm{~g} /$ day in women), whereas alcohol abuse ranks among risk factors for a number of diseases. Due to the risk of developing alcohol addiction and the fact that alcohol produces detrimental effects, alcohol intake should not be recommended to patients. Weight reduction is also known to have a beneficial influence on HDL-C concentrations: an approximately $0.4 \mathrm{mg} / \mathrm{dl}$ increase in $\mathrm{HDL}-\mathrm{C}$ is observed for every $1 \mathrm{~kg}$ decrease in body weight. The same effect has been observed for aerobic physical activity. An energy expenditure of about $1000 \mathrm{kcal}$ translates into an increase in the HDL-C level by about $3 \mathrm{mg} / \mathrm{dl}[32,45]$.

\subsection{Role of nutraceuticals and functional foods}

\section{Functional foods}

Functional foods perform a potentially important functional role supporting the achievement of therapeutic goals with respect to the concentrations of TC and individual lipid fractions. At present, the most thoroughly investigated and the most effective are food products containing phytosterols. The section below outlines only a few selected nutraceuticals with documented lipid-lowering properties.

\section{Phytosterols and stanols}

The principal phytosterols are sitosterol, campesterol and stigmasterol. They occur naturally in vegetable oils, vegetables, fresh fruit, whole grain products and legumes [6, 32]. They are also added to some margarines and yoghurts. The daily consumption of $2 \mathrm{~g}$ of phytosterols or stanols (synthesized from plant sterols; naturally occurring in fruit, nuts, grains and vegetable oils) can effectively lower LDL-C and TC levels by about 7-10\% $[6,46]$.

\section{MUFAs and PUFAs}

Special attention in this group should be focused on n-3 unsaturated fatty acids. Ingested in the amount of about 2-3 g/day, they can reduce TG levels by about 25-30\% [32, 45]. However, such supplementation can only translate into a small (of about 5\%) increase in LDL-C concentrations. The use of n-3 PUFA is recommended in the treatment of hypertriglyceridaemia in patients with very high TG concentrations as an adjuvant to pharmacological treatment.

\section{Red yeast rice}

The mechanism of pigments contained in fermented rice is identical to that in statins. This is due to the fact that monacolin $\mathrm{K}$ contained in red yeast rice is chemically identical to lovastatin [45]. It should be noted, though, that commercially available products containing monacolin $\mathrm{K}$ may vary in the dose of the compound, which will have an impact on the strength of effect. The products, however, can be a good solution for early pharmacologic treatment of dyslipidaemia in patients who are ineligible for statin therapy.

\subsection{Role of healthy lifestyle}

Some of the more common risk factors for dyslipidaemia, which are widespread in the Polish population include overweight and obesity $[1,11]$. It is therefore proposed that the achievement of appropriate body weight (body mass index (BMI) of $18.5-24.9 \mathrm{~kg} / \mathrm{m}^{2}$ ) should constitute one of the targets of the strategy to maintain normal lipoprotein concentrations [6]. In addition to BMI, another important factor to consider is the patient's waist circumference. Irrespective of BMI values in the normal range, an increased waist circumference (men $\geq 94 \mathrm{~cm}$; women $\geq 80 \mathrm{~cm}$ ) is a factor determining a higher risk of CVD.

The development of healthy eating habits should involve not only an appropriate balance between calorie intake and expenditure but also good proportions of basic nutrients. Fatty acids should not account for more than $30 \%$ of energy supply, and SFAs should not exceed $10 \%$ of total energy supply in dyslipidaemia-free individuals, while patients with lipid disorders should have a reduced dietary intake of SFAs (to maximum 7\%) [6]. Optimally, SFAs in the daily diet should be substituted for MUFAs and PUFAs, which can be achieved with diets based on plant products. This method of shaping dietary habits is consistent with the most recent food pyramid published by the World Health Organization (WHO). Eating habits which are based on plant products also provide a high amount of dietary fibre and a reduced intake of simple sugars. Complex carbohydrates 
should represent up to $55 \%$ of total energy supply. Dietary carbohydrates should be dominated by complex sugars, while simple sugars (i.e. monoand disaccharides) should not exceed $10 \%$ of total energy supply [6].

Lifestyle medicine is one of the most important constituent elements of dyslipidaemia prevention and treatment. The crucial role here is played by modifications of dietary habits, physical activity and supplementation based on functional foods. In the light of the current Guidelines, lifestyle modifications should be encouraged in each patient group [6, 32] as an intrinsic element of dyslipidaemia treatment.

\section{RECOMMENDATIONS}

- Non-pharmacological modifications are recommended in all dyslipidaemia patients.

- The intake of saturated fatty acids should be reduced to $<10 \%$ of total energy supply and to $<7 \%$ in dyslipidaemia patients.

- Trans-unsaturated fatty acids of natural origin should provide $<1 \%$ of all consumed calories. Trans-unsaturated fatty acids of industrial origins should be avoided.

- The daily intake of fruit should be at least $200 \mathrm{~g}$.

- The daily intake of vegetables should be at least $200 \mathrm{~g}$

- Fish should be consumed 1-2 times a week as a minimum.

- Regular physical activity (at least 4-5 times a week) should be promoted: moderate physical activity of at least 150 minutes a week or intensive physical activity of at least 75 minutes a week.

\section{PHARMACOLOGICAL TREATMENT OF DYSLIPIDAEMIA}

\subsection{Statins}

Lipid-lowering drugs, including statins, along with their history, mechanism of action, usage, side effects and clinical efficacy, have recently been described in a detailed study [46]. Statins have been in clinical use for 30 years. The two most powerful drugs from this group, atorvastatin and rosuvastatin, are predominantly used nowadays. Statins inhibit hydroxymethylglutaryl-CoA (HMG-CoA) reductase, which is a key enzyme for the synthesis of cholesterol in hepatocytes. As a result, an increase in the activity of LDL receptors (LDLR) on the cells is noted, together with an increased clearance of lipoproteins containing apolipoprotein B-100, i.e. LDL and VLDL remnants (including IDL). In comparative studies, atorvastatin and rosuvastatin used for 6 weeks at a dose of $10 \mathrm{mg} /$ day reduced the LDL-C concentration by $36.8 \%$ and $45.8 \%$, respectively; at a dose of $20 \mathrm{mg} /$ day - by $42 \%$ and $52.4 \%$, respectively; and at a dose of $40 \mathrm{mg} /$ day - by $47.8 \%$ and $55 \%$, respectively [47]. Statins cause a moderate reduction in TG concentration. Atorvastatin at doses of $10 \mathrm{mg} /$ day, $20 \mathrm{mg} /$ day and $40 \mathrm{mg} /$ day has been found to decrease the TG level by $20 \%, 22.6 \%$ and $26.8 \%$, respectively, and rosuvastatin used at the same doses - by $19.8 \%, 23.7 \%$ and $26.1 \%$, respectively. The two statins play the most prominent role due to the achievement of the therapeutic target for LDL-C. However, their suitability for different patient groups varies. For example, atorvastatin is a safe statin in patients with CKD, and rosuvastatin at moderate doses is recommended in the elderly, as it has the best safety profile in this patient population [5].

The achievement of therapeutic targets for LDL-C depends on the baseline LDL-C concentration, strength and dose of the statin. However, a doubling of the dose results in an additional decrease in the level of the lipid by only $6 \%$. This relatively small additional lipid-lowering effect is believed to be attributable to an increased activity of PCSK9 during statin treatment (a feedback mechanism linked to a decrease in LDL-C concentration and an increase in LDLRs on hepatocyte surface). The enzyme breaks down LDLRs in hepatocyte lysosomes. Consequently, after LDL-C particles are introduced into liver cells, they fail to return to the cell membrane to bind further lipoproteins [31, 32].

The main adverse reactions caused by statins include myotoxicity and new cases of diabetes (see Chapter 13) [5, 48]. The most common causes for discontinuing therapy are muscle symptoms. They include myalgia, ranging from mild to severe in intensity, muscle stiffness and tenderness, cramps and weakening of muscular strength. They can be accompanied (or not) by a raised creatine kinase (CK) level. Factors predisposing to the development of myopathy include age over 75 years, female gender, renal and hepatic dysfunction, hypothyroidism, alcohol abuse, excessive physical exertion, genetic susceptibility, perioperative period and concurrent use of drugs inhibiting the metabolism of statins such as clarithromycin, erythromycin, azole antifungals, dilitiazem, verapamil, amiodarone, fibrates (particularly gemfibrozil), cyclosporin, clopidogrel, sulphonamides, red yeast rice [5, 32]. Statins may exhibit diabetogenic properties, however carbohydrate disorders/diabetes are not an indication to discontinue statin therapy, as benefits in the form of CV risk reduction outweigh the side effects. In such cases, patient management comprises a hypoglycaemic diet, loss of excessive body weight and prescription of antidiabetic drugs, if appropriate [32]. 
Numerous RCTs have provided strong evidence that statins are highly effective in primary and secondary prevention of CVD. The lower the LDL-C level achieved, the lower the risk of $\mathrm{CV}$ events. The correlation has been clearly corroborated in a meta-analysis of 26 randomized clinical trials investigating statins [49]. A total of 21 studies (statins vs other interventions, mainly placebo) involving 126,526 patients have found that a $1 \mathrm{mmol} / \mathrm{l}(\sim 40 \mathrm{mg} / \mathrm{dl})$ decrease in LDL-C level results in a significant reduction of CV events by $21 \%$. The same study shows that intensive statin therapy compared to moderate statin treatment (five studies in a total of 39,612 patients) is associated with a significant decrease in CV events by $28 \%$ per $1 \mathrm{mmol} / \mathrm{l}$ of $\mathrm{LDL}-\mathrm{C}$ reduction $(40 \mathrm{mg} / \mathrm{dl})$. Statin-based therapy reduces the incidence of stroke, fatal coronary events and overall mortality [49].

\section{KEY POINTS TO REMEMBER}

- Statins are first-line drugs in the treatment of hypercholesterolaemia; they have the best documented efficacy of all lipid-lowering medications in the primary and secondary prevention of CVD.

- In view of the need to achieve the therapeutic target for LDL-C atorvastatin and rosuvastatin are currently the most commonly used statin drugs.

- During treatment, attention should be focused on side effects reported by patients, mostly muscle symptoms. If they occur, the recommended management should be followed (see Chapter 13).

\subsection{Fibrates}

The mechanism of action, therapeutic indications, side effects and clinical outcomes associated with fibrates have recently been described in the Polish literature [46]. The action mechanism of fibrates depends on the activation of transcription factors called peroxisome proliferator-activated receptors $\alpha$ (PPAR $\alpha)$ [38]. Fibrates are PPAR $\alpha$ ligands and peroxisome proliferators. Through the activation of PPAR $\alpha$, the drugs influence the expression of key genes encoding proteins involved in lipid metabolism. A decrease in TG concentration is linked to the activation of oxidative enzymes which enhance the oxidation of fatty acids in the liver, ultimately reducing the synthesis of these lipids, and to an increased activity of lipoprotein lipase - an enzyme found on the vascular endothelium which triggers the hydrolysis of triglycerides, and thus their catabolism. Fibrates induce an increase in the synthesis of Apo-Al and All, i.e. two protein components of HDL-C $[38,46]$.

Fibrates reduce the concentration of TG by $25-$ $50 \%$ and increase the level of HDL-C by $10-25 \%$. Currently, they are mainly used to treat hypertriglyceridaemia. In patients with severe hypertriglyceridaemia, pharmacotherapy should start with a fibrate in order to promptly reduce the serum concentration of TG, which represents a risk factor for acute pancreatitis [32, 46]. The preferred fibrate is fenofibrate. According to the most recent (2016) ESC/EAS Guidelines for the management of dyslipidaemia, combination therapy (statin plus fenofibrate) should be considered in cases where the concentration of TG persists over $200 \mathrm{mg} / \mathrm{dl}$ (> $2.3 \mathrm{mmol} / \mathrm{l}$ ) on statin treatment [6, 32].

Adverse reactions developing during fibrate treatment are rare and generally moderate in nature. Myopathy and raised aminotransferase levels have been reported. Fibrates also elevate creatinine concentrations. Notably, they are eliminated via the kidneys in 60-90\%, which restricts their use in patients with CKD. A rise in the concentration of homocysteine and cases of acute pancreatitis and thromboembolic disease have also been reported [46].

Large clinical trials on fenofibrate conducted in diabetic patients (FIELD - Fenofibrate Intervention and Event Lowering in Diabetes, and ACCORD Action to Control Cardiovascular Risk in Diabetes) randomized for fenofibrate treatment have failed to demonstrate any effect on CV risk compared to placebo $[50,51]$. However, a clinical benefit in reducing $\mathrm{CV}$ events has been noted in the subgroups of patients with atherogenic dyslipidaemia (elevated TG plus reduced HDL-C level). Unfortunately, there are no data from large RCTs on fibrate therapy given exclusively to patients with atherogenic dyslipidaemia. It should be noted that the U.S. Food and Drug Administration (FDA) has recently withdrawn its approval to combine nicotinic acid and fibrates with statins, as scientific evidence does not support a reduction in the risk of $\mathrm{CV}$ events following a decrease in TG or increase in $\mathrm{HDL}-\mathrm{C}$ levels due to the effect of the drugs.

\section{KEY POINTS TO REMEMBER}

- The main indication for fibrate treatment is severe hypertriglyceridaemia. In such cases, a fibrate should be used as a first-line drug (see Chapter 10.9).

- The first-line drugs in patients with hypertriglyceridaemia are statins. A fibrate may be considered as add-on to statin therapy in patients with persistent hypertriglyceridaemia (TG > $200 \mathrm{mg} / \mathrm{dl}$ or $2.3 \mathrm{mmol} / \mathrm{l}$ ) despite using statins. 


\subsection{Ezetimibe}

Ezetimibe selectively inhibits the uptake of cholesterol from the intestinal lumen into enterocytes by selectively blocking the sterol transport protein NPC1L1 (Niemann-Pick C1 protein) [52]. Due to a reduced absorption less cholesterol reaches the liver. As a result, the expression of LDL receptors on the surface of hepatocytes is elevated, leading to an increase in the hepatic uptake of endogenous cholesterol contained in LDL lipoproteins.

Ezetimibe therapy at a dose of $10 \mathrm{mg}$ lowers the concentration of LDL-C in the range of $15-25 \%$ [53-55]. However, considerable inter-individual variation is seen, and can be attributed to dietary variability (a cholesterol-rich diet increases the lipid-lowering effect of the drug) and, probably, variation of genes encoding the NPC1L1 protein. As a result, some patients may respond to ezetimibe monotherapy better than others [56]. The drug reduces the concentration of TG by $1.7-9.4 \%$ [53, 57] and brings a minimal (1.3-6.2\%) increase in the HDL-C level [58].

Combination therapy with ezetimibe and a statin - due to their complementary activity - results in a more pronounced decrease in the concentration of LDL-C than that achieved with both drugs in monotherapy [59]. Ezetimibe added to a statin further reduces the LDL-C concentration by $15-20 \%$. Published RCTs on ezetimibe have demonstrated a high lipid-lowering efficacy and a beneficial safety profile of combination therapy in a group of patients with primary hypercholesterolaemia [60], kidney failure [61], type 2 diabetes [62], metabolic syndrome [63], high CV risk [64] and acute coronary syndrome [44]. In all the studies, the optimal target concentration of LDL-C and a greater reduction in TC, non-HDL-C, TG and $A p o B$ concentrations were achieved much more frequently in the patient group receiving combination treatment as compared to statin monotherapy. Furthermore, the results of the Improved Reduction of Outcomes: Vytorin Efficacy International Trial (IMPROVE-IT) study have shown that a LDL-C decrease achieved with ezetimibe significantly lowers the incidence of CV events [44].

Ezetimibe is rapidly absorbed from the gastrointestinal tract, largely in the form of the pharmacologically active ezetimibe glucuronide. The bioavailability of the drug is not significantly affected by simultaneous food intake. It is metabolized in the intestine and liver. It is neither an inducer nor an inhibitor of the cytochrome P450. As a result, it does not interact with drugs metabolized by this cytochrome. The concentration profile of ezetimibe is characterized by several peaks over a 24 hours period, which shows that the time of administration does not alter its activity [65]. The drug is excreted primarily in the faeces (78\%), with a smaller portion excreted in the urine (11\%). The pharmacokinetic parameters of ezetimibe in the elderly and in patients with renal failure or mild hepatic failure are not significantly altered [65]. However, the drug is contraindicated in patients with moderate and severe liver dysfunction. In contrast to drugs blocking the reuptake of bile acids, ezetimibe does not interfere with the absorption of fat-soluble vitamins, thyroid hormone, warfarin and $\beta 1$ blockers. Ezetimibe inhibits the absorption of plant sterols and stanols, so their concomitant use is not indicated [32].

\section{KEY POINTS TO REMEMBER}

Ezetimibe in monotherapy should be considered in patients with statin intolerance and in the combination therapy when the target LDL-C concentration is not achieved at maximal tolerated statin doses.

\subsection{PCSK9 inhibitors}

PCSK9 is a protein responsible for LDL-C metabolism associated with receptors for LDL-C, which are present in the blood and on the surface of liver cells [66]. The protein binds to LDLR on the hepatocyte surface and - together with LDL-C - it undergoes endocytosis followed by the degradation of complexes in hepatic cell lysosomes. As a result, the number of LDL receptors on the hepatocyte surface and in the blood decreases, leading to an increase in the LDL-C level [66]. The mechanism has been accidentally discovered in patients with very high LDL-C levels and diagnosed autosomal dominant hypercholesterolaemia (a gain-offunction mutation in the PCSK9 protein) and in patients with very low LDL-C levels $(<20 \mathrm{mg} / \mathrm{dl}$ ) with a loss-of-function mutation following which the non-functional PCSK9 protein fails to bind to the LDLR, prompting the return of receptors back to the surface of hepatocytes and, ultimately, an effective reduction in LDL cholesterol [67]. The finding served as a basis for initiating studies to investigate PCSK9 protein inhibitors (mainly monoclonal antibodies) which could be used as an adjunct to statins to achieve an effective reduction of LDL-C. A number of molecules using the mechanism outlined above are currently under study. The most advanced are studies on two subcutaneously administered monoclonal antibodies: alirocumab (ODYSSEY) and evolocumab (PROFICIO). On 1 November 2016, Pfizer announced the discontinuation of studies on bococizumab (SPIRE trial). At present, results are awaited from studies evaluating the effect of the therapy on CV events (CVOT - cardiovascular outcomes trials). The first outcomes are expected in March 2017. 
So far, studies have been conducted in three groups of patients - at high CV risk, with familial hypercholesterolaemia and statin intolerance [66]. The studies have shown that the drugs effectively lower the LDL-C level (between 45\% and $65 \%$ compared to placebo, depending on the patient group; and between $35 \%$ and $45 \%$ compared to ezetimibe), and thus help achieve the therapeutic targets in these groups in up to $80-90 \%$ of study subjects. What is more, PCSK9 inhibitors favourably affect other lipid profile parameters as well. They are effective at reducing the level of non-HDL-C (on average by $50 \%$ compared to placebo), ApoB (by about 50\%), TG (15-20\%) and Lp(a) (by about 25\%), and increasing the concentrations of HDL-C (5-10\%) and ApoA1 (3-5\%) [66, 68]. Based on randomized phase III trials evaluating the efficacy of treatment with PCSK9 inhibitors with respect to lipid profile parameters, the drugs (alirocumab and evolocumab) have been approved both by the U.S. FDA and the European Medicine Agency (EMA) in the following indications: in adults with primary hypercholesterolaemia (heterozygous familial and non-familial types) or mixed dyslipidaemia, as an adjunct to diet: (1) in combination with a statin or statin with other lipid-lowering therapies in patients unable to reach $L D L-C$ goals with the maximum tolerated dose of a statin or (2) alone or in combination with other lipid-lowering drugs in patients who are statin-intolerant, or for whom a statin is contraindicated. In view of studies conducted in patients with homozygous FH (TAUSSIG and TESLA trials) evolocumab should also be considered in combination with other lipid-lowering drugs in adults and adolescents of at least 12 years of age diagnosed with homozygous $\mathrm{FH}$ [69]. The drugs are already reimbursed in a number of European countries. In Poland, a decision regarding their reimbursement will probably be made after the completion of two studies, FOURIER (evolocumab) (March 2017) and ODYSSEY OUTCOMES (alirocumab) (March 2018), which will provide answers to questions about the efficacy of treatment, effect on endpoints and safety of therapy.

Studies completed to date have failed to identify any significant adverse reactions of PCSK9 inhibitors in comparison to statins and/or ezetimibe. Patients may occasionally exhibit symptoms (redness and tenderness) at the site of injection. In addition, typical symptoms accompanying therapy with monoclonal antibodies can be observed, including rhinitis and pharyngitis $(<5 \%)$, upper respiratory tract infections (about $3 \%$ ), back pain (about $3 \%$ ), joint pain (about $2 \%$ ), flu (about 2\%) and nausea (about 2\%). Despite extensive research and debates surrounding the is- sue, no evidence has been found for an increased risk of muscle-related symptoms (myalgia and myopathy), an elevation in liver enzymes and creatine kinase, new cases of diabetes or cognitive disorders $[66,68,69]$.

\section{KEY POINTS TO REMEMBER}

- PCSK9 inhibitors may be considered in very high and high risk patients who, despite using maximal tolerated statin doses in combination with ezetimibe, still have high LDL-C levels, and in patients with statin intolerance (see Chapters 12.3 and 13).

- Studies conducted to date have not identified any significant adverse reactions associated with treatment using drugs from this group.

\section{5. lon-exchange resins}

Resins bind bile acids in the intestine, thus reducing their concentration in the enterohepatic circulation. In this way, via a feedback mechanism, the conversion of cholesterol into bile acids is initiated in the liver. Reduced cholesterol content in hepatocytes increases the expression of the LDLR, which in turn lowers the LDL-C level in the serum [70]. In some patients, resins may intensify the formation of VLDL in the liver, resulting in an increase in the serum concentration of TG. In addition, they lower the glucose level in diabetic patients. The addition of colesevelam to antidiabetic drugs significantly improves glycaemic control, however there are no data indicating that the treatment contributes to a decrease in CV risk [70].

lon-exchange resins used at maximal doses (cholestyramine 24 g/day, colestipol 20 g/day or colesevalam $4.5 \mathrm{~g} /$ day) reduce the LDL-C level by $18-25 \%$. They have not been shown to affect the $\mathrm{HDL}-\mathrm{C}$ level in a significant manner. In predisposed individuals (with diabetes or abdominal obesity), they may induce an increase in the concentration of TG. Cholestyramine treatment for the primary prevention in hypercholesterolaemia patients has been associated with a significant $19 \%$ reduction in CV events [71, 72].

lon-exchange resins are not absorbed from the gastrointestinal tract and exhibit no systemic toxicity. However, they frequently cause adverse gastrointestinal effects (constipation, flatulence, nausea). Also, they reduce the absorption of fat-soluble vitamins. To avoid a reduced absorption of other drugs, ion-exchange resins should be taken four hours before or 1 hour after the intake of other drugs. The best tolerated ion-exchange resin is colesevelam [73]. 


\section{KEY POINTS TO REMEMBER}

- Monotherapy with an ion-exchange resin should be considered in patients who are intolerant of statins, and may be considered in the combination therapy when the therapeutic target is not achieved at maximal tolerated statin doses.

- lon-exchange resins are safe to use during pregnancy and lactation.

NOTE: No ion-exchange resin products are currently available in Poland.

\subsection{Nicotinic acid}

Nicotinic acid (niacin) inhibits the process of lipolysis in the adipose tissue, decreasing the synthesis of free fatty acids (FFA) and their influx to the liver. The process leads to a decrease in FFA supplied to the liver and, consequently, to a reduced VLDL secretion. The decrease in VLDL synthesis results in a reduced production of IDL and LDL. Furthermore, niacin directly inhibits hepatic diacylglycerol acyltransferase 2 (DGAT2) - a key enzyme involved in triglyceride synthesis. Nicotinic acid increases the synthesis of apoA 1 in the liver, leading to a rise in the concentration of HDL-C [74]. Nicotinic acid at a dose of $2 \mathrm{~g} /$ day lowers the level of LDL-C by about 15-18\%, TG by about $20-40 \%$ and $L p(a)$ by $30 \%$, and increases the concentration of HDL-C by $25 \%[74,75]$.

Negative results obtained in two trials - Atherothrombosis Intervention in Metabolic Syndrome With Low HDL/High Triglycerides: Impact on Global Health Outcomes (AIM-HIGH) [76] and the Heart Protection Study 2 - Treatment of HDL to Reduce the Incidence of Vascular Events (HPS2 THRIVE) [77] - have considerably weakened the status of nicotinic acid in lipid-lowering therapy. In AIM-HIGH, adding extended-release niacin $(1,500-2,000 \mathrm{mg} / \mathrm{dl})$ to standard statin therapy has failed to induce an additional reduction in CV events despite a recorded increase in the HDL-C level from $35 \mathrm{mg} / \mathrm{dl}(0.91 \mathrm{mmol} / \mathrm{l})$ to $42 \mathrm{mg} / \mathrm{dl}$ $(1.08 \mathrm{mmol} / \mathrm{l})$, and reductions in TG from $164 \mathrm{mg} /$ dl $(1.85 \mathrm{mmol} / \mathrm{l})$ to $122 \mathrm{mg} / \mathrm{dl}(1.38 \mathrm{mmol} / \mathrm{l})$ and in LDL-C - from $74 \mathrm{mg} / \mathrm{dl}(1.91 \mathrm{mmol} / \mathrm{l})$ to $62 \mathrm{mg} /$ dl (1.60 mmol/l) [76]. Similarly, HPS2-THRIVE has not found any additional clinical benefit of a treatment based on extended-release niacin with laropiprant (a compound inhibiting the synthesis of prostaglandin D2 which is responsible for skin redness and hot flushes) in combination with a statin [77]. Compared to statin monotherapy, the treatment has been associated with significantly more infections, hyperglycaemia, new cases of diabetes, gastrointestinal and musculoskeletal symptoms, gastrointestinal bleeding and skin symptoms.

\section{KEY POINTS TO REMEMBER}

In 2013, EMA narrowed down the indications for an extended-release nicotinic acid product to the treatment of dyslipidaemias with high triglyceride levels and only as an alternative therapy. At the same time, niacin in combination with laropiprant was withdrawn from use. NOTE: No nicotinic acid products are currently available in Poland.

\subsection{Drug combinations and future perspectives}

Statins are highly effective at lowering the LDL-C level, however even treatment based on the most powerful statins - rosuvastatin (at 20-40 mg) and atorvastatin (at $40-80 \mathrm{mg}$ ) - is not able to fully eliminate CV risk [78]. Residual CV risk can be as high as $60-70 \%$, so attempts have been made for many years to develop new drugs that will make it possible to reduce the risk level (see Chapter 8) [78].

From the practical viewpoint it seems that the central goal is to achieve a reduction in residual risk associated with LDL-C. In this indication, the most prominent medications nowadays are PCSK9 inhibitors and ezetimibe as an element of combined therapy with statins [79]. In this case, however, it is necessary to wait for the results of studies assessing the cardiovascular endpoints for PCSK9 inhibitors [79]. Another factor to bear in mind is FDA's negative position on ezetimibe following the IMPROVE-IT trial, even though EMA and the most recent ESC/EAS guidelines for the management of dyslipidaemias recommend ezetimibe for second-line therapy (in combination with statins) when the therapeutic target is not achieved at maximal tolerated statin dose or in patients intolerant of statins or with contraindications to these drugs $[32,80]$. Another drug, which effectively reduces the concentration of $L D L-C$ is bempedoic acid (ETC-1002), which acts through inhibiting ATP citrate lyase $(\mathrm{ACL})$. In this case, however, results are awaited from phase III trials to determine whether the therapy is effective and safe [81].

It should be noted that some of the drugs which are commonly used in a number of countries are either rarely prescribed or unavailable in Poland. They include ion-exchange resins, nicotinic acid or some fibrates (bezafibrate).

Other drug combinations have failed to demonstrate efficacy in reducing residual risk associated with increased HDL-C levels (in trials evaluating nicotinic acid and CETP inhibitors - evacetrapib, dalcetrapib and torcetrapib; studies on anacetrapib are still ongoing) [82]. At this point, a note 
should be made of a new alternative drug which may potentially cause a significant increase in HDL-C and ApoA1 concentrations and reduce the inflammatory process, particularly in diabetic patients [83]. The drug, called apabetalone (RVX208), is the first oral medication selectively inducing the synthesis of ApoA-I [83]. However, further study results are needed to provide conclusive evidence for its efficacy and safety.

Debates are currently ongoing about the use of fibrates (mainly fenofibrate in Poland) for second-line treatment of patients with diabetes, particularly in view of negative results obtained in the FIELD and ACCORD trials, and guidelines issued by the American College of Cardiology (ACC)/American Heart Association (AHA) in November 2013 [84, 85]. In the most recent ESC/ EAS guidelines (2016), however, the focus is on the importance of decreasing TG levels for reducing the risk of CV events. The guidelines recommend treatment with fibrates (though not with gemfibrozil) in addition to statins in patients with mixed dyslipidaemia and with TG > $200 \mathrm{mg} / \mathrm{dl}$ (> $2.3 \mathrm{mmol} / \mathrm{l})$ [32].

\section{KEY POINTS TO REMEMBER}

- Combined treatment offers possibilities for an effective reduction of residual CV risk, which is particularly important for high-risk patients.

- Studies conducted to date have demonstrated the highest efficacy of LDL-C-reducing drugs (ezetimibe and PCSK9 inhibitors) in second-line therapy added to statin treatment.

- Other therapies associated with a reduction in HDL-C or TG levels have failed to show their efficacy in available clinical studies. Further trials are needed to verify their benefits.

\subsection{Recommendations for dyslipidaemia treatment}

Detailed recommendations for the treatment of dyslipidaemias are listed in Table XI, and recommendations for the intensity of lipid-lowering statin treatment in different CV risk groups are presented in Table XII.

Table XI. Recommendations for dyslipidaemia treatment

\begin{tabular}{|c|c|c|}
\hline Recommendations & $\begin{array}{l}\text { Class } \\
\text { of recommendation }\end{array}$ & $\begin{array}{l}\text { Level } \\
\text { of evidence }\end{array}$ \\
\hline $\begin{array}{l}\text { Statins at maximal recommended or tolerated doses are indicated to } \\
\text { achieve the therapeutic target }\end{array}$ & I & A \\
\hline $\begin{array}{l}\text { If the target of therapy is not achieved, a combination of a statin with } \\
\text { ezetimibe should be considered }\end{array}$ & Ila & B \\
\hline $\begin{array}{l}\text { If the target of therapy is not achieved, a combination of a statin with an } \\
\text { ion-exchange resin may be considered* }\end{array}$ & $\mathrm{IIb}$ & C \\
\hline $\begin{array}{l}\text { In patients intolerant of statins, ezetimibe or an ion-exchange resin* or their } \\
\text { combinations* should be considered }\end{array}$ & Ila & $C$ \\
\hline $\begin{array}{l}\text { PCSK9 inhibitors }{ }^{\#} \text { may be considered in patients with a high and very } \\
\text { high CV risk, with persisting high LDL-C concentrations despite treatment } \\
\text { with maximal tolerated statin doses, in combination with ezetimibe or in } \\
\text { patients who are intolerant of statins including: } \\
\text { - in patients with FH and CVD or other CV risk factors, family history of } \\
\text { early-onset CVD or high Lp(a) levels } \\
\text { - in patients with FH without CVD and with at least one other CV risk } \\
\text { factor who fail to achieve target LDL-C levels despite treatment with } \\
\text { maximal tolerated statin doses, in combination with ezetimibe } \\
\text { - in patients after a CV event or with complicated diabetes and LDL-C } \\
\text { levels persisting }>160 \mathrm{mg} / \mathrm{dl}(4.2 \mathrm{mmol} / \mathrm{l}) \text { despite optimal lipid-lowering } \\
\text { treatment }\end{array}$ & IIb & C \\
\hline $\begin{array}{l}\text { Statin treatment may be considered for first-line management in high-risk } \\
\text { patients with hypertriglyceridaemia to achieve a reduction in CV risk }\end{array}$ & IIb & B \\
\hline $\begin{array}{l}\text { Adding fenofibrate to statin therapy may be considered in patients from } \\
\text { high and very high risk groups with TG levels persisting }>200 \mathrm{mg} / \mathrm{dl} \text { ( } 2.3 \\
\mathrm{mmol} / \mathrm{l}) \text { despite statin treatment }\end{array}$ & $\mathrm{Ilb}$ & C \\
\hline
\end{tabular}

*Not used in Poland; \# evolocumab and alirocumab. 
Table XII. Recommendations for the intensity of lipid-lowering statin treatment in different CV risk groups

\begin{tabular}{|c|c|c|c|}
\hline Risk group & LDL-C - primary target & $\begin{array}{c}\text { Non-HDL-C - } \\
\text { secondary target }\end{array}$ & Type of therapy \\
\hline Very high risk & $\begin{array}{c}<70 \mathrm{mg} / \mathrm{dl}(<1.8 \mathrm{mmol} / \mathrm{l}) \\
\text { in patients treated with } \\
\text { a statin } \\
\text { When baseline LDL-C } \\
70-135 \mathrm{mg} / \mathrm{dl} \\
(1.8-3.5 \mathrm{mmol} / \mathrm{l}) \\
\text { Reduction by at least } 50 \%\end{array}$ & $\begin{array}{l}<100 \mathrm{mg} / \mathrm{dl} \\
(<2.6 \mathrm{mmol} / \mathrm{l})\end{array}$ & $\begin{array}{l}\text { Intensive lipid-lowering therapy } \\
\text { (\%decrease in LDL-C by 50-60\%) } \\
\text { - atorvastatin } 40-80 \mathrm{mg} / \text { day } \\
\text { - rosuvastatin } 20-40 \mathrm{mg} / \text { day } \\
\text { - simvastatin } 40 \mathrm{mg}+\text { ezetimibe } 10 \mathrm{mg} / \text { day } \\
\text { - atorvastatin } 20 \mathrm{mg}+\text { ezetimibe } 10 \mathrm{mg} / \text { day } \\
\text { - rosuvastatin } 10 \mathrm{mg}+\text { ezetimibe } 10 \mathrm{mg} / \text { day } \\
\text { or } \\
\text { Very intensive lipid-lowering therapy } \\
\text { (\%decrease in LDL-C by over } 60 \%) \\
\text { - atorvastatin } 40-80 \mathrm{mg}+\text { ezetimibe } 10 \mathrm{mg} / \text { day } \\
\text { - rosuvastatin } 20-40 \mathrm{mg}+\text { ezetimibe } 10 \mathrm{mg} / \text { day } \\
\text { To be considered: } \\
\text { PCSK9 inhibitors - evolocumab } 140 \mathrm{mg} \text { every } \\
\text { other week subcutaneously or } 420 \mathrm{mg} \text { once } \\
\text { a month; } \\
\text { alirocumab } 75-150 \text { mg every other week } \\
\text { subcutaneously }\end{array}$ \\
\hline High risk & $\begin{array}{c}\quad<100 \mathrm{mg} / \mathrm{dl} \\
(<2.6 \mathrm{mmol} / \mathrm{l}) \text { in patients } \\
\text { treated with a statin } \\
\text { When baseline LDL-C } \\
100-190 \mathrm{mg} / \mathrm{dl} \\
(2.6-4.9 \mathrm{mmol} / \mathrm{l}) \\
\text { Reduction by at least } 50 \%\end{array}$ & $\begin{array}{c}<130 \mathrm{mg} / \mathrm{dl} \\
(<3.3 \mathrm{mmol} / \mathrm{l})\end{array}$ & $\begin{array}{l}\text { Intensive lipid-lowering therapy } \\
\text { (\%decrease in LDL-C by at least 50\%) } \\
\text { - atorvastatin } 20-40 \mathrm{mg} / \text { day } \\
\text { - rosuvastatin } 10-20 \mathrm{mg} / \text { day } \\
\text { - simvastatin } 20-40 \mathrm{mg}+\text { ezetimibe } 10 \mathrm{mg} / \text { day } \\
\text { - atorvastatin } 10-20 \mathrm{mg}+\text { ezetimibe } 10 \mathrm{mg} / \text { day } \\
\text { - rosuvastatin } 5-10 \mathrm{mg}+\text { ezetimibe } 10 \mathrm{mg} / \text { day } \\
\text { When baseline LDL-C > } 190 \mathrm{mg} / \mathrm{dl} \text { (> } 4.9 \mathrm{mmol} / \mathrm{l} \text { ) } \\
\text { Very intensive lipid-lowering therapy } \\
\text { (\%decrease in LDL-C by over } 60 \% \text { ) } \\
\text { - atorvastatin } 40 \mathrm{mg}+\text { ezetimibe } 10 \mathrm{mg} / \text { day } \\
\text { - rosuvastatin } 20 \mathrm{mg}+\text { ezetimibe } 10 \mathrm{mg} / \mathrm{day} \\
\text { To be considered: } \\
\text { PCSK9 inhibitors - evolocumab } 140 \mathrm{mg} \text { every } \\
\text { other week subcutaneously or } 420 \mathrm{mg} \text { once } \\
\text { a month; } \\
\text { alirocumab } 75 \mathrm{mg} \text { every other week } \\
\text { subcutaneously or } 150 \mathrm{mg} \text { every other week } \\
\text { subcutaneously }\end{array}$ \\
\hline $\begin{array}{l}\text { Moderate } \\
\text { and low risk }\end{array}$ & $\begin{array}{l}<115 \mathrm{mg} / \mathrm{dl} \\
(<3 \mathrm{mmol} / \mathrm{l})\end{array}$ & - & $\begin{array}{l}\text { - } \text { simvastatin } 20-40 \mathrm{mg} / \mathrm{day} \\
\text { - atorvastatin } 10-20 \mathrm{mg} / \mathrm{day} \\
\text { - rosuvastatin } 5-10 \mathrm{mg} / \mathrm{day}\end{array}$ \\
\hline
\end{tabular}

\section{KEY POINTS TO REMEMBER}

- Statins are indicated at maximal recommended (depending on the patient group and CV risk) or tolerated doses to achieve the therapeutic target.

- If the target of therapy is not achieved, a combination of a statin with ezetimibe should always be considered.

- Ezetimibe should be considered in patients intolerant of statins or with contraindications to these drugs.

- PCSK9 inhibitors may be considered in very high and high risk patients who, despite treatment with maximal tolerated statin doses in combination with ezetimibe, still have high LDL-C levels, and in patients with statin intolerance.

- Fenofibrate may be used in combination with a statin in patients from high and very high risk groups with TG levels persisting $>200 \mathrm{mg} / \mathrm{dl}(>2.3 \mathrm{mmol} / \mathrm{l})$ despite statin treatment. 


\subsection{Severe hypertriglyceridaemia}

Severe hypertriglyceridaemia (HTG) is characterized by an elevated serum level of triglycerides to $>880 \mathrm{mg} / \mathrm{dl}$ (>10 mmol/l) which is not accompanied by an increase in LDL-C concentration [32]. The condition is associated with an increased risk of acute pancreatitis (AP). HTG can be divided into the familial type and chylomicronaemia syndrome. A useful method for the differentiation of severe HTG is cold flotation test which is performed to detect chylomicrons. Following centrifugation, serum samples are placed in the refrigerator at $4^{\circ} \mathrm{C}$

Table XIII. Secondary causes of hypertriglyceridaemia

\begin{tabular}{|l|}
\hline Causes of HTG \\
\hline Genetic predisposition \\
\hline Obesity \\
\hline Type 2 diabetes \\
\hline Alcohol use \\
\hline Diet rich in simple sugars \\
\hline Kidney disease \\
\hline Hypothyroidism \\
\hline $\begin{array}{l}\text { Pregnancy (TG level rises two-fold in the third } \\
\text { trimester of pregnancy) }\end{array}$ \\
\hline $\begin{array}{l}\text { Paraproteinaemia I autoimmune diseases: systemic } \\
\text { lupus erythematosus }\end{array}$ \\
\hline $\begin{array}{l}\text { Drugs: glucocorticosteroids, oral oestrogens, non- } \\
\text { cardioselective } \beta \text { blockers, thiazides, } \\
\text { retinoids, tamoxifen, protease inhibitors used for } \\
\text { treating HIV infection, cyclophosphamide, cyclosporin, } \\
\text { L-asparaginase, phenothiazines, second-generation } \\
\text { antipsychotics (clozapine, olanzapine) }\end{array}$ \\
\hline
\end{tabular}

for 16 hours. A layer of fat identified on the surface of the serum after the elapse of that time is indicative of the presence of chylomicrons [32].

\section{Familial hypertriglyceridaemia}

The condition is passed on in an autosomal dominant pattern. It typically manifests itself in adulthood in response to triggers including unbalanced high-fat diet, high carbohydrate consumption (> $60 \%$ of total caloric intake), alcohol consumption and obesity. It should always be verified whether the patient takes medications increasing TG levels (Table XIII). In many cases, a low-lipid diet and elimination of alcohol make it possible to reduce the TG level to reference values $(<150 \mathrm{mg} / \mathrm{dl}(<1.7 \mathrm{mmol} / \mathrm{l}))$ over a short period of about 2 weeks. Effective treatment is based on fibrates in monotherapy or in combination with omega-3 fatty acids (2-4 g/day) [6, 32].

\section{Chylomicronaemia syndrome}

Very high TG concentrations can also be a result of deficiency of lipoprotein lipase or lipase cofactor ApoC-II - a disorder inherited in an autosomal recessive pattern. The condition is called chylomicronaemia syndrome $[86,87]$. In its homozygous form, which affects $1 / 1,000,000$ people, symptoms present as early as in infancy and include skin xanthomas, lipemia retinalis, growth disturbances, recurrent acute pancreatitis, hepatosplenomegaly, mental disorders. In heterozygous individuals, the disease develops later in life. The treatment comprises a diet with a very low intake of fat in every form,

Table XIV. Types of hypertriglyceridaemia and management recommendations

\begin{tabular}{|c|c|c|}
\hline & Mild to moderate & Severe \\
\hline TG concentration & $150-880 \mathrm{mg} / \mathrm{dl}(1.7-10 \mathrm{mmol} / \mathrm{l})$ & $>880 \mathrm{mg} / \mathrm{dl}(>10 \mathrm{mmol} / \mathrm{l})$ \\
\hline Central target of therapy & Reduction of CV risk & Reduction of AP risk \\
\hline Primary target of therapy & Target LDL-C & Reduction of TG \\
\hline $\begin{array}{l}\text { Secondary target of } \\
\text { therapy }\end{array}$ & Target non-HDL-C level & $\begin{array}{l}\text { Target LDL-C and non-HDL-C levels if the } \\
\text { risk of AP is reduced }\end{array}$ \\
\hline $\begin{array}{l}\text { Non-pharmacological } \\
\text { treatment }\end{array}$ & $\begin{array}{l}\text { Lifestyle modification, body weight loss, } \\
\text { regular physical activity, low-fat diet, } \\
\text { cessation of alcohol intake }\end{array}$ & $\begin{array}{l}\text { Lifestyle modification, body weight } \\
\text { loss, total cessation of alcohol intake, } \\
\text { restrictive low-fat diet, AP treatment in } \\
\text { accordance with applicable guidelines }\end{array}$ \\
\hline Drugs & $\begin{array}{l}\text { Statins - first-line drugs (atorvastatin, } \\
\text { rosuvastatin); to consider: combined } \\
\text { therapy with a fibrate (when TG } \\
\text { concentration persists }>200 \mathrm{mg} / \mathrm{dl} \\
(>2.3 \mathrm{mmol} / / \mathrm{l}) \text { ), omega- } 3 \text { fatty acids }(2-4 \mathrm{~g} / \\
\text { day) - at maximal tolerated statin dose }\end{array}$ & $\begin{array}{l}\text { Fibrate in combination with omega-3 } \\
\quad \text { fatty acids ( } 2-4 \text { g/day) } \\
\text { Alternative treatment: nicotinic acid* }\end{array}$ \\
\hline Genetic tests & $\begin{array}{l}\text { Polygenic in form } \\
\text { No indications for genetic tests }\end{array}$ & $\begin{array}{l}\text { Very likely monogenic in form, } \\
\text { genetic tests indicated in children } \\
\text { and adolescents, cold flotation test } \\
\text { recommended to detect chylomicrons }\end{array}$ \\
\hline
\end{tabular}


both of animal and plant origin. Often, supplementing the diet with medium-chain fatty acids, which do not form chylomicrons after absorption, is necessary. In this form, fibrates are less effective than in familial hypertriglyceridaemia, and the prognosis is worse. In patients with chylomicronaemia syndrome treatment is considered effective if the TG level is $<500 \mathrm{mg} / \mathrm{dl}(<5.6 \mathrm{mmol} / \mathrm{l})$. HTG types and patient management recommendations are shown in Table XIV [32, 86, 87].

\section{Prevention of AP in hypertriglyceridaemia}

Hypertriglyceridaemia is the underlying cause of about $10 \%$ of all AP cases. It needs to be stressed that AP does not have to be secondary to severe hypertriglyceridaemia (TG > $880 \mathrm{mg} / \mathrm{dl}$ ( $>10 \mathrm{mmol} / \mathrm{l})$ ), but it may also develop at TG concentrations of $400-880 \mathrm{mg} / \mathrm{dl}(4.5-10 \mathrm{mmol} / \mathrm{l})$. A prominent rise in the risk of AP is observed in response to an additional factor increasing VLDL production, such as alcohol $[86,87]$.

\section{KEY POINTS TO REMEMBER}

Practical management guidelines:

1. High TG level $>400 \mathrm{mg} / \mathrm{dl}(>4.5 \mathrm{mmol} / \mathrm{l})$ and symptoms of AP - hospitalization.

2. High TG level $>400 \mathrm{mg} / \mathrm{dl}(>4.5 \mathrm{mmol} / \mathrm{l})$ with no symptoms - close monitoring on an outpatient basis until a decrease in the TG level: (a) diet with restricted calorie and fat intake (10-15\%), (b) complete cessation of alcohol consumption, (c) treatment: fenofibrate in monotherapy or in combination with omega-3 acids, (d) in patients with diabetes - introduction of intensive insulin therapy. In the majority of cases a decrease in TG is seen within 2-5 days.

\section{LDL-C APHERESIS - METHODOLOGY AND INDICATIONS}

$\mathrm{LDL}$-apheresis is a procedure to remove $\mathrm{LDL}$ from the blood serum rapidly. Although the method involves high costs and is time-consuming, it is recognized as an important adjuvant therapy for homozygous familial hypercholesterolaemia (hoFH) [88-91]. Clinical observations show that long-term LDL-apheresis in patients with severe hoFH contributes to the regression and stabilization of atheromatous plaques, improves CV outcome and reduces skin and tendon xanthomas [92]. A single procedure makes it possible to decrease LDL-C by $55-70 \%$ [93]. LDL-apheresis procedures should be repeated on a weekly to biweekly basis. Blood collected from the patient is first separated in a separator into morphotic elements and plasma which then passes into a set of LDL-C separation filters. Following filtration, plasma together with cellular elements is transfused back to the patient. The procedure takes approximately 4 hours. In addition to LDL-C, apheresis also removes VLDL, fibrinogen, $L p(a), \alpha 2$-macroglobulin and coagulation factors from blood plasma [91]. The time of initiation of therapy depends on the patient's response to lipid lowering drugs and the presence of coronary heart disease (the patient's risk level) [91-93]. The earlier the treatment is initiated, the better the patient's outcome. Whenever possible, LDL-apheresis should optimally be initiated in patients with hoFH at the age of 5 years and, at the latest, at the age of 8 years [93]. The method can be safely used during pregnancy $[88,91]$.

The most serious adverse reactions associated with LDL-apheresis include hypotonia, abdominal pain, nausea, vomiting, dizziness and headaches, hypocalcaemia, iron deficiency anaemia, allergic reactions, haemolysis and thrombocytopenia. On account of the risk of hypotonia in patients treated for arterial hypertension, a dose of their hypotensive drugs should be omitted on the day of the procedure. In patients treated with dextran sulphate or haemoperfusion, taking an angiotensin-converting-enzyme inhibitor carries the risk of severe hypotonia and is thus contraindicated [94]. Patients requiring ongoing oral anticoagulation therapy with warfarin or acenocoumarol should interrupt their treatment at least 4 days before the scheduled LDL-apheresis procedure, and should start taking low molecular weight heparin. Such patients also require monitoring of their complete blood count (CBC) and iron profile, and supplementation, as required. Antiplatelet therapy should not be interrupted.

LDL-apheresis procedures should only be performed in highly specialized medical centres. When the Guidelines were drafted, there were three such centres operating in Poland, based in Gdansk, Poznan and Szczecin.

\section{KEY POINTS TO REMEMBER}

- LDL-apheresis should be considered in the treatment of patients with hoFH as an adjunct therapy [88-94].

- In exceptional situations, LDL-apheresis is used in patients with the heterozygous form of familial hypercholesterolemia (heFH), when further progression of clinically symptomatic atherosclerosis is observed despite treatment with maximal statin doses.

- LDL-apheresis is recommended when despite a diet and pharmacotherapy at maximal tolerated doses the LDL-C level persists for 6 months $\geq 300 \mathrm{mg} / \mathrm{dl}(\geq 7.7 \mathrm{mmol} / \mathrm{l})$ or $\geq 200 \mathrm{mg} / \mathrm{dl}$ ( $\geq 5.2 \mathrm{mmol} / \mathrm{l})$ in patients with documented coronary heart disease. 


\section{TREATMENT OF LIPID DISORDERS IN SELECTED POPULATIONS}

\subsection{Children and adolescents}

There are no reliable data assessing the efficacy and safety of long-term treatment of dyslipidaemias in children and adolescents. The generally held view is that treatment should be initiated during childhood [95]. The deferral of appropriate therapy until adulthood can lead to cardiovascular diseases at a young age. Therapeutic recommendations for children and adolescents are largely extrapolated from studies on $\mathrm{FH}$ and studies conducted in adults.

The target in the treatment of dyslipidaemia in children and adolescents is the LDL-C level $<130 \mathrm{mg} /$ $\mathrm{dl}\left(<3.4 \mathrm{mmol} / \mathrm{l}\right.$, under the $95^{\mathrm{th}}$ percentile), and in children with diabetes $<100 \mathrm{mg} / \mathrm{dl}(<2.6 \mathrm{mmol} / \mathrm{l})-$ or an $\mathrm{LDL}-\mathrm{C}$ reduction by at least $50 \%[96,97]$.

The treatment of dyslipidaemia in children and adolescents consists of health education, lifestyle modifications and pharmacotherapy. Education should involve all members of the patient's family. The scope of information and the way it is communicated should take into account the child's age and the efficiency of communicating with carers. It is necessary to allow an appropriate amount of time for providing information. If required, the task should take several appointments. Information provided to patients and their families should include causes and effects of lipid disorders, risk factors for cardiovascular diseases, and rules and importance of therapy. Individual counselling should be ensured, and the opinions, fears and doubts of young patients and their families should be properly addressed. Patient management decisions should also be made collectively. It is reasonable to minimize the risk of contradictory information being provided, particularly by physicians and nurses within the same medical practice, or by medical professionals in a specialist healthcare unit. Successful education is facilitated by previously established good therapeutic relations and knowledge of psychosocial factors which either support changes in behaviour (e.g. positive emotions, high social status) or hinder them (stress, family tensions, social deprivation) $[6,98]$. Lifestyle changes include introduction and reinforcement of good eating habits, focus on more physical activity, achievement of healthy body weight, prevention of passive smoking and, in adolescents, elimination of active smoking and alcohol consumption. Lifestyle measures should be introduced in all children over the age of 2 years, when their LDL-C level is > $130 \mathrm{mg} / \mathrm{dl}$ ( $3.4 \mathrm{mmol} / \mathrm{l}$ ) and/or the TG concentration is elevated (children under 10 years of age with TG $\geq 100$ $\mathrm{mg} / \mathrm{dl}(\geq 1.1 \mathrm{mmol} / \mathrm{l})$; children aged $10-19$ years with TG levels $\geq 130 \mathrm{mg} / \mathrm{dl}(\geq 1.5 \mathrm{mmol} / \mathrm{l})$ ) [99].

Dietary treatment should be initiated in all children with dyslipidaemia over the age of 2 years. Earlier dietary modifications should be prescribed by an experienced physician in a specialist healthcare unit, in cooperation with a dietician. They require close monitoring of the child's development $[99,100]$. If the effects of dietary treatment undertaken in the family physician's practice are unsatisfactory, the patient and their family should be referred for a dietary consultation (not included in health services provided by the National Health Fund) or to a specialist healthcare unit (outpatient clinic for cardiac or metabolic diseases), which provides such services. An elevated LDL-C level is an indication for decreasing the energy intake from fats to $30 \%$ (including $<7 \%$ of saturated fats), substituting saturated for unsaturated fats, and reducing the daily cholesterol intake to $<200 \mathrm{mg}$ [96]. It is recommended to increase the intake of dietary fibre (to about $10 \mathrm{~g}$ at the age of 5 years, $15 \mathrm{~g}$ at the age of 10 year and $20 \mathrm{~g}$ at the age of 15 years), sea fish, vegetables, fruit, nuts and seeds; opt for low-fat milk and enrich the diet with plant sterols and stanols (to $20 \mathrm{~g} /$ day) $[97,100]$. An increased TG level is an indication to cut down on simple sugars, increase the intake of dietary fibre and complex sugars, and reduce body weight.

Parents should be encouraged to impose a ban on watching television in children under the age of 2 years. In older children, time spent in front of TV/ computer should be reduced to 2 hours a day, and they should be encouraged to engage in physical activity for up to 90 minutes daily $[97,99,101]$.

Table XV. Initiation of pharmacotherapy in children and adolescents, risk factors and lipid levels [96-99] Patient characteristics Lipid parameters and their concentrations

\begin{tabular}{|lc|}
\hline Without cardiovascular risk factors & LDL-C $\geq 190 \mathrm{mg} / \mathrm{dl}(\geq 4.9 \mathrm{mmol} / \mathrm{l})$ \\
\hline $\begin{array}{l}\text { With one high* risk factor and two intermediate } \\
\text { factors, family history of early-onset cardiovascular disease }\end{array}$ & LDL-C $\geq 160 \mathrm{mg} / \mathrm{dl}(\geq 4.2 \mathrm{mmol} / \mathrm{l})$ \\
\hline With diabetes & LDL-C $\geq 130 \mathrm{mg} / \mathrm{dl}(\geq 2.6 \mathrm{mmol} / \mathrm{l})$ \\
\hline With or without risk factors & TG $\geq 200 \mathrm{mg} / \mathrm{dl}(\geq 2.2 \mathrm{mmol} / \mathrm{l})$ \\
\hline
\end{tabular}

${ }^{*}$ High risk factors: hypertension requiring pharmacotherapy, end-stage renal disease, $B M I>97$ percentile. ${ }^{* \star}$ Intermediate risk factors: arterial hypertension without pharmacotherapy, $H D L<1.0 \mathrm{mmol} / \mathrm{l}(<40 \mathrm{mg} / \mathrm{dl}), \mathrm{BMI} 95-97$ percentile, chronic inflammatory disease (rheumatoid arthritis, systemic lupus erythematosus), nephrotic syndrome. 
Pharmacotherapy should be introduced 6 months after the lifestyle modification, if the therapeutic goals have not been achieved. Its long-term efficacy and safety have not been determined. With regard to statins, the prevailing view is that they are well tolerated [102]. The lipid parameter levels at which pharmacotherapy is recommended in children and adolescents $\geq 10$ years are shown in Table XV.

Statin therapy can be prescribed by family physicians to children > 10 years of age (except for children with $\mathrm{FH}$, where the Polish Lipid Expert Forum recommends statins in children $>8$ years of age, and in children with the homozygous form $<8$ years of age at LDL-C concentrations $>500 \mathrm{mg} / \mathrm{dl}$
$(12.9 \mathrm{mmol} / \mathrm{l}))[96]$. The treatment should be based on results of lipid profiling tests performed twice in the period between 2 weeks and 3 months in the fasting state, and evaluation of $\mathrm{CV}$ risk factors. The therapy is started with the lowest available dose which is taken once daily, in the evening [96, 97]. The dose should be increased slowly, depending on the therapeutic outcome achieved, while monitoring potential adverse effects. Before initiating treatment, the activity of aminotransferases and creatine kinase should be determined. The level of aminotransferases should be evaluated again approximately 6 weeks after introducing statin treatment [95-97]. Ezetimibe therapy should be started under the supervision of a phy-

Table XVI. Drugs used in the treatment of dyslipidaemias in children and adolscents [96, 100]

\begin{tabular}{|c|c|c|c|c|}
\hline \multirow[t]{2}{*}{ Drug(s) } & \multicolumn{2}{|c|}{ Doses } & \multirow{2}{*}{$\begin{array}{l}\text { Possible side effects } \\
\text { (selection) }\end{array}$} & \multirow[t]{2}{*}{ Contraindications in children } \\
\hline & Starting & Maximal & & \\
\hline \multicolumn{3}{|l|}{ Statins: } & \multirow{5}{*}{$\begin{array}{c}\text { Liver damage, myalgia, } \\
\text { myopathy, rhabdomyolysis, } \\
\text { gastrointestinal disorders, } \\
\text { fatigue, insomnia, } \\
\text { headaches, skin lesions, } \\
\text { peripheral neuropathy, } \\
\text { lupus like syndrome }\end{array}$} & \multirow{5}{*}{$\begin{array}{l}\text { Drug hypersensitivity reactions, } \\
\text { statin-associated myopathy, } \\
\text { active liver disease, high } \\
\text { aminotransferase activity or } \\
\text { threefold exceeding of the normal } \\
\text { range during statin treatment, } \\
\text { kidney failure, severe infections, } \\
\text { serious injuries and surgical } \\
\text { procedures, severe electrolytic, } \\
\text { metabolic and hormonal disorders, } \\
\text { uncontrolled epilepsy }\end{array}$} \\
\hline Simvastatin & $5 \mathrm{mg}$ & $40 \mathrm{mg}$ & & \\
\hline Atorvastatin & $5 \mathrm{mg}$ & $40 \mathrm{mg}$ & & \\
\hline Rosuvastatin & $5 \mathrm{mg}$ & $20 \mathrm{mg}$ & & \\
\hline Pravastatin & $5 \mathrm{mg}$ & $\begin{array}{c}20 \mathrm{mg} \\
\text { until } 13 \text { years } \\
40 \mathrm{mg} \\
\text { until } 18 \text { years }\end{array}$ & & \\
\hline \multicolumn{3}{|c|}{ Resins binding bile acids: } & \multirow{2}{*}{$\begin{array}{c}\text { Headaches, flatulence, } \\
\text { constipation, vomiting, } \\
\text { diarrhoea, dyspepsia, } \\
\text { abdominal pain, abnormal } \\
\text { stools, nausea, abdominal } \\
\text { distension }\end{array}$} & \multirow{2}{*}{$\begin{array}{l}\text { Drug hypersensitivity reactions, } \\
\text { intestinal or biliary obstruction }\end{array}$} \\
\hline Colesevelam** & $1.25 \mathrm{~g}$ & $3.75 \mathrm{~g}^{*}$ & & \\
\hline \multicolumn{3}{|c|}{ Drug inhibiting cholesterol absorption: } & \multirow{2}{*}{$\begin{array}{l}\text { Myalgia, myopathy and } \\
\text { rhabdomyolysis, fatigue, } \\
\text { headaches, abdominal pain, } \\
\text { diarrhoea, flatulence with } \\
\text { passing gas, dyspepsia, } \\
\text { GERD, nausea, elevated } \\
\text { aminotransferase level }\end{array}$} & \multirow{2}{*}{$\begin{array}{l}\text { Drug hypersensitivity reactions, } \\
\text { liver dysfunction, unexplained high } \\
\text { level of aminotransferases }\end{array}$} \\
\hline Ezetimibe & $10 \mathrm{mg}$ & $10 \mathrm{mg}^{\star}$ & & \\
\hline
\end{tabular}

KEY POINTS TO REMEMBER

- Dyslipidaemia treatment should be initiated during childhood, as the deferral of therapy until adulthood can lead to cardiovascular diseases at a young age.

- The target of dyslipidaemia treatment in children and adolescents is the LDL-C level $<130 \mathrm{mg} / \mathrm{dl}$ $(<3.4 \mathrm{mmol} / \mathrm{l})$, and in children with diabetes $<100 \mathrm{mg} / \mathrm{dl}(<2.6 \mathrm{mmol} / \mathrm{l})$ or a reduction in the LDL-C level by at least $50 \%$.

- Health education should be provided both to the patient and to all members of the patient's family. Lifestyle recommendations in children and adolescents are similar to those applicable to adults; dietary treatment in the family physician's practice should not be undertaken in children before the age of 2 years.

- Pharmacotherapy should be initiated 6 months after introducing lifestyle modifications if no therapeutic effect has been achieved; statins may be initiated in children $>10$ years of age ( $>8$ years of age in children with heterozygous familial hypercholesterolaemia), starting with the lowest available dose. 
sician at a specialist healthcare unit. The safety of use and efficacy of the drug in patients under 17 years of age have not been assessed. Moreover, there are no precise recommendations regarding the dosage regimen. The situation is similar for colesevelam, which has been approved for the treatment of adults (unavailable in Poland) [99, 100]. The doses of lipid-lowering drugs in children together with side effects and contraindications are listed in Table XVI.

\subsection{The elderly}

Cholesterol is a significant risk factor for coronary heart disease. The correlation is slightly less pronounced in elderly patients. A $1 \mathrm{mmol}(38.7 \mathrm{mg} / \mathrm{dl})$ reduction in the TC level is associated with a decrease in CV mortality in patients aged 40-49 years by about $50 \%$ (hazard ratio $(H R)-0.44$ ), and in patients aged $80-89$ by $15 \%(H R-0.85)[25,103]$.

The primary method of preventing CVD in elderly patients is the promotion of healthy lifestyle. So far, there have not been any studies assessing the efficacy and safety of lipid-lowering therapy in primary prevention in the elderly population [103]. A post-hoc analysis of the Justification for the Use of Statins in Primary Prevention: An Intervention Trial Evaluating Rosuvastatin (JUPITER) study with rosuvastatin in a subgroup of elderly and younger patients (under 70 years of age) has shown that the degree of reduction of the combined endpoint is independent of age [104]. To prevent one CV event over a period of 4 years, statin treatment should be provided to 24 elderly patients and 36 patients at a younger age [104]. The continuation of lipid-lowering treatment in patients who started therapy under 75 years of age is believed to be a rational option. According to the most recent (2016) ESC/EAS guidelines for the management of dyslipidaemias, lipid-lowering treatment in the elderly population without coronary heart disease should be considered in patients who, aside from age, have at least one other risk factor: smoking, arterial hypertension, diabetes or dyslipidaemia [32]. In secondary prevention, statin treatment is recommended to elderly patients diagnosed with CVD according to the same therapeutic principles as in younger patients [32, 105, 106].

Elderly age is a factor which significantly affects the pharmacokinetics of drugs, chiefly at the stage of distribution (increase in adipose tissue mass and $\alpha 1$-acid glycoprotein, reduced water content and albumin concentration) and elimination (impaired renal function, slower hepatic metabolism) [32, 107-110]. Treatment applied to this patient group is further complicated by multiple morbidities, need to use polypharmacotherapy and non-compliance with medical advice. Elderly age is an independent factor for an increased risk of statin intolerance [5]. Therefore, the International Lipid Expert Panel (ILEP) recommends statins with hydrophilic properties (rosuvastatin, pravastatin) for the treatment of elderly patients, as they are associated with a higher level of therapeutic safety [5]. Statin treatment should begin at small doses which should be gradually increased until the achievement of the target LDL-C concentration [32]. A temporary discontinuation of statin therapy should be considered in elderly patients in situations increasing the risk of statin intolerance such as hypothyroidism, severe acute infection, extensive surgery and malnutrition, bearing in mind that the interruption of therapy increases the risk of all-cause and CV mortality [5].

\section{KEY POINTS TO REMEMBER}

- Statin treatment in elderly patients with CVD should follow the same rules as in younger patients.

- Due to multiple morbidities, risk of interactions and modified drug pharmacokinetics, it is recommended to initiate statin treatment at low doses and then carefully increase the dose until the target LDL-C is achieved (the same as in younger individuals under 65 years of age).

- In primary prevention, statin treatment should be considered when, in addition to age, there is at least one other risk factor such as arterial hypertension, smoking, diabetes or dyslipidaemia.

\subsection{Familial hypercholesterolaemia (FH)}

Familial hypercholesterolaemia occurs most commonly in the heterozygous form (HeFH). Homozygous $\mathrm{FH}$ is very rare: based on recent epidemiological data, its incidence is estimated at $1: 300,000$. On the basis of a meta-analysis of six large observational studies, in accordance with the criteria issued by the Dutch Lipids Clinics Network, heFH in Poland has been diagnosed in approximately one per 250 individuals aged 20-79 years [24], which corresponds roughly to a total of $122,590 \mathrm{FH}$ patients in the Polish population (based on Central Statistical Office data on the population of Poland, 2014). The causes, diagnostic criteria and management strategies in $\mathrm{FH}$ have lately been addressed in a number of publications by experts from scientific societies and other expert groups [111-115].

The most common cause of $\mathrm{FH}$ is a mutation in the LDL receptor gene. $A$ less common cause is a mutation in the LDL protein $(A p o B)$ gene, and the least common (1-3\%) - a mutation in the gene responsible for the synthesis of the enzyme PCSK9. 
Table XVII. Diagnostic criteria for heterozygous familial hypercholesterolaemia (HeFH) based on the Dutch Lipid Clinic Network [3, 32]

\begin{tabular}{|c|c|c|}
\hline & Criteria & Score [points] \\
\hline \multirow[t]{2}{*}{ Family history } & $\begin{array}{l}\text { First-degree relative with premature CVD and/or with LDL-C }>95^{\text {th }} \text { centile } \\
\qquad(190 \mathrm{mg} / \mathrm{dl}-5.0 \mathrm{mmol} / \mathrm{l})\end{array}$ & 1 \\
\hline & $\begin{array}{l}\text { First-degree relative with tendon xanthomas and/or }<18 \text { years of age } \\
\text { with } L D L-C>95^{\text {th }} \text { centile }(155 \mathrm{mg} / \mathrm{dl}-4.0 \mathrm{mmol} / \mathrm{l})\end{array}$ & 2 \\
\hline \multirow[t]{2}{*}{$\begin{array}{l}\text { Individual medical } \\
\text { history }\end{array}$} & $\begin{array}{l}\text { Premature CVD (under } 55 \text { years of age in men and under } 60 \text { years of age } \\
\text { in women) }\end{array}$ & 2 \\
\hline & Premature cerebral or peripheral artery disease & 1 \\
\hline \multirow{2}{*}{$\begin{array}{l}\text { Physical } \\
\text { examination }\end{array}$} & Tendon xanthomas & 6 \\
\hline & Arcus senilis under 45 years of age & 4 \\
\hline \multirow[t]{4}{*}{ LDL-C } & $\geq 330 \mathrm{mg} / \mathrm{dl}(\geq 8.5 \mathrm{mmol} / \mathrm{l})$ & 8 \\
\hline & $250-329 \mathrm{mg} / \mathrm{dl}(6.5-8.4 \mathrm{mmol} / \mathrm{l})$ & 5 \\
\hline & $190-249 \mathrm{mg} / \mathrm{dl}(5.0-6.4 \mathrm{mmol} / \mathrm{l})$ & 3 \\
\hline & $155-189 \mathrm{mg} / \mathrm{dl}(4.0-4.9 \mathrm{mmol} / \mathrm{l})$ & 1 \\
\hline DNA testing & Mutation in LDLR, ApoB or PCSK9 genes & 8 \\
\hline
\end{tabular}

*Interpretation: > 8 points - definite HeFH, 6-8 points - probable HeFH, 3-5 points - possible HeFH.

The PCSK9 mutation, of the gain-of-function type, is responsible for the breakdown of LDLRs in hepatocyte lysosomes. Consequently, they do not return to the cell surface for new LDL particles, resulting in a significant increase in the LDL-C level. Genetic diagnosis requires DNA testing. However, it is not always possible to identify the mutation responsible for the disease. Patients with $\mathrm{HeFH}$ inherit the condition from one parent. If they have a defect in the LDLR, only a half of all LDL receptors function normally.

The disease is a factor strongly predisposing to premature atherosclerosis. The risk of coronary disease is high: CV mortality in $\mathrm{FH}$ patients aged between 20 and 39 years can be up to 100 times higher than in the same disease-free population [2, 116]. The clinical diagnosis takes into account high LDL-C levels in the patient and their first-degree relatives (parents, siblings, children), premature CVD in the patient and their first-degree relatives, tendon xanthomas (not always), and premature arcus senilis (Table XVII). Genetic testing, despite determining the diagnosis, does not influence the treatment. The experiences of European healthcare centres indicate that genetic tests corroborating the diagnosis are performed in less than $25 \%$ of all patients. This is motivated by the fact that determining the LDL-C concentration in the closest family members in combination with detailed history and physical examination not only substantiate the diagnosis but in fact make it possible to establish the clinical diagnosis of HeFH in such individuals and undertake their treatment.

$\mathrm{HeFH}$ patients should receive intensive statin treatment - atorvastatin ( $80 \mathrm{mg} /$ day) or rosuvastatin (40 mg/day). If the target LDL-C concentration
$<100 \mathrm{mg} / \mathrm{dl}(<2.6 \mathrm{mmol} / \mathrm{l})$ or $<70 \mathrm{mg} / \mathrm{dl}(<1.8$ $\mathrm{mmol} / \mathrm{l})$ in patients with CVD fails to be achieved with an optimal maximally tolerated statin dose, ezetimibe should be added [32]. If the two-drug therapy does not lead to the achievement of target LDL-C values, the addition of PCSK9 inhibitors (evolocumab or alirocumab) should be considered (see Chapter 10.8). In children, the main focus is on dietary treatment. A statin may be considered in children older than 8 years (see Chapter 12.1) [96].

\section{KEY POINTS TO REMEMBER}

- Heterozygous familial hypercholesterolaemia is a much more common condition than previously thought: the incidence in the Polish population is one case per 250 adults (corresponding to almost 125,000 people aged over 20 years).

- Cascade family screening should be performed in all members of the patient's family.

- HeFH is a factor, which very significantly increases the risk of premature coronary disease.

- HeFH patients receive intensive statin treatment - atorvastatin (40-80 mg/day) or rosuvastatin (20-40 mg/day).

- If the target LDL-C concentration ( $<100 \mathrm{mg} /$ $\mathrm{dl}(<2.6 \mathrm{mmol} / \mathrm{l})$ or $<70 \mathrm{mg} / \mathrm{dl}(<1.8 \mathrm{mmol} / \mathrm{l})$ in patients diagnosed with (VD) is not achieved, the addition of ezetimibe should be considered; if the target still is not achieved or the patient is intolerant of statins, the addition of PCSK9 inhibitors (evolocumab or alirocumab) may be considered. 


\subsection{Metabolic syndrome and diabetes}

Metabolic syndrome (MetS) refers to the coexistence of at least three out of five factors listed below:

- waist circumference $\geq 80 \mathrm{~cm}$ in women and $\geq 94 \mathrm{~cm}$ in men,

- TG concentration $\geq 150 \mathrm{mg} / \mathrm{dl}(\geq 1.7 \mathrm{mmol} / \mathrm{l})$ or dyslipidaemia treatment,

- HDL-C concentration $<50 \mathrm{mg} / \mathrm{dl}(<1.3 \mathrm{mmol} / \mathrm{l})$ in women and $<40 \mathrm{mg} / \mathrm{dl}(<1.0 \mathrm{mmol} / \mathrm{l})$ in men or dyslipidaemia treatment,

- systolic arterial pressure $\geq 130 \mathrm{~mm} \mathrm{Hg}$ and/or diastolic arterial pressure $\geq 85 \mathrm{~mm} \mathrm{Hg}$ or hypotensive therapy,

- fasting glucose level $\geq 100 \mathrm{mg} / \mathrm{dl}(\geq 5.6 \mathrm{mmol} / \mathrm{l})$ or hypoglycaemic treatment [6, 32].

MetS patients are affected by the so-called atherogenic dyslipidaemia, which involves mainly hypertriglyceridaemia and low HDL-C concentration; the concentration of LDL-C can be elevated or in the normal range, dominated by the fraction of sdLDL, which additionally increases the risk level in these patients [32]. The increase in $\mathrm{CV}$ risk in affected patients is much higher than the simple sum of risks associated with individual constituents of the syndrome It is associated with a three- to sixfold increase in the risk of diabetes and a nearly twofold increase in all-cause mortality and CV events [6, 32].

Diabetes is a strong independent factor for CV risk. Since diabetes is associated with a three- to fivefold risk increase, it is considered to be equivalent to CVD (particularly diabetes with complica- tions and (an)other risk factor(s)) [6]. All diabetic patients are classified as being at high or very high risk. Consequently, they should receive intensive treatment comprising both non-pharmacological interventions and pharmacotherapy [6, 32]. In patients with type 2 diabetes without other risk factors and organ complications, the goal of lipid-lowering therapy is lowering the LDL-C level below $100 \mathrm{mg} / \mathrm{dl}(2.5 \mathrm{mmol} / \mathrm{l})$. The secondary target of therapy in this group is to reduce the concentration of non-HDL-C below $130 \mathrm{mg} / \mathrm{dl}$ (3.3 $\mathrm{mmol} / \mathrm{l})$ [32]. Patients with diagnosed CVD or severe CKD, and patients over 40 years of age with coexisting risk factors and organ damage, should be considered as being at very high risk, and measures should be undertaken with a view to lowering the LDL-C level below $70 \mathrm{mg} / \mathrm{dl}(1.8 \mathrm{mmol} / \mathrm{l})$ or, as a minimum, to half of their baseline value [32]. The secondary target of therapy in this patient group is to reduce the concentration of nonHDL-C below $100 \mathrm{mg} / \mathrm{dl}$ (2.6 mmol/l) [32]. Since the Heart Protection Study (HPS), scientific trials have demonstrated that all patients with type 2 diabetes benefit significantly from statin treatment (with/without the addition of ezetimibe), regardless of their baseline LDL-C value $[44,117-$ $119]$. As the lipid profile in type 2 diabetes is often typical of atherogenic dyslipidaemia (i.e. raised TG and lowered HDL-C concentrations), fibrates as an add-on therapy to statins may bring an additional benefit manifested as a reduced incidence of CV events, however evidence in support of this strategy is currently insufficient $[50,51]$. It must be

\section{RECOMMENDATIONS}

- The recommended management in patients with metabolic syndrome is body weight reduction achieved via a change in eating habits and increased physical activity (class of recommendation and level of evidence: I A).

- Patients with type 2 diabetes and diagnosed CVD or severe CKD, as well as patients over 40 years of age with at least one risk factor or organ damage, should receive treatment aimed at a reduction in LDL-C concentration $<70 \mathrm{mg} / \mathrm{dl}(<1.8 \mathrm{mmol} / \mathrm{l})$ and, as a secondary target, a decrease in the concentration of non-HDL-C below $100 \mathrm{md} / \mathrm{dl}(<2.6 \mathrm{mmol} / \mathrm{l})$ (class of recommendation and level of evidence: I B).

- Patients with type 2 diabetes without CVD and/or organ damage should receive treatment aimed at LDL-C reduction below $100 \mathrm{mg} / \mathrm{dl}(<2.6 \mathrm{mmol} / \mathrm{l})$ and, as a secondary target, a decrease in the concentration of non-HDL-C below $130 \mathrm{mg} / \mathrm{dl}(<3.3 \mathrm{mmol} / \mathrm{l})$, and ApoB below $100 \mathrm{mg} / \mathrm{dl}$ (class of recommendation and level of evidence: I B).

- If statin treatment brings no desirable effect, ezetimibe as an add-on therapy to statins should be considered (class of recommendation and level of evidence: Ila B).

- In patients with type 2 diabetes, a fibrate can be added to statin therapy when the TG concentration persists $>200 \mathrm{mg} / \mathrm{dl}(2.3 \mathrm{mmol} / \mathrm{l})$ (class of recommendation and level of evidence: Ilb B)

- PCSK9 inhibitors may be considered in patients with diabetes and the LDL-C level persisting > $160 \mathrm{mg} / \mathrm{dl}$ despite treatment with maximal tolerated statin doses, in combination with ezetimibe or in patients who are intolerant of statins (class of recommendation and level of evidence: Ilb C).

- Patients with type 1 diabetes and coexisting microalbuminuria and CKD should be treated with statins irrespective of their baseline LDL-C concentration in order to reduce the baseline LDL-C concentration by a minimum of $50 \%$ (class of recommendation and level of evidence: I C). 
stressed, however, that available evidence comes from trials with distinctive methodological limitations, and additional sub-group analyses have confirmed the significant status of fenofibrate treatment in diabetic patients. In addition, the current ESC/EAS guidelines (2016) provide indisputably that fibrate therapy may be considered in all HTG patients treated with statins when the TG levels are $>200 \mathrm{mg} / \mathrm{dl}(2.3 \mathrm{mmol} / \mathrm{l})[32]$

In patients with type 1 diabetes, the lipid profile may be within the normal range, which can be attributed to the beneficial effect of insulin therapy, however their HDL-C particles (so-called dysfunctional $\mathrm{HDL}$ ) [34] and LDL-C may be potentially atherogenic. Patients suffering from type 1 diabetes with coexisting microalbuminuria and chronic kidney disease should be treated with statins irrespective of their baseline LDL-C levels. The goal of treatment in this group should be a decrease in the baseline LDL-C value by a minimum of 50\% [32].

\subsection{Ischaemic heart disease}

\section{Stable ischaemic heart disease}

The rules for the treatment of dyslipidaemia in patients with IHD (stable angina, history of myocardial revascularization, history of myocardial infarction) are no different from the course of action, which is undertaken in other patients who are at very high CV risk. The central goal in dyslipidaemia treatment is the concentration of LDL-C, and the target concentration of cholesterol depends on its baseline value [6, 32]:

\begin{tabular}{|cc|}
\hline Baseline LDL-C level & Target LDL-C level \\
\hline$>135 \mathrm{mg} / \mathrm{dl}(>3.5 \mathrm{mmol} / \mathrm{l})$ & $<70 \mathrm{mg} / \mathrm{dl}(>1.8 \mathrm{mmol} / \mathrm{l})$ \\
\hline $70-135 \mathrm{mg} / \mathrm{dl}$ & Minimum $50 \%$ reduction \\
$(1.8-3.5 \mathrm{mmol} / \mathrm{l})$ & in LDL-C level \\
\hline
\end{tabular}

The foundation of dyslipidaemia treatment is non-pharmacological therapy, however the diagnosis of dyslipidaemia should be promptly followed by the initiation of pharmacotherapy. First-line drugs for the treatment of patients with IHD are statins. Hypercholesterolaemia treatment, especially in patients who are not in the elderly group, should begin with a statin dose that is expected with a high degree of probability to lower cholesterol to the target value. In patients at a high risk of adverse effects induced by statins, however, treatment should be started at a small dose and, after controlling the concentration of LDL-C, the dose should be increased, if necessary. If statin treatment at a high dose proves ineffective, another lipid-lowering drug with a different mechanism of action should be added. The first choice should be ezetimibe or, alternatively, a PCSK9 inhibitor (see Chapter 10.8). If high sta- tin doses are not tolerated by the patient, a low dose of statin should be used, in the majority of cases in combination with another lipid-lowering drug such as ezetimibe or, alternatively, a PCSK9 inhibitor. If the patient develops statin intolerance symptoms even in response to low statin doses, the therapy should be based on drugs from other groups (e.g. ezetimibe or, alternatively, a PCSK9 inhibitor) or their combinations [32]. In isolated cases, therapeutic benefits can be obtained with fibrates as well as foods enriched with stanols or sterols.

\section{KEY POINTS TO REMEMBER}

- First-line drugs for the treatment of patients with ischaemic heart disease are statins.

- The target LDL-C concentration is $<70 \mathrm{mg} / \mathrm{dl}$ $(<1.8 \mathrm{mmol} / \mathrm{l})$, and in patients with baseline LDL-C concentrations in the range of 70-135 $\mathrm{mg} / \mathrm{dl}(1.8-3.5 \mathrm{mmol} / \mathrm{l})$ it should be reduced by a minimum of $50 \%$.

\section{Acute coronary syndrome}

All patients hospitalized for acute coronary syndrome should be treated with high doses of statin in the acute phase of the disease. Therapy should be continued or initiated as soon as possible after hospital admission regardless of the baseline LDL-C level. The concentration of LDL-C should be checked 4-6 weeks after myocardial infarction and the treatment regimen should be modified, if required [32]. Further management of dyslipidaemia should be the same as in patients with stable ischaemic heart disease.

\section{KEY POINTS TO REMEMBER}

- All patients in the acute phase of the disease should be treated with a high-dose statin (optimally with rosuvastatin $40 \mathrm{mg}$ or atorvastatin $80 \mathrm{mg}$ ). Therapy should be continued or initiated as soon as possible after the patient's hospital admission regardless of the baseline LDL-C concentration.

- After hospitalization, the target LDL-C concentration is $<70 \mathrm{mg} / \mathrm{dl}(<1.8 \mathrm{mmol} / \mathrm{l})$, and in patients with baseline LDL-C concentrations in the range of $70-135 \mathrm{mg} / \mathrm{dl}(1.8-3.5 \mathrm{mmol} / \mathrm{l})$ it should be reduced by a minimum of $50 \%$.

\subsection{Heart failure}

Several studies have shown that statin therapy in patients with IHD and in primary prevention lowers the risk of heart failure (HF) [120]. Highdose statin therapy, compared to low-dose statin 
treatment, has also been demonstrated to reduce the risk of hospitalization due to HF in the above groups [121]. Patients with advanced forms of chronic HF typically have lower cholesterol levels. As opposed to individuals without heart failure, low cholesterol concentrations in patients suffering from heart failure are associated with a worse prognosis [122, 123]. Although observational studies suggest that statins have a beneficial impact on mortality risk in patients with $\mathrm{HF}$, no such effect has been confirmed in interventional studies [122-124].

\section{KEY POINTS TO REMEMBER}

- Statin-based lipid-lowering therapy should not be used in patients in whom the only indication is heart failure.

- Continuation of statin treatment should be considered in patients with ischaemic heart disease.

\subsection{Stroke}

Statins used in primary prevention lower the risk of stroke by an average of $22 \%$ [125]. A similar effect of drugs from this group has been found in patients after non-cardioembolic stroke of ischaemic aetiology [126]. Following stroke or transient ischaemic attack (TIA), patients are often affected not only by the risk of another cerebrovascular event but also other serious CV events $[6,32]$. Also, patients in this group are frequently at a risk of other conditions of atherosclerotic origin. The aetiology of stroke may affect the effects of lipid-lowering treatment. The therapeutic benefits may be the greatest in patients with atherothrombotic disease causing stroke or TIA. In contrast, haemorrhagic stroke patients may not benefit from such therapy or it may even have a detrimental effect in them, particularly if no evidence for atherosclerosis is found [32].

\section{KEY POINTS TO REMEMBER}

- Intensive statin treatment should be recommended in patients from high and very high risk groups in primary prevention of stroke.

- Intensive statin treatment should be recommended in patients following stroke or transient ischaemic attack of ischaemic rather than non-cardioembolic aetiology, in secondary prevention of stroke.

- Lipid-lowering treatment should be recommended in patients with other diseases of atherosclerotic origin in primary prevention of stroke.

\subsection{Chronic kidney disease}

Since patients with chronic kidney disease (CKD) are at a very high CV risk, the initiation of statin treatment is based on the evaluation of total CV risk in accordance with prevention guidelines [6]. At the same time, on the basis of data from the Alberta Kidney Disease Network, it must be noted that the direct correlation between CV risk and LDL-C is weaker in patients with CKD not receiving dialysis therapy than in the general population [127]. The finding above can be attributed to an increased role of atherogenic dyslipidaemia in patients with CKD, which is characterized by lower LDL-C and higher sdLDL concentrations, a decrease in HDL and an increase in TG concentrations. Therefore, the LDL-C concentration alone may be less helpful for making decisions on the implementation of treatment in patients with advanced chronic kidney disease not requiring dialysis therapy [127]. The decision should depend on the evaluation of total cardiovascular risk taking into account the patient's age, and the degree of kidney failure and/or estimated glomerular filtration rate (eGFR) [127, 128]. Based on such evaluation the incidence of fatal CVD and non-fatal myocardial infarction in patients with CKD aged $>50$ years, both men and women, exceeds 10/1,000, which justifies the indication of a potential benefit of statin treatment [127, 128]. The KIDIGO (Kidney Disease: Improving Global Outcomes) guidelines define statin doses, which are optimal for different stages of chronic kidney failure rather than for different LDL-C levels. Drugs eliminated via liver metabolism (atorvastatin, fluvastatin, pitavastatin, ezetimibe) are the preferred option in this patient group. Statins metabolized by CYP3A4 may lead to side effects due to multiple drug interactions, and are not recommended [129, 130].

Benefits of statin therapy have been noted in patients with stage 2 and 3 CKD (based on Pravastatin Pooling Project - 19,737 patients followed up for an average of 64 months, and the largest study investigating statins - Heart Protection Study). The greatest benefits are noted in patients with coexisting CKD and diabetes [131]. There is no clear evidence to conclude beyond doubt that statin or statin/ezetimibe therapy is beneficial in adults with stage 5 CKD undergoing dialysis treatment. Cardiovascular mortality in this patient group is mainly associated with heart failure and cardiac dysrhythmia [131, 132]. However, treatment continuation is indicated in those patients who were treated for dyslipidaemia at the time of starting dialysis therapy.

Full lipid profiling is recommended at an early stage in patients with CKD, mainly in order to identify severe forms of hypercholesterolaemia 
and hypertriglyceridaemia, and rule out modifiable/secondary causes of dyslipidaemia [32]. Lipid profile control is recommended only if it affects clinical decisions, e.g. for the purpose of monitoring the patient's compliance with statin therapy or determine 10-year CV risk in younger patients with CKD who are not currently treated with a statin [32]. It needs to be noted that recommendations for the treatment of dyslipidaemia in chronic kidney disease are based solely on a few large RCTs, meta-analyses and post-hoc analyses of patient subgroups from large clinical trials of statins.

Summing up, the level of CV risk in patients with stage 3-5 chronic kidney disease is considered to be very high (see Table $\mathrm{V}$ ). Intensive statin and/or ezetimibe treatment is recommended in patients not requiring dialysis therapy. Statins should not be used, or should be used with extreme caution, in patients who undergo dialysis but are free from CVD induced by atherosclerosis [32].

\section{RECOMMENDATIONS}

- Patients with stage 3-5 chronic kidney disease are classified as being at high or veryhigh CV risk (class of recommendation and level of evidence: I A)

- Statins alone or in combination with ezetimibe are recommended in patients not requiring dialysis therapy (class of recommendation and level of evidence: I A).

- Statins are not recommended in patients who require dialysis therapy but have not been diagnosed with cardiovascular diseases (class of recommendation and level of evidence: III A).

- If a patient treated with a statin or statin/ ezetimibe combination requires dialysis therapy, the continuation of statin treatment is recommended (class of recommendation and level of evidence: Ila C).

\subsection{Peripheral vascular disease}

Atherosclerotic lesions are the predominant cause (over 95\% of cases) of chronic lower limb ischaemia. Often, the symptoms of lower limb ischaemia including intermittent claudication are the first clinical manifestation of systemic atherosclerosis [32]. It is currently known that atherosclerotic lesions in peripheral arteries are an independent factor contributing to the risk of CV events including acute coronary syndrome and stroke. Such patients require active pharmacological and non-pharmacological management in order to improve their outcome. Lipid-lowering therapy in this patient group has been shown not only to inhibit the progression of atherosclerosis in the peripheral arterial bed but also to reduce the risk of serious events in other beds (coronary, cerebral) [6]. A meta-analysis of 18 clinical trials encompassing over 10,000 patients with lower limb atherosclerosis has shown that lipid-lowering therapy leads to a nearly $20 \%$ reduction in the risk of CV events and a 14\% decrease in all-cause mortality $[32,133]$.

\section{KEY POINTS TO REMEMBER}

- The therapeutic goals in patients with peripheral atherosclerosis are the same as in other patients in the group of very high risk $(\mathrm{LDL}-\mathrm{C}<70 \mathrm{mg} / \mathrm{dl}(<1.8 \mathrm{mmol} / \mathrm{l})$ or LDL-C reduction by a minimum of $50 \%$ at the baseline LDL-C level of $70-135 \mathrm{mg} / \mathrm{dl}(1.8-3.5$ $\mathrm{mmol} / \mathrm{l})$ ), and drugs of choice are statins at maximal tolerated doses.

- Non-pharmacological lifestyle modifications, including cessation of smoking, physical activity, walking training, etc., are also very important, as they have a beneficial effect on the lipoprotein level and also stimulate the development of collateral circulation and improve the metabolism of ischaemic muscles.

\subsection{Autoimmune, rheumatic and inflammatory diseases}

Autoimmune, rheumatic and inflammatory diseases are accompanied by an increase in the risk of CVD, which is not always associated with elevated TC and LDL-C levels (a phenomenon referred to as lipid paradox) [134]. An increased CV risk which is present in a number of diseases - including systemic lupus erythematosus, psoriasis, psoriatic arthritis, antiphospholipid syndrome, rheumatoid arthritis, ankylosing spondylitis, ulcerative colitis or Crohn's disease - is linked to vasculitis and endothelial dysfunction, and consequently to an increased severity of atherosclerosis [135-137]. Consequently, patients with these diseases have higher CV morbidity and mortality rates compared with the general population [138]. There are currently no indications for the preventive use of lipid-lowering drugs only on the basis of the presence of autoimmune, rheumatic or inflammatory diseases, and measures for the prevention and treatment of dyslipidaemia do not differ from generally applicable rules. It should be noted, though, that autoimmune, rheumatic and inflammatory diseases can be accompanied by increased concentrations of lipid parameters secondary to anti-inflammatory treatment of the diseases [139]. 


\section{KEY POINTS TO REMEMBER}

- There are no indications for the preventive use of lipid-lowering drugs only on the basis of the presence of autoimmune diseases, and measures for the prevention and treatment of dyslipidaemia do not differ from generally applicable rules.

- Before initiating dyslipidaemia treatment in individuals with autoimmune and rheumatic diseases it should be noted that the evaluation of $\mathrm{CV}$ risk in this patient group on the basis of the traditional SCORE system may not be sufficient, and the actual risk level may be higher than estimated.

\subsection{Pregnancy and breast-feeding}

Statin treatment should be discontinued in women at least 3 months before a planned pregnancy, during pregnancy and lactation [140]. Statins are teratogenic, and are rated as category $X$ drugs, meaning that the risks they involve markedly outweigh any benefits. However, the risk of foetal damage in women receiving chronic statin treatment is not high, so in the case of accidental pregnancy women should be reassured, and their gynaecologist/obstetrician must be informed immediately [141, 142]. The only lipid-lowering drugs, which are safe to use during pregnancy are ion-exchange resins (currently unavailable in Poland) [143]. The best-tolerated resin is colesevelam. The continuation of LDL-apheresis in pregnant women with hoFH is both safe and indicated [140, 143]. Contraceptive methods, which are indicated in women of reproductive age diagnosed with $\mathrm{FH}$ [140] include lowdose oestrogen oral contraceptives, intra uterine devices (IUDs) and condoms. Since high-dose oestrogen oral contraceptives may increase the concentrations of TG and LDL-C, it is crucial to monitor the lipid profile in women with $\mathrm{FH}$ who take medications of this kind. In addition, medical consultations should be provided to all women of reproductive age whose parents have been diagnosed with $\mathrm{FH}$, as the risk of homozygous $\mathrm{FH}$ in their children is as high as 25\% [140-145].

\section{KEY POINTS TO REMEMBER}

Lipid lowering treatment should be discontinued in women at least 3 months before a planned pregnancy, during pregnancy and lactation. The only lipid-lowering drugs, which are safe to use during pregnancy are ion-exchange resins (currently unavailable in Poland).

\subsection{Cognitive disorders}

The treatment of lipid disorders in patients with cognitive disorders is a particularly difficult challenge both in the context of pharmacotherapy of dyslipidaemia (interactions with other drugs), patient compliance and data showing that a very substantial decrease in LDL-C may potentially lead to an exacerbation of cognitive disorders. The problem has been omitted in a range of key guidelines [129], however as awareness is growing, it requires a cautious approach and close monitoring during therapy. Small observational studies indicate that statins have a protective effect on the development of cognitive disorders [32]. Although it can be noted at very remote follow-up due to vascular protective effects of the drugs, most data derived from randomized and observational studies fail to confirm the efficacy of statin treatment in preventing the development of cognitive disorders in elderly patients [146]. Isolated data from observational studies point to such benefits in patients with type 2 diabetes [147] and atrial fibrillation [148], which may result from the effect of cognitive disorders on drug use, not the other way round [146]. There are, as yet, no reliable data describing the impact of long-term statin use on the development of cognitive disorders at a later time, and mechanisms proposed to account for such impact fail to fully confirm the correlation [149]. A potential protective effect of statins cannot be excluded at this stage, either.

\section{KEY POINTS TO REMEMBER}

- Patients with cognitive disorders should be subject to all standard recommendations for the treatment of dyslipidaemia depending on the lipid levels, coexisting diseases and total cardiovascular risk.

- Monitoring of patient compliance and side effects is recommended, involving the patient's carers, if practicable.

\subsection{HIV/AIDS, terminal diseases, palliative states}

Terminal diseases and palliative states require a cautious assessment of benefits and the potential risk of side effects in dyslipidaemia treatment $[4,98]$. Since patients with these conditions have typically been excluded from large randomized clinical trials, scientific evidence is weak, and leads to controversies and differences in the approach recommended in guidelines published to date. Recent studies have also demonstrated that the discontinuation of statin treatment in palliative patients is not associated with a deteriora- 
tion of CV parameters including mortality. In fact, it has been noted to bring about a significant improvement in the quality of life in these patients [150]. The data are still insufficient to draw any definite conclusions, however an individual patient approach should sometimes be considered, always bearing in mind that the discontinuation of statin treatment may entail an increase in the risk of CV events $[4,5]$.

Preliminary and small studies do not point to an increased hepatotoxicity of statins in patients from these groups, though special attention should be paid to potential drug interactions, especially in view of the fact that these patients often take multiple medications. A particular focus should be placed on interactions between statins and protease inhibitors in HIV patients due to the CYP3A4 metabolism, leading to an elevated risk of myopathy and rhabdomyolysis [32]. While TC and LDL-C concentrations in the patient groups listed above are often reduced, treatment may have an adverse impact on the lipid profile. Highly active antiretroviral therapy (HAART), mainly consisting of protease inhibitors, has a negative effect on the lipid profile, particularly on the development of atherogenic dyslipidaemia [151]. Following a diagnosis of dyslipidaemia, a change of drugs used in HAART may be considered. Alternatively, pravastatin may be considered as a drug, which is recommended in HIV patients because it is only minimally metabolized by the P450 cytochrome isoenzyme system. Aside from pravastatin, other drugs, which may be considered include atorvastatin, rosuvastatin, pitavastatin (unavailable in Poland) and fluvastatin. Detailed information about drug interactions in HIV patients is available at www.hiv-druginteractions.org. Combining simvastatin or lovastatin with protease inhibitors or with efavirenz (NNRTI - non-nucleoside reverse transcriptase inhibitor) is not recommended.

Also, attention should be paid to the fact that the level of CV risk in HIV patients is higher (even

\section{KEY POINTS TO REMEMBER}

- The treatment in patients with HIV/AIDS, cancerous diseases and palliative states should be adjusted to the level of CV risk and the benefits, which can be achieved by the patient in long-term therapy.

- The therapeutic targets should correspond to the targets of therapy defined for patients who are at high CV risk.

- Since non-pharmacological management is insufficient in the majority of HIV patients receiving antiretroviral treatment, the addition of statins should be considered in their treatment. In patients who are intolerant of statins the therapeutic option is ezetimibe. above $60 \%$ ) than in HIV-free patients, and antiretroviral drugs, especially protease inhibitors, cause an up to twofold increase in that risk [32]. Similarly, in cancer patents the pleiotropic activity of drugs used for dyslipidaemia and optimal lipid profile control may be crucial for preventing a marked rise in CV risk, for example in patients who have completed chemotherapy [152].

\subsection{Liver diseases}

For years, elevated aminotransferase levels were recognised by physicians as a contraindication to statin therapy. As a result, patients at high CV risk frequently received no lipid-lowering treatment at all [5]. However, further experimental and clinical studies as well as cohort observations showed that the direct mechanisms potentially responsible for hepatocyte damage secondary to statin therapy were in fact unknown, whereas the phenomenon of a symptomless increase in aminotransferase level accompanying statin treatment was rare $(<1 \%)$ and transient in nature [5]. In February 2012, FDA was the first institution to recommend that liver enzyme tests (ALT - alanine transaminase) should be performed prior to the initiation of therapy, while routine monitoring throughout therapy is necessary only in the event of clinical symptoms [5]. The view was upheld by other associations and in expert opinions including the International Lipid Expert Panel (ILEP) [5] or the recent ESC/EAS 2016 guidelines [32].

Furthermore, available studies indicate that statin therapy should be continued and benefits can be achieved even by patients with hepatitis induced by hepatitis $B$ virus (HBV) and hepatitis $C$ virus (HCV), though not in acute and active forms of the disease $[5,153]$. Potential therapeutic benefits comprise a significant decrease in the risk of hepatocellular carcinoma by up to $28 \%$ in HBV and HCV patients, or a reduction in the incidence of hepatitis $C$ virus in the blood achieved through inhibiting its replication $[5,154]$.

Available studies also point to the beneficial role of statins in patients with primary biliary cirrhosis (PBC) in terms of improved course of the disease but primarily in terms of $C V$ risk reduction in this patient group [5]. Even greater therapeutic benefits can be noted in patients with non-alcoholic fatty liver disease (NAFLD) and non-alcoholic steatohepatitis (NASH), which are diseases currently leading to liver cirrhosis more often than alcoholic disease [5]. The diseases are frequently accompanied by hypertriglyceridaemia with a reduced level of HDL-C and an increased incidence of atherogenic VLDL and LDL lipoprotein subfractions [5]. Available studies have found statin therapy to be very effective at reducing CV morbidity and mortality in the group of NAFLD patients com- 
pared to patients not receiving statin treatment (68 vs. $39 \%, p=0.007$ ) [154]. Study results also show that statin therapy in these patient groups is safe $[5,32]$. Consequently, low-dose statin treatment may be considered in NAFLD or NASH patients with baseline ALT concentrations > $3 \times$ upper limit of normal (ULN), however their ALT levels must be monitored on a monthly basis for 3 months, and four times a year afterwards. The therapeutic management in chronic liver diseases is described in Chapter 14.

\section{KEY POINTS TO REMEMBER}

- Liver enzyme tests (ALT) should be performed prior to the initiation of treatment, while routine monitoring throughout therapy is not necessary (indicated only in the event of clinical symptoms).

- Due to beneficial effects on the course of the disease and its complications, and a decrease in CV risk, statin treatment should be used in patients with hepatitis B and C.

- Statin therapy is safe in patients with NAFLD/NASH; it contributes to an improved course of the disease, and reduces the CV risk in a much more significant manner than in individuals with normal liver function.

\section{ADVERSE EFFECTS ASSOCIATED WITH DYSLIPIDAEMIA TREATMENT/STATIN INTOLERANCE}

Statin intolerance is a phenomenon which has been observed for many years, however it has lately become a focus of interest due to the introduction of new drugs for combined therapy (primarily ezetimibe and PCSK9 inhibitors but also ETC-1002) and studies investigating the inefficacy of statin treatment with an emphasis on statin nonresponse, statin non-adherence, statin discontinuation or statin intolerance $[4,5,155]$. Statin intolerance should be defined as the lack of possibility to use a statin therapy - both with respect to a statin drug and its dose - that would be appropriate for the existing cardiovascular risk [5, 32]. In other words, statin intolerance refers not only to the lack of statin treatment because of clinical or biochemical symptoms (so-called complete intolerance) but also to the treatment with insufficiently high statin doses or with insufficiently potent statins in relation to the CV risk level [5, 156]. In March 2015, the International Lipid Expert Panel (ILEP) proposed the following definition of statin intolerance:

1. inability to tolerate at least 2 different statins one statin at the lowest starting average daily dose and the other statin at any dose,
2. intolerance associated with confirmed, intolerable statin-related adverse effect(s) or significant biomarker abnormalities,

3. symptoms or biomarker changes resolution or significant improvement upon dose decrease or discontinuation,

4. symptoms or biomarker changes not attributable to established predispositions such as drug-drug interactions and recognized conditions increasing the risk of statin intolerance [5]. It needs to be noted that there are multiple risk factors which may increase the likelihood of statin intolerance including physical activity, particularly after its initiation or increase in intensity; hepatic and/or renal diseases, hypothyroidism, vitamin D deficiency [157], alcohol intake, rheumatic diseases, extensive surgical procedures, low body weight, female gender or old age [5, 158]. The consensus prepared by ILEP addressed in detail all the risk factors enumerated above, and presented patient management recommendations aimed at reducing the risk of intolerance and ensuring the possibility to continue statin therapy [5].

A discussion of the problem of statin intolerance should involve several key aspects. In 90\% of cases, symptoms of intolerance develop within the initial 6 months after starting therapy or increasing the statin dose, and in $75 \%$ of cases - during the initial 12 months of therapy. The likelihood of intolerance symptoms developing a year after the start of therapy or dose increase is low, unless a risk-increasing factor (disease, new drug interacting with statins) emerges [5, 158]. The most common causes of statin intolerance are muscle symptoms (affecting up to $29 \%$ of patients) [158] manifested as pain (myalgia), contractions, muscle weakness with or without an accompanying increase in the level of creatine kinase (CK) (myopathy), with or without muscle inflammation (myositis). Myonecrosis and rhabdomyolysis occur extremely rarely $(<2 / 100,000$ patient-years) and may frequently be linked to a genetic predisposition, an exacerbation of concomitant disease or a therapeutic error [5, 32, $156,158]$. Other symptoms of statin intolerance including hair loss, sleep disorder [159], influenza-like symptoms, lupus-like symptoms, skin rashes, gastrointestinal symptoms, decreased libido or gynecomastia are rare, and it is often difficult to attribute them directly to statin treatment. Furthermore, available studies fail to show any causality between statin therapy and symptom development [5]. Excluding individual risk factors which may lead to statin intolerance, attention should always be paid to the so-called "nocebo effect", where patients starting statin treatment actually expect the development of symptoms based on information about possible adverse ef- 
fects found in the patient information leaflet or via the internet, or received from other patients taking the same medications $[5,156]$. In most cases, such symptoms can be easily eliminated by collecting a detailed history from the patient (including the onset of symptoms, their location and severity). In statin-intolerant patients, appropriate management (step-by-step approach involving proper history taking and gradual exclusion of causes underlying statin intolerance, prompt introduction of appropriate measures) may enable the continuation of statin therapy in over $90 \%$ of these patients. Consequently, complete statin intolerance is a rare phenomenon, occurring only in $1-2 \%$ of cases $[5,156]$.

The following patient management is recommended in the event of statin intolerance $[5,32$, 158]:

1. If the patient reports muscle pain at CK $\geq 4$ ULN, statin treatment should be discontinued for 4-6 weeks until the regression of pain and CK normalization.

2. If the patient reports tolerable muscle pain at CK $<4$ ULN, a reduction in statin dose and treatment continuation with close monitoring of CK may be considered; if clinical symptoms are exacerbated and/or the CK concentration is increased, statin treatment should be discontinued for 4-6 weeks until the regression of pain and CK normalization.

3. If the patient reports intolerable muscle pain at CK $<4$ ULN, statin treatment should be discontinued for $2-4$ weeks until the regression of pain and CK normalization.

4. Following the regression of symptoms/CK normalization, treatment with another highly effective statin (preferably atorvastatin or rosuvastatin) should be initiated at an appropriately reduced dose, so that after 4-6 weeks, if the patient experiences no symptoms, the starting dose adjusted to the patient's risk level can be resumed (applicable to item 1 ) or another statin at a corresponding dose (in accordance with Roberts' rule) adjusted to the patient's risk level can be introduced (applicable to item 3).

5. If intolerance symptoms persist, options that may be considered include a further reduction in statin dose, statin administration every other day, 1-2 times per week (with a proven efficacy for atorvastatin and rosuvastatin) or the addition of ezetimibe to an appropriately adjusted statin dose. In cases of complete statin intolerance the addition of fenofibrate to ezetimibe treatment may be considered.

6. PCSK9 inhibitors may be considered in patients at high and very high CV risk, with persistently high LDL-C concentrations in statin-intolerant patients.

\section{RECOMMENDATIONS FOR MONITORING LIPIDS AND BIOCHEMICAL PARAMETERS DURING DYSLIPIDAEMIA TREATMENT}

The side effects associated with statin use, and the management recommended after their development, are described in detail in the opinion of the ILEP, while statin-induced muscle symptoms - in the EAS Consensus Panel statement [158]. The present section is based on the documents referred to above and on recommendations provided in the most recent (2016) ESC/ EAS guidelines for the management of dyslipidaemias [32].

Lipid profiling should be performed $8 \pm 4$ weeks after the initiation of pharmacotherapy and within the same time frame if the drug or the drug dose is modified. The most common side effects of statin therapy are statin-associated muscle symptoms (SAMS). They can be serious (myopathy and rhabdomyolysis) and milder, manifested as muscle contractions and pain (myalgia) and/or muscle weakness. Myopathy can be accompanied by an increase in the level of creatine kinase (see Chapter 13). Postulated pathomechanisms for muscle symptoms include mitochondrial dysfunction, reduced energy generation or muscle protein degradation $[48,160]$.

It is recommended to determine the CK level before the introduction of a statin (also a fibrate). There is no need to perform routine CK tests during therapy. The only indications for CK testing are muscle complaints. Myopathy can be associated with a rise in CK levels, however the symptom may also be absent. Rhabdomyolysis is characterized by a marked increase in the level of the enzyme, myoglobinemia, myoglobinuria (dark urine), acute renal failure (oliguria, increase in the concentration of creatinine $\geq 0.5 \mathrm{mg} / \mathrm{dl}$ and potassium). Consequently, the emergence of severe muscle symptoms accompanied by a high increase in CK should be followed by the evaluation of symptoms and biochemical parameters, and immediate hospital referral $[32,158]$. In the event of muscle symptoms, EAS suggests the following course of action: discontinuation of statin therapy for 6 weeks and, after a treatment-free period, introduction of one or two other statins also with a 6-week interval between them [158]. The above strategy makes it possible to verify whether the muscle complaints are statin-associated, in which case they subside after the discontinuation of treatment and return after using another drug from this group. In SAMS patients, experts suggest a statin at a maximal tolerated dose in combination with another lipid-lowering agent - or a non-statin drug. The preferred option is ezetimibe, followed by an anion exchange resin (colesevelam - unavailable in Poland) or a fibrate 
$[32,158]$. An alternative option is to use PCSK9 inhibitors [32].

According to ESC/EAS experts, statin discontinuation is indicated if the CK level is >10x ULN, and CK is 4-10x ULN, if accompanied by muscle symptoms [32]. In the former case, the patient's renal function should be examined and CK should be monitored every 2 weeks. In the latter case, CK should be monitored until its normalization and followed by the introduction of another statin at a lower dose. If the CK level is < 10x ULN, and no muscle symptoms are observed, the therapy can be continued, while monitoring the CK levels. The treatment should also be discontinued if the patient finds the symptoms intolerable, even though the CK is in the normal range [32].

Statin-induced liver damage is a very rare occurrence. The general rule should be to determine the concentration of aminotransferases (ALT) before starting treatment. There is no need to monitor enzyme activity during therapy on a routine basis. However, the test should be performed if the patient develops symptoms indicative of hepatotoxicity (pain, unusual fatigue, weakness and jaundice). The symptoms listed above and/or an increase in ALT over $3 \times$ ULN, are an indication for discontinuing the therapy. Statins are not used in patients with acute hepatitis. Chronic liver diseases are not regarded as contraindications, however experts recommend liver enzyme monitoring on a monthly basis for the initial 3 months after drug use, and four times a year afterwards [32, 158]. If the baseline values are found to have increased

\section{KEY POINTS TO REMEMBER}

- The concentration of lipids should be assessed 4-8 weeks after the initiation of pharmacotherapy, following a change in drug dose or a change of drug.

- The most common side effects of statins are muscle complaints. Statin-induced hepatotoxicity is very rare.

- Statins have diabetogenic properties, however an increased glucose concentration (or even the development of diabetes) is not a reason for discontinuing the use of the drug, as the benefit (i.e. risk reduction) outweighs the harm.

- Before a statin is used, it is recommended to assess the concentrations of CK, ALT and TSH. Before introducing a fibrate, CK and ALT/AST as well as creatinine levels should also be assessed.

- There is no need to monitor the CK and ALT levels on an ongoing basis, however the tests are recommended if the patient has muscle or liver symptoms. $\geq 2 \times$, ILEP experts recommend the discontinuation of statin treatment. Following the normalization of liver enzyme levels, therapy should be initiated with a different statin drug [5].

Experts recommend thyroid-stimulating hormone (TSH) testing before the initiation of statin treatment, as hypothyroidism is a risk factor for myopathy. Although statins exhibit a diabetogenic effect, there is no recommendation to evaluate the level of glycaemia before and during treatment, as even the development of diabetes is not an indication for discontinuing the use of the drug. In our view, periodic glycaemic tests are nevertheless beneficial, particularly in individuals with risk factors predisposing to the development of diabetes (e.g. carbohydrate disorders, obesity) [161]. In fibrate-treated patients, in addition to baseline CK and aminotransferase tests, creatinine concentration should also be determined [32].

\section{CAUSES OF INEFFECTIVE TREATMENT OF DYSLIPIDAEMIAS}

Dyslipidaemia is one of the main modifiable risk factors for cardiovascular diseases. The primary biochemical target in the treatment of dyslipidaemias is to effectively lower the concentration of the LDL fraction $[6,32]$. According to the current recommendations, the target in patients from high CV risk groups is to reduce their LDL-C level below $100 \mathrm{mg} / \mathrm{dl}(2.6 \mathrm{mmol} / \mathrm{l})$, and in $\mathrm{pa}$ tients from very high-risk groups - below $70 \mathrm{mg} / \mathrm{dl}$ $(1.8 \mathrm{mmol} / \mathrm{l})$ or by a minimum of $50 \%$ relative to the baseline values [32]. This scale of reduction in the concentration of LDL-C can be achieved only by introducing an intensive lipid lowering treatment (atorvastatin at 40-80 mg a day, rosuvastatin at ca. 20-40 mg a day or maximal doses of weaker statins) [32]. In monotherapy, aside from atorvastatin or rosuvastatin, a decrease in LDL-C by $50 \%$ of its baseline value can only be achieved with simvastatin at a daily dose of $80 \mathrm{mg}$. The dose, however, is not currently recommended, since the risk of adverse effects and intolerance of treatment markedly outweighs potential benefits resulting from therapy. It must be remembered that the tolerance of dyslipidaemia treatment is as important as its efficacy. Dyslipidaemia is a chronic and intrinsically symptomless disorder. Each $40 \mathrm{mg} / \mathrm{dl}(1 \mathrm{mmol} / \mathrm{l})$ decrease in LDL-C concentration is known to translate into a $20 \%$ relative reduction in fatal cardiovascular disease and a $17 \%$ decrease in the risk of stroke [32, 49].

However, there is no direct correlation between successful treatment and the patient's well-being. Rather, the success of therapy is expressed as a percentage of eliminated potential CV events. Ultimately, then, the success of therapy is crucially dependent on the establishment 
of appropriate physician-patient relationships, so that the patient is able to properly understand the goal and expected effects of treatment. The physician-patient relationship is increasingly frequently described with reference to such terms as compliance, adherence or persistence. Initially, the terms were used mainly in the context of therapy of arterial hypertension, however they are also perfectly suited for addressing problems related to the efficacy of dyslipidaemia treatment.

\subsection{Compliance}

In medical contexts, compliance refers to the observance of medical advice or adherence to the physician's recommendations. In this sense, however, the term may have negative connotations. Furthermore, it reduces the patient's role in the treatment process to following the physician's orders/recommendations. Based on other sources, compliance can be understood as the "degree of adherence to medical recommendations" [32, 155]. The term is thus very broad and difficult to define precisely. In simple terms, the quality of compliance can be determined on the basis of the efficacy of treatment of a given condition - in this case dyslipidaemia. Over the past few years, the efficacy has improved. Based on the results obtained in the 3ST-POL trial conducted in 20072008, the recommended concentrations for total cholesterol were achieved in nearly $10 \%$ of patients with risk factors and nearly $16 \%$ of patients without risk factors, and target LDL levels - in $15.6 \%$ and $22.7 \%$ of patients, respectively. The trial included only patients treated on an outpatient basis [162]. In the same period, according to the Polish results of the EUROASPIRE study, the target concentration of total cholesterol was achieved in up to $70 \%$ of patients, and the target concentration of LDL-C - in $39 \%$ of patients [163]. More recent studies focused on the efficacy of treatment in Poland, such as CEPHEUS carried out in 20112012, are more optimistic, with target LDL-C concentrations achieved in approx. 50\% of patients treated in secondary or primary prevention [164] At the same time, however, the mean reduction in LDL-C concentration in the CEPHEUS study was only $20 \%$ compared to the baseline value [164] Consequently, the efficacy of dyslipidaemia treatment in Poland definitely persists at a level, which is far from satisfactory.

\subsection{Adherence, non-response (non- adherence) and persistence}

Adherence and persistence are two other terms describing selected aspects of the physician-patient relationship [155]. Adherence is usually understood as the patient's cooperation in following therapeutic recommendations, whereas persistence stands for perseverance in continuing therapy. Other terms frequently used in this context are non-adherence and non-response, referring to failure to adhere to therapeutic recommendations (the concept of non-response is also used to describe the patient's inappropriate response to statin treatment, i.e. situations where no $L D L-C$ reduction is observed or the reduction is lower than expected [165]). In simple terms, patients are asked whether they comply with therapeutic recommendations and to what extent they follow the prescribed treatment regimen. Polish data describing this aspect are not optimistic, either. According to the 3ST-POL trial [162] 25\% of patients stopped taking statins as early as 3 months after the initiation of treatment. After 3 years, therapy was continued only by $15 \%$ of patients. In the CEPHEUS study [164], approximately $92 \%$ of patients declared taking "cholesterol-lowering" drugs every day. At the same time, however, $18 \%$ of subjects forgot to take their medication once a month, about $10 \%$ - once per 2 weeks, and about $3.5 \%$ - more often than once a week. In addition, almost one in 10 patients admitted stopping treatment after the achievement of target cholesterol levels. Only $83.6 \%$ of patients declared taking statins a year after their hospitalization for acute coronary syndrome or myocardial revascularization. Furthermore, the average doses of statins they declared using were far from expected - rosuvastatin $14.6 \mathrm{mg} / \mathrm{dl}$ and atorvastatin $32.8 \mathrm{mg} / \mathrm{dl}[21]$.

Treatment discontinuation is a very serious problem, and an error committed by patients and physicians. It is also potentially dangerous, particularly in patients classified as being at high and very high risk, due to the possibility of atheromatous plaque instability and the risk of (another) cardiovascular event $[4,32]$. Studies have shown that the discontinuation of treatment is linked to a threefold increase in all-cause mortality and a fourfold rise in cardiovascular mortality [166]. Achieving the target concentration of LDL-C with a good tolerance of the drug dose used represents a proof that the treatment strategy is effective and shows indisputably that the therapy should be maintained. In such circumstances, stopping the treatment or reducing the statin dose may lead to a rapid rise in the concentration of LDL-C and, as a result, increase the level of CV risk.

\subsection{Therapeutic inertia}

The role of the physician in the therapeutic process is naturally fundamental. In the treatment of dyslipidaemias, the physician estimates the patient's total cardiovascular risk, verifies indications for the introduction of pharmacotherapy, selects a specific drug (or drugs), and monitors 
the safety and efficacy of the adopted patient management regimen. The phenomenon of the so-called therapeutic inertia has been observed in Poland, particularly in outpatient treatment facilities, for many years. In dyslipidaemia treatment, the problem manifests itself primarily as:

- Belittling the importance of non-pharmacological management;

- Unjustified deferral in the introduction of pharmacotherapy for dyslipidaemia;

- Use of statin doses which are too low in relation to the adopted therapeutic targets;

- Lack of statin dose modifications if the treatment is ineffective;

\section{KEY POINTS TO REMEMBER}

- The efficacy of dyslipidaemia treatment in Poland is still unsatisfactory. Data in this regard collected over the past decade reveal discrepancies, which result in part from the selection of the study populations (subjects treated on an outpatient/inpatient basis) and subsequent modifications of therapeutic recommendations. However, taking into account a clear tendency for a gradual reduction in the target concentration of LDL-C in consecutive guidelines, it should be concluded that the treatment of dyslipidaemias in Poland is effective in less than a half of all patients.

- Therapeutic failure is partially a consequence of the nature of dyslipidaemia: the condition is clinically silent and chronic, which has a negative impact on compliance, adherence and persistence. With regard to patients, it appears that the main cause of non-adherence is the fact that they are not aware of the chronic nature of dyslipidaemia and have no awareness of the direct correlation existing between the efficacy (or inefficacy) of dyslipidaemia therapy and the actual risk of myocardial infarction, stroke or fatal cardiovascular disease.

- Finally, therapeutic inertia remains a serious problem among physicians who have unjustified concerns both about using statins in a strength and dose appropriate for therapeutic targets, and about using combined therapy. A common negative consequence of inappropriate approaches adopted by patients and physicians is a persistently high rate of treatment discontinuation.

- Taking into account the prevalence of dyslipidaemia and its direct association with the prevalence of cardiovascular system disorders, the efficacy of dyslipidaemia therapy is a very important public health problem.
- Unjustified interruption of statin treatment;

- Apprehension about using combined therapy. Analyzing therapeutic inertia, attention should be focused again on the outcomes of the 3ST-POL and CEPHEUS studies [162, 164]. Despite a 4-year interval between them, the average doses of the most commonly used statins were comparable in both studies: about $20 \mathrm{mg}$ daily for atorvastatin and simvastatin. In the CEPHEUS study [164], 90\% of the subjects took one lipid-lowering drug (statin), and only ca. $6 \%$ of the patients were on combined therapy. However, a year after hospitalization for acute coronary syndrome or myocardial revascularization only $0.5 \%$ of patients declared using a statin with ezetimibe, and $1.9 \%$ - a statin and fibrate combination [21]. Despite ongoing debates and some concerns about available data, combinations of a statin and fibrate, and a statin and ezetimibe, are not only effective (both in the context of biochemical effects and specific patient groups - in the clinical context) but also safe and well-tolerated. The signatories of the Sopot Declaration [167] have stated clearly that a combined therapy of dyslipidaemias is used too rarely in Poland. Finally, it needs to be noted that lipid profiling should be performed every $6-8$ weeks until the achievement of target concentrations of different lipid fractions. The common practice in outpatient treatment, however, is based on fixed doses of statins without biochemical monitoring of treatment results $[6,32,168]$.

\section{ORGANIZATION OF POLISH HEALTHCARE IN DYSLIPIDAEMIAS}

The main burden in the prophylaxis, prevention, diagnosis and treatment of lipid disorders rests on family physicians (primary care physicians) [7]. The prophylactic and therapeutic management should always involve improvements in lifestyle and eating habits, which may require consultations with a dietician [8]. The treatment of dyslipidaemias requires cooperation between primary care physicians and medical specialists (internists, cardiologists, diabetologists, nephrologists and neurologists).

Screening for dyslipidaemias should be performed in individuals with at least one risk factor for cardiovascular diseases (e.g. arterial hypertension, obesity, nicotine dependence syndrome, adverse family history) and in all men $>40$ years of age and women $>50$ years of age, post-menopausal women, women with gestational diabetes and gestational hypertension, individuals infected with HIV or undergoing HAART, men with erectile dysfunction as well as in all cases accompanied by symptoms indicative of CVD.

Regular lipid profiling should be performed in individuals:

- diagnosed with cardiovascular disease, 
- diagnosed with familial hypercholesterolaemia,

- with a family history of premature cardiovascular diseases,

- diagnosed with diabetes,

- diagnosed with chronic kidney disease,

- diagnosed with autoimmune, rheumatic and inflammatory diseases,

- in chronic smokers,

- infected with HIV or undergoing HAART.

The cooperation between family (primary care) physicians and specialists in the diagnosis and treatment of dyslipidaemias should focus, first and foremost, on the aspects listed below: (1) suspicion or diagnosis of familial hypercholesterolaemia (and other genetic diseases accompanied by severe lipid disorders), (2) statin intolerance in patients at a risk of myopathy, hepatopathy or diabetes, (3) severe hypercholesterolaemia/dyslipidaemia resistant to treatment with available drugs, (4) severe hypertriglyceridaemia, (5) initiation of dyslipidaemia in children.

\section{KEY POINTS TO REMEMBER}

- The main burden in the prophylaxis, prevention, diagnosis and treatment of lipid disorders rests on family physicians (primary care physicians). The prophylactic and therapeutic management should always involve improvements in lifestyle and eating habits. The treatment of lipid disorders requires cooperation between primary care physicians and medical specialists.

\section{Conflict of interest}

Prof. Maciej Banach: lectures: Abbott//Mylan, Abbott Vascular, Actavis, Amgen, KRKA, MSD, Sanofi-Aventis; consultations: Abbott Vascular, Amgen, Daichii Sankyo, Esperion, MSD, Resverlogix, Sanofi-Aventis; Prof. Piotr Jankowski: lectures: Amgen, KRKA, MSD, Sanofi-Aventis; consultations: Amgen, MSD, Sanofi-Aventis; Prof. Jacek Jóźwiak: lectures: Valeant, Beoehringer Ingelheim, Śląskie Laboratoria Analityczne; consultations: Valeant, Bayer, Bioton, Beoehringer Ingelheim, Śląskie Laboratoria Analityczne; Prof. Barbara Cybulska: lectures: Amgen, Sanofi, consultations: MSD, Amgen, Sanofi; Prof. Adam Windak: lectures: MSD, Sanofi-Aventis; consultations: MSD, Sanofi Aventis, Polpharma, Merck; Prof. Tomasz Guzik: lectures: Abbott, G-Pharma, Servier (France); Srteering committee/consultations: Novartis, Sanofi-Aventis, Bayer, ALK-Abello; Prof. Artur Mamcarz: lectures: Abbott//Mylan, Actavis, Amgen, Apotex, AstraZeneca, Gedeon Richter, MSD, Polpharma, Sandoz, Sanofi-Aventis, Valeant; consultations: MSD, Polpharma, Valeant; Prof. Marlena Broncel: lectures, articles for: MSD, Sanofi, Amgen, Pfizer, Fournier, Bioton, Polpharma; Prof. Tomasz Tomasik: cooperation: Pfizer and Valeant.

\section{References}

1. Zdrojewski T, Solnica B, Cybulska B, et al. Prevalence of lipid abnormalities in Poland. The NATPOL 2011 survey. Kardiol Pol 2016; 74: 213-23.

2. Rynkiewicz A, Cybulska B, Banach M, et al. Management of familial heterozygous hypercholesterolemia: Position Paper of the Polish Lipid Expert Forum. J Clin Lipidol 2013; 7: 217-21.

3. Colantonio LD, Bittner V, Reynolds K, et al. Association of serum lipids and coronary heart disease in contemporary observational studies. Circulation 2016; 133: 256-64.

4. Banach M, Serban MC. Discussion around statin discontinuation in older adults and patients with wasting diseases. J Cachexia Sarcopenia Muscle 2016; 7: 396-9.

5. Banach M, Rizzo M, Toth P, et al. Statin intolerance - an attempt at a unified definition. Position paper from an International Lipid Expert Panel. Arch Med Sci 2015; 11: 1-23.

6. 2016 European Guidelines on cardiovascular disease prevention in clinical practice: The Sixth Joint Task Force of the European Society of Cardiology and Other Societies on Cardiovascular Disease Prevention in Clinical Practice (constituted by representatives of 10 societies and by invited experts): Developed with the special contribution of the European Association for Cardiovascular Prevention and Rehabilitation (EACPR). Eur Heart J 2016; 37: 2315-81.

7. Jóźwiak J. Czynniki ryzyka - dyslipidemia. In: Ocena wybranych czynników ryzyka sercowo-naczyniowego w ogólnopolskiej 5-letniej prospektywnej obserwacji kohorty pacjentów POZ. Jóźwiak J (ed.). Wydawnictwo Politechniki Częstochowskiej 2013.

8. Jóźwiak J. Dyslipidemie. In: Medycyna rodzinna. Podręcznik dla lekarzy i studentów. Windak A, Mastalerz-Migas A, Chlabicz S (eds.). Termedia, Poznan 2015.

9. Rywik S, Broda G, Piotrowski W, et al. Epidemiologia chorób układu krążenia. Program Pol-MONICA Warszawa. Kardiol Pol 1996; 44 (Suppl. 2): 7-35.

10. Tendera M, Kozakiewicz K, Bartnik M, et al. Występowanie głównych czynników ryzyka choroby niedokrwiennej serca w grupie 41927 osób objętych akcją prewencji pierwotnej w Polsce południowej (Southeren Poland Epidemiological Survey - SPES). Wiad Lek 2001; 54: 293-303.

11. Zdrojewski T, Bandosz P, Szpakowski P, et al. Rozpowszechnienie głównych czynników ryzyka chorób układu sercowo-naczyniowego w Polsce. Wyniki badania NATPOL PLUS. Kardiol Pol 2004; 61 (Suppl. 4): 1-26.

12. Pająk A, Wiercińska E, Polakowska M, et al. Rozpowszechnienie dyslipidemii $u$ mężczyzn i kobiet W wieku 20-74 lat $w$ Polsce. Wyniki programu WOBASZ. Kardiol Pol 2005; 63 (Suppl. 4): 620-6.

13. Jóźwiak J, Mastej M, Lukas W, et al. LIPIDOGRAM2003 - Ocena i porównanie parametrów pełnego lipidogramu i wskaźnika masy ciała BMI w zależności od płci i wieku w populacji pacjentów Polski południowej i zachodniej. Część II: częstość występowania zaburzeń lipidowych w zależności od płci i BMI. Probl Med Rodz 2005; 7: 33-9. 
14. Jóźwiak J, Mastej M, Lukas W, et al. Czy problem zaburzeń lipidowych $\mathrm{w}$ równym stopniu dotyczy różnych regionów Polski? Kardiol Pol 2006; 64 (Supl. 2): $137-45$.

15. Jóźwiak J, Mastej M, Lukas W, et al. Badanie LIPIDOGRAM2004 vs. LIPIDOGRAM 2006. Czy sytuacja epidemiologiczna w zakresie zaburzeń lipidowych uległa zmianie? Probl Med Rodz 2007; 9: 78-81.

16. Pająk A, Szafraniec K, Polak M, et al. Changes in the prevalence, management and treatment of hypercholesterolemia and other dyslipidemias over 10 years in Poland. The WOBASZ study. Pol Arch Med Wewn 2016; doi: 10.20452/pamw.3464.

17. Konduracka E, Jóźwiak J, Mastej M, et al. Prevalence of dislipidemia and general ineffectiveness of its treatment In both primary and secondary prevention of coronary heart disease within family medicine framework - results of LIPIDOGRAM 2005 a nationwide epidemiological study. Dislipidemia in Poland - ineffective treatment. Przegl Lek 2008; 65: 834-7.

18. Kaess B, Jozwiak J, Mastej M, et al. Association between anthropometric obesity measures and coronary artery disease: a cross-sectional survey of 16,657 subjects from 444 Polish cities. Heart 2010; 96: 131-5.

19. Tomasik T, Jozwiak J, Windak A, et al. Prevention of coronary heart disease in primary medical care in Poland: results from the LIPIDOGRAM Study. Eur J Cardiovasc Prev Rehabil 2011; 18: 287-96.

20. Kaess BM, Jóźwiak J, Nelson CP, et al. The relation of rapid changes in obesity measures to lipid profile - insights from a nationwide metabolic health survey in 444 Polish cities. PLoS One 2014; 9: e86837.

21. Jankowski P, Czarnecka D, Łukaszewska A, et al. Factors related to the effectiveness of hypercholesterolemia treatment following hospitalization for coronary artery disease. Pol Arch Med Wewn 2016; 126: 388-94.

22. Jankowski P, Czarnecka D, Badacz L, et al. Practice setting and secondary prevention of coronary artery disease. Arch Med Sci in press.

23. Baranowski J, Windak A. Optymalizacja polskiego systemu finansowania podstawowej opieki zdrowotnej. http://www.ey.com/Publication/vwLUAssets/Sprawne_Panstwo_Optymalizacja_POZ/\$FILE/ Sprawne-Panstwo-Optymalizacja-POZ-05092012.pdf

24. Pająk A, Szafraniec K, Polak M, et al. Prevalence of familial hypercholesterolemia: a meta-analysis of six large, observational, population-based studies in Poland. Arch Med Sci 2016; 12: 687-96.

25. Lewington S, Whitlock G, Clarke R, et al. Blood cholesterol and vascular mortality by age, sex, and blood pressure: a meta-analysis of individual data from 61 prospective studies with 55,000 vascular deaths. Lancet 2007; 370: 1829-39.

26. Di Angelantonio E, Sarwar N, Perry P, et al. Major lipids, apolipoproteins, and risk of vascular disease. JAMA 2009; 302: 1993-2000.

27. Rysz-Górzyńska M, Banach M. Subfractions of highdensity lipoprotein (HDL) and dysfunctional $\mathrm{HDL}$ in chronic kidney disease patients. Arch Med Sci 2016; 12: 844-9.

28. Glasser SP, Mosher A, Howard G, Banach M. What is the association of lipid levels and incident stroke? Int J Cardiol 2016; 220: 890-4.

29. Zdrojewski T, Jankowski P, Bandosz P, et al. Nowa wersja systemu oceny ryzyka sercowo-naczyniowego i tablic SCORE dla populacji Polski. Kardiol Pol 2015; 73: 958-61.
30. Quispe R, Manalac RJ, Faridi KF, et al. Relationship of the triglyceride to high-density lipoprotein cholesterol (TG/HDL-C) ratio to the remainder of the lipid profile: The Very Large Database of Lipids-4 (VLDL-4) study. Atherosclerosis 2015; 242: 243-50.

31. Banach M, Serban C, Aronow WS, et al. Lipid, blood pressure and kidney update 2013. Int Urol Nephrol 2014; 46: 947-61.

32. Catapano AL, Graham I, De Backer G, et al. 2016 ESC/ EAS Guidelines for the Management of Dyslipidaemias. The Task Force for the Management of Dyslipidaemias of the European Society of Cardiology (ESC) and European Atherosclerosis Society (EAS) Developed with the special contribution of the European Assocciation for Cardiovascular Prevention \& Rehabilitation (EACPR). Eur Heart J 2016; 37: 2999-3058.

33. Martin SS, Blaha MJ, Elshazly MB, et al. Comparison of a novel method vs the Friedewald equation for estimating low-density lipoprotein cholesterol levels from the standard lipid profile. JAMA 2013; 310: 2061-8.

34. Otocka-Kmiecik A, Mikhailidis DP, Nicholls SJ, et al. Dysfunctional HDL: a novel important diagnostic and therapeutic target in cardiovascular disease? Prog Lipid Res 2012; 51: 314-24.

35. Kotani K, Serban MC, Penson P, et al. Evidence-based assessment of lipoprotein(a) as a risk biomarker for cardiovascular diseases - some answers and still many questions. Crit Rev Clin Lab Sci 2016; 53: 370-8.

36. Banach M. Lipoprotein (a) - we know so much yet still have much to learn. J Am Heart Assoc 2016; 5: e003597.

37. Banach M, Serban C, Sahebkar A, et al.; Lipid and Blood Pressure Meta-analysis Collaboration (LBPMC) Group. Impact of statin therapy on coronary plaque composition: a systematic review and meta-analysis of virtual histology intravascular ultrasound studies. BMC Med 2015; 13: 229.

38. Nikolic D, Castellino G, Banach M, et al. PPAR agonists, atherogenic dyslipidemia and cardiovascular risk. Curr Pharm Des 2016; doi: 10.2174/13816128226661610 06151134

39. What is residual risk. Residual Risk Reduction Initiative. http://www.r3i.org/definition.php

40. Kones R. Molecular sources of residual cardiovascular risk, clinical signals, and innovative solutions: relationship with subclinical disease, undertreatment, and poor adherence: implications of new evidence upon optimizing cardiovascular patient outcomes. Vasc Health Risk Manag 2013; 9: 617-70.

41. Reith C, Armitage J. Management of residual risk after statin therapy. Atherosclerosis 2016; 245: 161-70.

42. Booth JN 3rd, Colantonio LD, Howard G, et al. Healthy lifestyle factors and incident heart disease and mortality in candidates for primary prevention with statin therapy. Int J Cardiol 2016; 207: 196-202.

43. Fruchart JC, Davignon J, Hermans MP, et al.; Residual Risk Reduction Initiative (R3i). Residual macrovascular risk in 2013: what have we learned? Cardiovasc Diabetol 2014; 13: 26.

44. Cannon CP, Blazing MA, Giugliano RP, et al.; IMPROVE-IT Investigators. Ezetimibe added to statin therapy after acute coronary syndromes. N Engl J Med 2015; 372: 2387-97.

45. Sahebkar A, Serban MC, Gluba-Brzózka A, et al. Lipidmodifying effects of nutraceuticals: an evidence-based approach. Nutrition 2016; 32: 1179-92. 
46. Szostak WB, Szostak-Węgierek D, Cybulska B. Rola i miejsce farmakoterapii w profilaktyce miażdżycy. In: Historia badań nad miażdżycą. Szostak WB (red.). ITEM Publishing, Warsaw 2016.

47. Jones PH, Davidson MH, Stein EA, et al. Comparison of the efficacy and safety of rosuvastatin versus atorvas tatin, simvastatin, and pravastatin across doses (STEL-

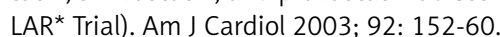

48. Muntean DM, Thompson PD, Catapano AL, et al. Statin-associated myopathy and the quest for biomarkers: can we effectively predict statin-associated muscle symptoms? Drug Discov Today 2016 Sep 12. pii: S1359-6446(16)30321-X, doi: 10.1016/j.drudis.2016. 09.001.

49. Cholesterol Treatment Trialists' Collaboration (CTT). Efficacy and safety of more intensive lowering of LDL cholesterol: a meta-analysis of data from 170000 participants in 26 randomised trials. Lancet 2010; 376: 1670-81.

50. Keech A, Simes RJ, Barter P, et al. Effects of long-term fenofibrate therapy on cardiovascular events in 9795 people with type diabetes mellitus (the FIELD study): a randomised controlled study. Lancet 2005; 366: 1849-61.

51. ACCORD Study Group. Ginsberg HM, Lovato LC, et al. Effects of combination lipid therapy in type 2 diabetes mellitus. N Engl J Med 2010; 362: 1563-74.

52. Garcia-Calvo M, Lisnock J, Bull HG. The target of ezetimibe is Niemann-Pick C1-like 1 (NPC1L1). Proc Natl Acad Sci USA 2005; 102: 8132-7.

53. Bays HE, Moore PB, Drehobl MA, et al. Effectiveness and tolerability of ezetimibe in patients with primary hypercholesterolemia: pooled analysis of two phase II studies. Clin Ther 2001; 23: 1209-30.

54. Knopp RH, Gitter H, Truitt T, et al. Effects of ezetimibe, a new cholesterol absorption inhibitor on plasma lipids in patients with primary hypercholesterolemia. Eur Heart J 2003; 24: 729-41.

55. Mikhailidis DP, Wierzbicki AS, Daskalopoulou SS, et al. The use of ezetimibe in achieving low density lipoproteins lowering goals in clinical practice: position statement of United Kingdom consensus panel. Curr Med Res Opin 2005; 21: 959-69.

56. Simon JS, Karnoub MC, Devlin DJ, et al. Sequence variation in NPC1L1 and association with improved LDL-cholesterol lowering in response to ezetimibe treatment. Genomic 2005; 86: 648-56.

57. Gazi LF, Daskalopoulou SS, Nair DR, et al. Effect of ezetimibe in patients who cannot tolerate statins or cannot get to the low density lipoprotein cholesterol target despite taking a statin. Curr Med Res Opin 2007; 23: 2183-92.

58. Dujovne CA, Ettinger MP, McNeer JF, et al. Efficacy and safety of a potent new selective cholesterol absorption inhibitor, ezetimibe, in patients with primary hypercholesterolemia. Am J Cardiol 2002; 90: 1092-7.

59. Gagne C, Bays HE, Weiss SR, et al. Efficacy and safety of ezetimibe added to ongoing statin therapy for treatment of patients with primary hypercholesterolemia. Am J Cardiol 2002; 90: 1084-91.

60. Kastelein JJ, Akdim F, Stroes ES, et al. Simvastatin with or without ezetimibe in familial hypercholesterolemia. N Engl J Med 2008; 358: 1431-43.

61. Baigent C, Landray MJ, Reith C, et al. The effects of lowering LDL cholesterol with simvastatin plus ezetimibe in patients with chronic kidney disease (Study of Heart and Renal Protection): a randomised placebo-controlled trial. Lancet 2011; 377: 2181-92.
62. Goldberg RB, Guyton JR, Mazzone T, et al. Ezetimibe/ simvastatin vs atorvastatin in patients with type $2 \mathrm{di}$ abetes mellitus and hypercholesterolemia: the VYTAL study. Mayo Clin Proc 2006; 81: 1579-88.

63. Robinson JG, Ballantyne CM, Grundy SM, et al. Lipid-altering efficacy and safety of ezetimibe/simvastatin versus atorvastatin in patients with hypercholesterolemia and the metabolic syndrome (from the VYMET study). Am J Cardiol 2009; 103: 1694-702.

64. Ballantyne CM, Weiss R, Moccetti T, et al. Efficacy and safety of rosuvastatin $40 \mathrm{mg}$ alone or in combination with ezetimibe in patients at high risk of cardiovascular disease (results from the EXPLORER study). Am J Cardiol 2007; 99: 673-80.

65. Bays H. Ezetimibe. Expert Opin Investig Drugs 2002; 11: 1587-604.

66. Dragan S, Serban MC, Banach M. Proprotein convertase subtilisin/kexin 9 inhibitors: an emerging lipid-lowering therapy? J Cardiovasc Pharmacol Ther 2015; 20: 157-68.

67. Abifadel $M$, Varret $M$, Rabès JP, et al. Mutations in PCSK9 cause autosomal dominant hypercholesterolemia. Nat Genet 2003; 34: 154-6.

68. Banach M, Rizzo M, Obradovic $M$, et al. PCSK9 inhibition - a novel mechanism to treat lipid disorders? Curr Pharm Des 2013; 19: 3869-77.

69. Banach M, Aronow WS, Serban MC, et al. Lipids, blood pressure and kidney update 2015. Lipids Health Dis 2015; 14: 167.

70. Ooi CP, Loke SC. Colesevelam for type 2 diabetes mellitus: an abridged Cochrane review. Diabet Med 2014; 31: 2-14.

71. The Lipid Research Clinics Coronary Primary Prevention Trial results. I. Reduction in incidence of coronary heart disease. JAMA 1984; 251: 351-64.

72. The Lipid Research Clinics Coronary Primary Prevention Trial. Results of 6 years of post-trial follow-up. The Lipid Research Clinics Investigators. Arch Intern Med 1992; 152: 1399-410.

73. He L, Wickremasingha P, Lee J, et al. Lack of effect of colesevelam $\mathrm{HCl}$ on the single-dose pharmacokinetics of aspirin, atenolol, enalapril, phenytoin, rosiglitazone, and sitagliptin. Diabetes Res Clin Pract 2014; 104: 401-9.

74. Kamanna VS, Kashyap ML. Mechanism of action of niacin. Am J Cardiol 2008; 101: 20B-26B.

75. Bruckert E, Labreuche J, Amarenco P. Meta-analysis of the effect of nicotinic acid alone or in combination on cardiovascular events and atherosclerosis. Atherosclerosis 2010; 210: 353-61.

76. AIM-HIGH Investigators, Boden WE, Probstfield JL, Anderson $\mathrm{T}$, et al. Niacin in patients with low HDL cholesterol levels receiving intensive statin therapy. $\mathrm{N}$ Engl J Med 2011; 365: 2255-67.

77. HPS2-THRIVE Collaborative Group, Landray MJ, Haynes R, Hopewell JC, et al. Effects of extended-release niacin with laropiprant in high-risk patients. N Engl J Med 2014; 371: 203-12.

78. Hobbs FD, Banach M, Mikhailidis DP, et al. Is statin-modified reduction in lipids the most important preventive therapy for cardiovascular disease? A pro/ con debate. BMC Med 2016; 14: 4.

79. Serban MC, Banach M, Mikhailidis DP. Clinical implications of the IMPROVE-IT trial in the light of current and future lipid-lowering treatment options. Expert Opin Pharmacother 2016; 17: 369-80.

80. Banach M, Aronow WS, Serban C, et al. Lipids, blood pressure and kidney update 2014. Pharmacol Res 2015; 95-96: 111-25. 
81. Nikolic D, Mikhailidis DP, Davidson MH, et al. ETC-1002: a future option for lipid disorders? Atherosclerosis 2014; 237: 705-10.

82. Toth PP, Barylski M, Nikolic D, et al. Should low highdensity lipoprotein cholesterol (HDL-C) be treated? Best Pract Res Clin Endocrinol Metab 2014; 28: 353-68.

83. Nikolic D, Rizzo M, Mikhailidis DP, et al. An evaluation of RVX-208 for the treatment of atherosclerosis. Expert Opin Investig Drugs 2015; 24: 1389-98.

84. Stone NJ, Robinson JG, Lichtenstein AH, et al. 2013 ACC/AHA guideline on the treatment of blood cholesterol to reduce atherosclerotic cardiovascular risk in adults: a report of the American College of Cardiology/American Heart Association Task Force on Practice Guidelines. Circulation 2014; 129 (25 Suppl 2): S1-45.

85. Sahebkar A, Serban MC, Mikhailidis DP, et al. Head-tohead comparison of statins versus fibrates in reducing plasma fibrinogen concentrations: a systematic review and meta-analysis. Pharmacol Res 2016; 103: 236-52.

86. Hegele RA, Ginsberg HN, Chapman MJ, et al. The polygenic nature of hypertriglyceridemia implications for definition, diagnosis and management. Lancet Diabet Endocrinol 2014; 2: 655-66.

87. Chapman MJ, Ginsberg HN, Amarenco P, et al. Triglyceride-rich lipoproteins and high-density lipoprotein cholesterol in patients at high risk of cardiovascular disease: evidence and guidance for management. Eur Heart J 2011; 32: 1345-61.

88. Thompson GR, Barbir M, Davies D, et al. Recommendations for the use of LDL apheresis. Atherosclerosis 2008; 98: 247-55.

89. Harada-Shiba M, Arai H, Oikawa S, et al. Guidelines for the management of familial hypercholesterolemia. J Arterioscler Thromb 2012; 19: 1043-60.

90. Goldberg AC, Hopkins PN, Toth PP, et al. National Lipid Association Expert Panel on Familial Hypercholesterolemia. Familial hypercholesterolemia: screening, diagnosis and management of pediatric and adult patients: clinical guidance from the National Lipid Association Expert Panel on Familial Hypercholesterolemia. J Clin Lipidol 2011; 5: S1-8.

91. Stefanutti C, Julius U. Lipoprotein apheresis: state of the art and novelties. Atheroscler Suppl 2013; 14: 19-27.

92. Schuff-Werner P, Fenger S, Kohkschein P. Role of lipid apheresis in changing times. Clin Res Cardiol Suppl 2012; 7: 7-14

93. Cuchel M, Bruckert E, Ginsberg HN, et al. Homozygous familial hypercholesterolemia: new insights and guidance for clinicians to improve detection and clinical management. A position paper from the Consensus Panel on Familial Hypercholesterolemia of the European Atheroslcerosis Society. Eur Heart J 2014; 35: 2146-57.

94. Keller C, Grutzmacher P, Bahr F, et al. LDL-apheresis with dextran sulphate and anaphylactoid reactions to ACE inhibitors. Lancet 1993; 341: 60-1.

95. Cybulska B, Kłosiewicz-Latoszek L. Komentarz do artykułu „Ocena skuteczności i bezpieczeństwa stosowania statyn u dzieci chorych na rodzinną hipercholesterolemię". Medycyna Praktyczna 2016; http://www. mp.pl/artykuly/26863 (30 czerwca 2016).

96. Myśliwiec M, Walczak M, Małecka-Tendera E, et al. Management of familial hypercholesterolemia in children and adolescents. Position paper of the Polish Lipid Expert Forum. J Clin Lipidol 2014; 8: 173-80.

97. Stolarz-Skrzypek K, Bednarski A, Drożdż D, Czarnecka D. Prewencja miażdżycy u dzieci - rola statyn i kwasu acetylosalicylowego. Przegl Lek 2013; 70: 57-64.
98. Perk J, De Backer G, Gohlke H, et al.; Fifth Joint Task Force of the European Society of Cardiology and Other Societies on Cardiovascular Disease Prevention in Clinical Practice; European Association for Cardiovascular Prevention and Rehabilitation. European Guidelines on cardiovascular disease prevention in clinical practice (version 2012): The Fifth Joint Task Force of the European Society of Cardiology and Other Societies on Cardiovascular Disease Prevention in Clinical Practice (constituted by representatives of nine societies and by invited experts). Atherosclerosis 2012; 223: 1-68.

99. Peterson AL, MCBride PE. A review of guidelines for dyslipidemia in children and adolescents. WMJ 2012; 111: 274-81.

100. Goldwire M. Screening and treatment of pediatric dyslipidemias. US Pharm 2014; 39: 52-6.

101. Cameron C, Craig CL, Bull FC, Bauman A. Canada's physical activity guides: has their release had an impact? Can J Public Health 2007; 98 Suppl. 2: S161-9.

102. Lamaida N, Capuano E, Pinto L, et al. The safety of statins in children. Acta Paediatr 2013; 102: 857-62.

103. Reiner Z. Primary prevention of cardiovascular disease with statins in the elderly. Curr Atheroscler Rep 2014; 16: 420.

104. Glynn RJ, Koenig W, Nordestgaard BG, et al. Rosuvastatin for primary prevention in older persons with elevated C-reactive protein and low to average low-density lipoprotein cholesterol levels: exploratory analysis of a randomized trial. Ann Intern Med 2010; 152: 488-96.

105. Brugts JJ, Yetgin T, Hoeks SE, et al. The benefits of statins in people without established cardiovascular disease but with cardiovascular risk factors: metaanalysis of randomised controlled trials. BMJ 2009; 338: b2376.

106. Cholesterol Treatment Trialists' (CTT) Collaboration, Fulcher J, O'Connell R, Voysey M, et al. Efficacy and safety of LDL-lowering therapy among men and women: meta-analysis of individual data from 174,000 participants in 27 randomised trials. Lancet 2015; 385: 1397-405.

107. Hunt D, Young P, Simes J, et al. Benefits of pravastatin on cardiovascular events and mortality in older patients with coronary heart disease are equal to or exceed those seen in younger patients: results from the LIPID trial. Ann Intern Med 2001; 134: 931-40.

108. Gransbo K, Melander O, Wallentin L, et al. Cardiovascular and cancer mortality in very elderly post-myocardial in-farction patients receiving statin treatment. J Am Coll Cardiol 2010; 55: 1362-9.

109. Jabłecka A, Korzeniowska K, Smolarek I. Farmakokinetyka leków w wieku podeszłym. Pol Arch Med Wewn 2008; 118 (Suppl): 43-6.

110. Cybulska B, Kłosiewicz-Latoszek L. Czy warto leczyć hiperlipidemię u ludzi starszych. In: Zaburzenia lipidowe. Cybulska B, Kłosiewicz-Latoszek L (eds.). Termedia, Poznan 2010; 171-84.

111. Nordesgaard BG, Chapman MJ, Humphries SE, et al.; European Atherosclerosis Society consensus panel. Familial hypercholesterolemia is underdiagnosed and undertreated in the general population: guidence for clinicians to prevent coronary artery disease. Eur Heart J 2013; 34: 3478-90.

112. Rynkiewicz A, Cybulska B, Banach M, et al. Postępowanie $w$ heterozygotycznej hipercholesterolemii rodzinnej. Stanowisko Forum Ekspertów Lipidowych. Kardiol Pol 2013; 71: 107-11. 
113. Watts GF, Gidding S, Wierzbicki AS, et al. Integrated guidance on the care of familial hypercholesterolemia from the International FH Foundation. J Clin Lipidol 2014; 8: 148-72.

114. Gidding SS, Champagne MA, de Ferranti SD, et al. The Agenda for Familial Hypercholesterolemia: A Scientific Statement from the American Heart Association. Circulation 2015; 132: 2167-92.

115. Santos RD, Gidding SS, Hegele RA, et al. Defining severe familial hypercholesterolemia and the implications for clinical management: a consensus statement from the International Atherosclerosis Society Severe Familial Hypercholesterolemia Panel. Lancet Diabetes Endocrinol 2016; 4: 850-61.

116. Vallejo-Vaz AJ, Kondapally Seshasai SR, Cole D, et al. Familial hypercholesterolaemia: a global call to arms. Atherosclerosis 2015; 243: 257-9.

117. Shepherd J, Barter P, Carmena R, et al. Effect of lowering LDL cholesterol substantially below currently recommended levels in patients with coronary heart disease and diabetes: the Treating to New Targets (TNT) study. Diabetes Care 2006; 29: 1220-6.

118. Colhoun HM, Betteridge DJ, Durrington PN, et al. Primary prevention of cardiovascular disease with atorvastatin in type 2 diabetes in the Collaborative Atorvastatin Diabetes Study (CARDS): multicentre randomised placebocontrolled trial. Lancet 2004; 364: 685-96.

119. Cholesterol Treatment Trialists' Collaboration, Kearney PM, Blackwell L, Collins R, et al. Efficacy of cholesterol-lowering therapy in 18,686 people with diabetes in 14 randomised trials of statins: a meta-analysis. Lancet 2008; 371: 117-25.

120. Preiss D, Campbell RT, Murray HM, et al. The effect of statin therapy on heart failure events: a collaborative meta-analysis of unpublished data from major randomized trials. Eur Heart J 2015; 36: 1536-46.

121. Liu G, Zheng XX, Xu YL, et al. Meta-analysis of the effect of statins on mortality in patients with preserved ejection fraction. Am J Cardiol 2014; 113: 1198-204.

122. Deo SV, Rababa'h A, Altarabsheh SE, et al. Statin therapy improves long-term survival in non-ischaemic cardiomyopathy: a pooled analysis of 4500 patients. Heart Lung Circ 2014; 23: 985-7.

123. Kjekshus J, Apetrei E, Barrios V, et al. Rosuvastatin in older patients with systolic heart failure. N Engl J Med 2007; 357: 2248-61.

124. Tavazzi L, Maggioni AP, Marchioli R, et al. Effect of rosuvastatin in patients with chronic heart failure (the GISSI-HF trial): a randomised, double-blind, placebo-controlled trial. Lancet 2008; 372: 1231-9.

125. Taylor F, Huffman MD, Macedo AF, et al. Statins for the primary prevention of cardiovascular disease. Cochrane Database Syst Rev 2013; 1: CD004816.

126. Amarenco P, Labreuche J. Lipid management in the prevention of stroke: review and updated meta-analysis of statins for stroke prevention. Lancet Neurol 2009; 8: 453-63.

127. Tonelli M, Muntner P, Lloyd A, et al.; Alberta Kidney Disease Network. Association between LDL-C and risk of myocardial infarction in CKD. J Am Soc Nephrol 2013; 24: 979-86.

128. Wanner C, Tonelli M; Kidney Disease: Improving Global Outcomes Lipid Guideline Development Work Group Members. KDIGO Clinical Practice Guideline for Lipid Management in CKD: summary of recommendation statements and clinical approach to the patient. Kidney Int 2014; 85: 1303-9.
129. European Association for Cardiovascular Prevention \& Rehabilitation; Reiner Z, Catapano AL, De Backer $\mathrm{G}$, et al. Guidelines ESCCfP and Committees. ESC/EAS Guidelines for the management of dyslipidaemias: the Task Force for the management of dyslipidaemias of the European Society of Cardiology (ESC) and the European Atherosclerosis Society (EAS). Eur Heart J 2011; 32: 1769-818.

130. Reiner Z. Similarities and differences between European and United States guidelines for the management of dyslipidaemias. Kardiol Pol 2015; 73: 471-7.

131. Rysz J, Gluba-Brzózka A, Banach M, Więcek A. Should we use statins in all patients with chronic kidney disease without dialysis therapy? The current state of knowledge. Int Urol Nephrol 2015; 47: 805-13.

132. Morris PB, Ballantyne CM, Birtcher KK, et al. Review of clinical practice guidelines for the management of LDL-related risk. J Am Coll Cardiol 2014; 64: 196-206.

133. Aung PP, Maxwell HG, Jepson RG, Price JF, Leng GC. Lipid-lowering for peripheral arterial disease of the lower limb. Cochrane Database Syst Rev 2007; 4: CD000123.

134. Michalak A, Samborski P, Grzymisławski M. Gospodarka lipidowa i ryzyko chorób sercowo-naczyniowych w wybranych chorobach autoimmunologicznych. Forum Zab Metabol 2015; 6: 152-69.

135. Peters MJ, Symmons DP, McCarey D, et al. EULAR evidence-based recommendations for cardiovascular risk management in patients with rheumatoid arthritis and other forms of inflammatory arthritis. Ann Rheum Dis 2010; 69: 325-31.

136. Gladman DD, Ang M, Su L, et al. Cardiovascular morbidity in psoriatic arthritis. Ann Rheum Dis 2009; 68: 1131-5.

137. Thorburn CM, Ward MM. Hospitalizations for coronary artery disease among patients with systemic lupus erythematosus. Arth Rheum 2003; 48: 2519-23.

138. Liao KP, Cai T, Gainer, et al. Lipid and lipoprotein levels and trend in rheumatoid arthritis compared to the general population. Arthritis Care Res (Hoboken) 2013; 65: 2046-50.

139. Liao KP, Playford MP, Frits $M$, et al. The association between reduction in inflammation and changes in lipoprotein levels and HDL cholesterol efflux capacity in rheumatoid arthritis. J Am Heart Assoc 2015; 4: e001588.

140. Thorogood M, Seed M, De Mont K. Guideline Development Group. Management of ferility in women with familial hypercholesterolemia summary of NICE guidance. Br J Obstet Gynecol 2009; 116: 478-9.

141. Avis HJ, Hutten BA, Twickler MT, et al. Pregnancy in women suffering from familial hypercholesterolemia: a harmful period for both mother and newborn? Curr Opin Lipidol 2009; 20: 484-90.

142. Kusters DM, Homsma SJ, Hutten BA, et al. Dilemmas in a tretment of women with familial hypercholesterolemia during pregnancy. Neth J Med 2010; 68: 299-303.

143. Ito MK, McGowan MP, Moriarty PM. Management of familial hypercholesterolemia in adult patients: recommendations from the National Lipid Association Expert Panel on Familial Hypercholesterolemia. J Clin Lipidol 2011; 5 (3 Suppl): S38-S45.

144. van de Graaf A, Hutten BA, Kastelein JJ, et al. Premature cardiovascular disease in young women with heterozygous familial hypercholesterolemia. Expert Rev Cardiovasc Ther 2006; 4: 345-51.

145. Watts GF, Gidding S, Wierzbicki AS, et al. Integrated guidance on the care of familial hyercholesterolemia 
from the International FH Foundation. Int J Cardiol 2014; 171: 309-25.

146. Power MC, Weuve J, Sharrett AR, et al. Statins, cognition, and dementia-systematic review and methodological commentary. Nat Rev Neurol 2015; 11: 220-9.

147. Heymann AD, Ravona-Springer R, Moshier EL, et al. Statin use is associated with better cognitive function in elderly with type 2 diabetes. J Alzheimers Dis 2015; 47: 55-9.

148. Chao TF, Liu CJ, Chen SJ, et al. Statins and the risk of dementia in patients with atrial fibrillation: a nationwide population-based cohort study. Int J Cardiol 2015; 196: 91-7.

149. Banach M, Rizzo M, Nikolic D, et al. Intensive LDL-cholesterol lowering therapy and neurocognitive function. Pharmacol Ther 2016 Nov 16. pii: S0163-7258(16)30210-8. doi: 10.1016/j.pharmthera.2016.11.001.

150. Kutner JS, Blatchford PJ, Taylor DH Jr, et al. Safety and benefit of discontinuing statin therapy in the setting of advanced, life-limiting illness: a randomized clinical trial. JAMA Intern Med 2015; 175: 691-700.

151. Melzi S, Carenzi L, Cossu MV, et al. Lipid metabolism and cardiovascular risk in HIV-1 infection and HAART: present and future problems. Cholesterol 2010; 2010: 271504.

152. Tashakkor AY, Moghaddamjou A, Chen L, Cheung WY. Predicting the risk of cardiovascular comorbidities in adult cancer survivors. Curr Oncol 2013; 20: e360-70.

153. Cohen DE, Anania FA, Chalasani N; National Lipid Association Statin Safety Task Force Liver Expert Panel. An assessment of statin safety by hepatologists. Am J Cardiol 2006; 97: 77C-81C.

154. Lai SW, Liao KF, Lai HC, et al. Statin use and risk of hepatocellular carcinoma. Eur J Epidemiol 2013; 28: 485-92.

155. Banach M, Stulc T, Dent R, Toth PP. Statin non-adherence and residual cardiovascular risk: there is need for substantial improvement. Int J Cardiol 2016; 225: 184-96.

156. Patel J, Martin SS, Banach M. Expert opinion: the therapeutic challenges faced by statin intolerance. Expert Opin Pharmacother 2016; 17: 1497-507.

157. Michalska-Kasiczak M, Sahebkar A, Mikhailidis DP, et al.; Lipid and Blood Pressure Meta-analysis Collaboration (LBPMC) Group. Analysis of vitamin D levels in patients with and without statin-associated myalgia a systematic review and meta-analysis of 7 studies with 2420 patients. Int J Cardiol 2015; 178: 111-6.

158. Stroes ES, Thompson PD, Corsini A, et al. Statin - associated muscle symptoms: impact of statin therapy - European Atherosclerosis Society Consensus Panel Statement an Assessment, Aetiology and Management. Eur Heart J 2015; 36: 1012-22.

159. Broncel M, Gorzelak-Pabiś P, Sahebkar A, et al.; Lipid and Blood Pressure Meta-analysis Collaboration (LBPMC) Group. Sleep changes following statin therapy: a systematic review and meta-analysis of randomized placebo-controlled polysomnographic trials. Arch Med Sci 2015; 11: 915-26.

160. Gluba-Brzozka A, Franczyk B, Toth PP, et al. Molecular mechanisms of statin intolerance. Arch Med Sci 2016; 12: 645-58.

161. Barylski M, Nikolic D, Banach M, et al. Statins and new-onset diabetes. Curr Pharm Des 2014; 20: 3657-64.

162. Śliż D, Filipiak KJ, Naruszewicz M, et al. Differences in achieving treatment goals with statin use in various regions of Poland - 3ST-POL study results. Ann Agric Environ Med 2016; 23: 16-9.
163. Pajak A, Jankowski P, Kawecka-Jaszcz K, et al. Changes in secondary prevention of coronary artery disease in the post-discharge period over the decade 1997-2007. Results of the Cracovian Program for Secondary Prevention of Ischaemic Heart Disease and Polish parts of the EUROASPIRE II and III surveys. Kardiol Pol 2009; 67: 1353-9.

164. Wełnicki M, Folga A, Sudot K, Mamcarz A. Efficacy of hypercholesterolemia treatment in Poland. Analysis of the CEPHEUS study results. Pol Przegl Kardiol 2014; 16: 5-11.

165. Ridker PM, Mora S, Rose L; JUPITER Trial Study Group. Percent reduction in LDL cholesterol following high-intensity statin therapy: potential implications for guidelines and for the prescription of emerging lipid-lowering agents. Eur Heart J 2016; 37: 1373-9.

166. Kim MC, Cho JY, Jeong HC, et al. Impact of postdischarge statin withdrawal on long-term outcomes in patients with acute myocardial infarction. Am J Cardiol 2015; 115: 1-7.

167. Wożakowska-Kapłon B, Filipiak KJ, Mamcarz A, et al. Actual problems of dyslipidaemia treatment in Poland - $2^{\text {nd }}$ Declaration of Sopot. Experts' Group Consensus endorsed by the Polish Cardiac Society Working Group on Cardiovascular Pharmacotherapy. Kardiol Pol 2014; 72: 847-53.

168. Banach M, Nikolic D, Rizzo M, Toth PP. IMPROVE-IT: what have we learned? Curr Opin Cardiol 2016; 31: 426-33. 